\title{
EXPLORING TRADE-OFFS IN AUV CONTROLLER DESIGN FOR SHARK TRACKING
}

\author{
A Thesis \\ Presented to \\ the Faculty of California Polytechnic State University \\ San Luis Obispo
}

\author{
In Partial Fulfillment \\ of the Requirements for the Degree \\ Master of Science in General Engineering
}

by

Louis James Bertsch IV

March 2011 
(C) 2011

Louis James Bertsch IV

ALL RIGHTS RESERVED 


\section{COMMITTEE MEMBERSHIP}

TITLE: Exploring trade-offs in AUV Controller Design for Shark Tracking

AUTHOR: Louis James Bertsch IV

DATE SUBMITTED: $\quad$ March 2011

COMMITTEE CHAIR: Christopher Clark, Ph.D.

COMMITTEE MEMBER: Robert Crockett, Ph.D.

COMMITTEE MEMBER: Dan Walsh, Ph.D. 


\begin{abstract}
Exploring trade-offs in AUV Controller Design for Shark Tracking
\end{abstract}

\author{
Louis James Bertsch IV
}

This thesis explores the use of an Autonomous Underwater Vehicle (AUV) to track and pursue a tagged shark through the water. A controller was designed to take bearing and range to the shark tag and then control the AUV to pursue it.

First, the ability of a particle filter to provide an accurate estimation of the location of the shark relative to the AUV is explored. Second, the ability of the AUV to follow the shark's path through the water is shown. This ability allows for localized environmental sampling of the shark's preferred path. Third, various path weightings are used to optimize the efficiency of pursuing the shark. This demonstrates that the proposed controller is efficient and effective. Fourth, the benefits of the addition of a second AUV are explored and quantified. The secondary AUV is shown to maintain formation without direct communication from the primary AUV. However, the communication of the AUVs increases the accuracy of all measurements and allows for future expansion in the complexity of the controller. Fifth, the effects of predicting the shark's future movement is explored. Sixth, the effect of noise in the signal from the shark tag is tested and the level of noise at which the AUV can no longer pursue the shark is shown. This investigates the real world ability of the controller to accept noisy inputs and still generate the appropriate response. Finally, the positive results of the previous sections are combined and tested for various noise levels to show the improved controller response even under increased noise levels.

To validate the proposed estimator and controller, seven tests were conducted. All tests were conducted on existing shark path data recorded by a stationary 
acoustic receiver and a boat mounted acoustic receiver. Tests were conducted on data sets from two different species of sharks, (Shovelnose and White) with two very different swimming behaviors. This shows the solution's flexibility in the species of shark tracked. 


\section{Acknowledgements}

First I'd like to thank my advisor Dr. Clark for all his help, insight and enthusiasm. Without him none of this would have been possible.

It is an honor for me to thank my outstanding committee members, Dr. Walsh and Dr. Crockett. Both of them have been key to my success and growth here at Calpoly.

Thanks to all my friends and colleagues at Calpoly that helped and encouraged me along the way. A special thanks goes out to all those who helped me debug code until 6 in the morning. I'd also like to express my sincere gratitude to all the wonderful faculty at Calpoly that have helped me learn and advance my education over the years.

I'd like to thank my family and friends for all their love and support. I'd like to thank my mother, Theresa Messner, for all her time spent helping me and for always answering my questions of why as a kid. She fostered my love of knowledge even as a child. I'd like to thank my father, Jim Bertsch III, for all his guidance and being there to bounce ideas and emails off. He has provided me with sound advice through the years. I am also indebted to my grandparents, Lou and Betty Messner, Jim Bertsch II, and Mary and Bill Samaras. The helped me afford to go to college and fostered in me a love of the ocean and a desire to pursue higher education.

I would also like to thank my lovely fiancé, Courtney Woolling, for her love and encouragement. She's stayed by my side and helped motivate me throughout all the late nights working.

Finally I'd like to thank God for helping me accomplish this great undertaking. He gave me the motivation and determination to finish. 


\section{Contents}

List of Tables $\quad$ x

List of Figures $\quad$ xi

1 Introduction 1

1.1 Background info on AUVs . . . . . . . . . . . . . . 1

1.2 Current Research in AUVs . . . . . . . . . . . . . . 2

1.3 Why study sharks? . . . . . . . . . . . . . . 4

1.4 Current methods of collecting data on sharks . . . . . . . . . 5

1.5 Shark Tracking . . . . . . . . . . . . . . . 8

1.6 What is the range of detection? . . . . . . . . . . . . . 9 9

1.7 Shark swimming behavior . . . . . . . . . . . . . . 11

1.8 What is the range of shark behavior modification? . . . . . . . . 13

1.9 Path Following . . . . . . . . . . . . . . . . . . . 15

1.10 Objectives . . . . . . . . . . . . . . . 16

1.11 How the proposed method will advance AUV research . . . . . . . 17

2 Problem Statement 18

2.1 Cost Function . . . . . . . . . . . . . . . . . . . 18

2.2 Constraints . . . . . . . . . . . . . . . 20

2.3 Assumptions . . . . . . . . . . . . . . . . . . . . . . 22

2.4 Optimal solution ...................... 22

3 Shark Tracking Controller $\quad 24$

3.1 Controller Block Diagram . . . . . . . . . . . . . 24

3.2 Shark State Estimator . . . . . . . . . . . . . . 25 
3.3 Desired Point Planner . . . . . . . . . . . . . . . . . . . . . . . . 29

3.4 Point Tracker . . . . . . . . . . . . . . . . . . . . . . . 32

3.5 Determining of Gains . . . . . . . . . . . . . . . . . 35

3.6 The Second AUV . . . . . . . . . . . . . . . . . . 37

3.7 Shark Position Prediction to reduce Cost . . . . . . . . . . . . 39

3.8 Signal Noise . . . . . . . . . . . . . . . . . . . . . . . . . . . . . 40

3.9 Code Execution Summary ～. . . . . . . . . . . . . . . . . . 41

4 Implementation $\quad 44$

4.1 Effective Controller Characteristics . . . . . . . . . . . . 44

4.2 Data sets . . . . . . . . . . . . . . . . . . 45

4.3 Ocean and Simulation similarities and differences . . . . . . . 52

5 Results 55

5.1 Particle Filter Accuracy _. . . . . . . . . . . . . . 56

5.2 Path Weighting . . . . . . . . . . . . . . . . 58

5.3 Optimal Path Weighting . . . . . . . . . . . 60

5.4 Addition of a Second AUV . . . . . . . . . . . . . . . 68

5.5 Future Planning . . . . . . . . . . . . . . . . . 71

$5.6 \quad$ Noise . . . . . . . . . . . . . . . . . . . . . . . . . . . . 73

5.7 Combined Test of Methods . . . . . . . . . . . . . . . 74

6 Discussion $\quad 83$

6.1 Inherent Benefits of Solution Method . . . . . . . . . . . 83

6.2 Particle filter Accuracy . . . . . . . . . . . . . . . . . . . 84

6.3 Path Following . . . . . . . . . . . . . . . . 85

6.4 Optimal Path Weighting . . . . . . . . . . . . 86

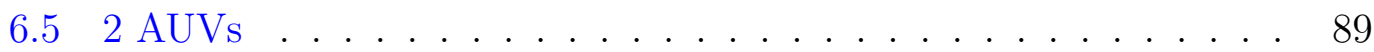

6.6 Future Planning . . . . . . . . . . . . . . . . . . . . 9 91

$6.7 \quad$ Noise . . . . . . . . . . . . . . . . . . . . . . . 93

6.8 Combined Methods Test . . . . . . . . . . . . . . 96

$\begin{array}{lll}7 \text { Conclusion } & 99\end{array}$

7.1 What this solution provides . . . . . . . . . . . . 99 
7.2 Knowledge learned about this solution . . . . . . . . . . . 100

7.3 Limitations . . . . . . . . . . . . . . . . . . . . . 101

7.4 Future Work . . . . . . . . . . . . . . . . . . 101

$\begin{array}{lc}\text { Bibliography } & 103\end{array}$ 


\section{List of Tables}

4.1 Summary of Data Sets . . . . . . . . . . . . . . . . 48

5.1 Results of Data Sets with Various Weightings . . . . . . . . 66

5.2 Results of Data Sets with Various Weightings Averaged Over all Data Sets . . . . . . . . . . . . . . 67

5.3 Results of Data Sets with Various Noise Levels . . . . . . . . . . . 76

5.4 Results of Data Sets with Various Noise Levels . . . . . . . . . . . 79

5.5 Average and Standard Deviation of Particle Shark Error . . . . . 80 


\section{List of Figures}

3.1 Controller Block Diagram _ . . . . . . . . . . . . 25

3.2 Diagram of Particle Weightings _ . . . . . . . . . . . . 28

3.3 Diagram of Shark Doubling Back . . . . . . . . . . . . . 31

3.4 Multiple AUV tracking benefit . . . . . . . . . . . . . . . 38

3.5 Multiple AUV tracking benefit . . . . . . . . . . . . . . 39

3.6 Diagram of Shark Angles . . . . . . . . . . . . . . . . . . . 42

4.1 Shovelnose Shark Trajectory . . . . . . . . . . . . . . . . . 46

4.2 White Shark Trajectory . . . . . . . . . . . . . . . 47

4.3 Data Set $1 \ldots \ldots \ldots \ldots \ldots \ldots$

4.4 Data Set $2 \ldots \ldots \ldots \ldots \ldots$

4.5 Data Set $3 \ldots \ldots \ldots \ldots \ldots$

4.6 Data Set $4 \ldots \ldots \ldots \ldots \ldots \ldots$

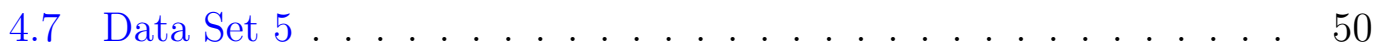

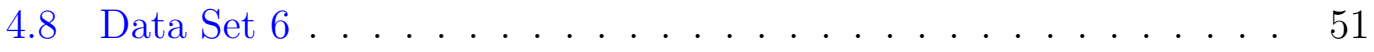

4.9 Data $\operatorname{Set} 7 \ldots \ldots \ldots \ldots \ldots \ldots \ldots$

5.1 Particle Filter Error _ . . . . . . . . . . . . . . . 57

5.2 Standard Deviation of Particle Filter . . . . . . . . . . 58

5.3 Shark path vs. AUV path for various weights . . . . . . . 59

5.4 Cost Functions for Data Set $4 \mathrm{w} / \mathrm{a}$ path weight of $0 \ldots \ldots 6$

5.5 Cost Functions for Data Set $4 \mathrm{w} / \mathrm{a}$ path weight of $0.5 \ldots \ldots 61$

5.6 Cost Functions for Data Set $4 \mathrm{w} / \mathrm{a}$ path weight of $1 \ldots 61$ 
5.7 Cost Functions for Data Set $1 \mathrm{w} /$ various Path Weightings . . . . 63

5.8 Cost Functions for Data Set 2 w/ various Path Weightings . . . . 64

5.9 Cost Functions for Data Set $3 \mathrm{w} /$ various Path Weightings . . . . 64

5.10 Cost Functions for Data Set $4 \mathrm{w} /$ various Path Weightings . . . . 65

5.11 Cost Functions for Data Set 5 w/ various Path Weightings . . . . 65

5.12 Path of Second AUV for Data Set 1 . . . . . . . . . . . . . 69

5.13 Path of Second AUV for Data Set 1 . . . . . . . . . . . . . 69

5.14 Distance from Shark of Second AUV for Data Set 5 . . . . . . . . 70

5.15 Path of Second AUV for Data Set 5 . . . . . . . . . . . . . 70

5.16 Comparison of Particle Filter Accuracy for Multiple AUVs . . . . 71

5.17 Comparison of Particle Filter Standard Deviation for Multiple AUVs 72

5.18 Avg Cost and Error vs Prediction Time, Shovelnose Shark . . . . 73

5.19 Avg Cost and Error vs Prediction Time, White Shark . . . . . . . 74

5.20 Cost Functions for Data Set 4 for various Noise Levels . . . . . . 75

5.21 Cost Functions for Data Set 5 for various Noise Levels . . . . . . 75

5.22 AUV Path for Data Set 7 without Noise . . . . . . . . . . . . 78

5.23 AUV Path for Data Set 7 with High Noise . . . . . . . . . . . . . 80

5.24 Distance From Shark for Data Set 6 without Noise . . . . . . . . 81

5.25 Distance From Shark for Data Set 6 with High Noise . . . . . . . 81

5.26 Distance From Shark for Data Set 7 without Noise . . . . . . . . 82

5.27 Distance From Shark for Data Set 7 with High Noise . . . . . . . 82 


\section{Chapter 1}

\section{Introduction}

The focus of this project is to demonstrate the feasibility of and demonstrate an optimal solution for the tracking and pursuit of a tagged shark by an Autonomous Underwater Vehicle. This chapter highlights some of the current research in the fields of Autonomous Underwater Vehicles and shark tracking. The question of why attempt to track sharks is answered. Swimming speeds of several sharks are investigated to prove that the Iver2 Autonomous Underwater Vehicle is capable of keeping up with the sharks. How the pursuing Autonomous Underwater Vehicle may affect the behavior of the shark being tracked is also researched. How this project will benefit the fields of Autonomous Underwater Vehicle and shark behavior research is proposed.

\subsection{Background info on AUVs}

The term AUV stands for autonomous underwater vehicle, and is used to describe a vehicle capable of operating in the underwater environment and operating without a human in the loop. The real advantage of AUVs is that they 
provide greater spatial-temporal information. This is because AUVs are capable of having various sensors mounted to their hulls to record vast amounts of data while in operation. AUVs can accomplish tasks that humans cannot. AUVs can be used in conditions that are hazardous to divers or require work that divers cannot do. AUVs allow humans to record data on areas or subjects previously unobservable.

\subsection{Current Research in AUVs}

Currently research in the field of AUVs is focusing on localization and acoustic mapping of underwater environments. The ocean presents a different set of challenges for autonomous robots than typical land based operations. Very little of the ocean is mapped resulting in an unknown area of operations. Ocean currents can move the AUV off its planned trajectory. Unlike in air, radio waves die out much faster in water, resulting in a need for a different method of communication underwater. This is particularly limiting as GPS positioning is only available to the AUV while on the surface. Under the water, the AUV must rely on other sensors to determine its location. Various methods have been researched to accomplish positional tracking of the AUV itself. These include SBL and LBL[25], inertial recording[18], dead reckoning[20], optical flow[8][7] and combined sensor readings[16] to determine how the AUV is moving under the water. These methods are not perfect however, but can be used to fairly accurately estimate the current location of the AUV.

Research is also being done using AUVs to locate and track objects underwater. Work has been done using an acoustic receiver to detect acoustic tags on 
fish to record their position, but not track them. In the study "Use of a MultiSensored AUV to Telemeter Tagged Atlantic Sturgeon and Map Their Spawning Habitat in the Hudson River, USA", an AUV was given a pre-decided mission path to execute and it just noted the position of any tags within range and scanned the area with sonar [13]. Another paper, "Experimental Result of AUVbased Acoustic Tracking System of Sperm Whales", described research being done on tracking of whales through the water using hydrophones to pick up the clicks the whales made [24]. While clicks were not detectable in real-time, the idea behind it was novel. The benefit of this tracking method would be that the animal wouldn't have to be tagged in order to be tracked, but this would not work for tracking sharks because sharks do not communicate using noises.

Much research has been done on various interpretations of the pursuit evasion problem from a game theory standpoint. In the paper "An Iterative Learning Process Based on Bayesian Principle in Pursuit-evasion Games", Research on the pursuit evasion problem has studied iterative learning in pursuit-evasion games [17]. In "Coordinated Control of Multiple Mobile Robots in Pursuit-Evasion Games", the use of multiple robots tracking a single evader was also studied [15]. Another interesting feature of this study was concurrent mapping and pursuit of the evader. This is particularly applicable to this problem as little of the ocean floor has been mapped, meaning that our AUV must also define the limits of its environment while tracking the shark. Another study, "Differential Games and Optimal Pursuit Evasion Strategies", is particularly applicable [14]. This study took a mathematical approach to showing that proportional control is the optimal solution of a pursuit evasion game. This is particularly useful as the inputs of the proposed controller, distance and bearing as relayed to the AUV from its acoustic receivers, lend themselves well to proportional control. Another study 
deals with formation control while tracking a superior evader [26]. It describes how several pursuers can capture a superior evader by using formation control to encircle it.

\subsection{Why study sharks?}

Sharks are the most feared ocean predator. But why are sharks feared so much? Each year more people die from dog attacks or jellyfish stings than shark attacks. According to the Florida Museum of Natural History website, during the years of 2001-2009 there were a total of 230 dog attack fatalities compared to only 8 fatalities due to shark attacks in the US [22]. Why doesn't the idea of swarming jellyfish elicit the same response as a single shark in the water? Perhaps this fear can be attributed to the lack of knowledge of sharks. People fear what they don't know and this is increased with sharks as the only exposure most people have to sharks is of a predatory nature.

This lack of knowledge is due to the fact that sharks are difficult to observe in the wild. This is particularly difficult with sharks that migrate or spend their lives in the open ocean. The species of sharks that are known to migrate are the Blue Shark, the Oceanic Whitetip and the Great White Shark [6]. The White shark was only recently discovered to be a migratory shark. In 2005 a White shark named Nicole surprised researchers by making the 12,400 mile transoceanic journey from South Africa to Australia and back in nine months [3]. Not only was it "the fastest recorded swim back and forth across an ocean made by a marine creature" but showed researchers that White sharks are migratory creatures. If this was only recently learned then we still have a lot more to learn not only 
about this species of shark, but sharks in general.

An increased understanding of sharks would not only benefit sharks themselves, but also people. More people could enjoy the beaches without fear. However the greatest benefit of learning more about these sharks would come from applying that increased knowledge to prevent the unfortunate events wherein a shark does mistake a human for one of their natural food sources.

\subsection{Current methods of collecting data on sharks}

To locate sharks, the current methods involve luring the shark to the researchers (or thrill seekers as the case may be) by taking advantage of their predatory aspects. Sharks are lured up to the boat by 'chumming' the water, the process of throwing fish oil and blood into the water to make the shark think there is a free meal. Another way to locate sharks for tagging is to go to locations known for sharks and float a decoy behind the boat shaped like the shark's natural prey [6]. During these encounters the shark is in hunting mode. How can information be found about other aspects of the shark's life when encounters are limited to solely predatory encounters? Currently there are several methods of acquiring information about sharks in the wild; however, there is a need for a better solution.

One method of getting information about sharks is acoustic tagging. This method involves 'tagging' a shark with an acoustic device that sends out information on its position every few seconds (depending on the frequency of the tag). Each tag has a unique identifier that at the time of tagging is linked with a particular shark. Information on its gender, size, species, and health is recorded. Later if the shark swims within range of a device capable of reading the signal the tag is 
sending out, the shark's position can be recorded. Also if caught, the shark's tag can be read with the device and information about the shark can be updated. These tags allow researchers to record the information on individual sharks in their area, and track a shark's growth over time. However, this system has some drawbacks associated with it. This type of tag does not record information on what the shark did or where it went while outside the observational area of a tag detector. The range of a tag detector is roughly $1 \mathrm{~km}$ and "depends on the frequency of the transducer and the power output of the tag" according to the Pfleger Institute of Environmental Research [23]. In the paper "Tracking Large Marine Predators in Three Dimensions" the range of the sensors they used were reliable up to $1000 \mathrm{~m}$ then dropped off between $1000-2000 \mathrm{~m}$ with no readings beyond $2300 \mathrm{~m}[2]$. This means that when the shark leaves the range of the detector, its behavior and locations are unknown. A shark can swim from PLACE A in the summer to PLACE B in the winter and then return to PLACE A the following summer and the researchers don't know if it was 10 meters beyond the sensor range or 10,000 unless another researcher at PLACE B happens to record the shark and notify the researchers at PLACE A. This situation did happen several years ago when a White shark from the waters around Mexico was recorded in the waters off Hawaii. Before this it was unknown were the sharks off Mexico went during the winter months [6]. This is a real problem for recording information on migratory sharks or sharks in the open ocean.

Another method of obtaining data on shark migration is another type of tag, the Pop up Archival Tag (PAT). These tags are attached to a shark and then record data on where the shark goes afterward. Information like depth, location, water temperature, etc. is recorded. At a pre-chosen date and time which are programmed into the tags directly by the researchers- the tags stop data 
collection and free themselves automatically from the shark and then float to the surface [4]. Once at the ocean surface, the tag starts sending transmissions containing the collected data to ARGOS instruments mounted on environmental satellites that have polar orbits. The great advantage of these tags is that they are capable of relaying a summary of the stored data to the research team without being recovered, therefore increasing the likelihood and ease of obtaining the data [4]. This is also a problem. The PAT tags send back summarized data, that while useful may not give a clear image of the shark's behavior, just an overall migration pattern. If the tag is recovered, however, the full data set can be downloaded. This however happens rather infrequently. For example, in the paper "Migration and habitat of White sharks" paper, in which "of the 29 PAT tags deployed, 20 successfully transmitted data on the movements and habitat preferences of White sharks, while nine did not report" [27]. Three tags were recovered and more information was gleaned from them, however they were only recovered because they ended up drifting to shore.

A third method of studying shark migratory behavior was being conducted on juvenile Lemon sharks by researchers in Bimini. This method is very low tech and requires a human to record its position. A float on the surface marks the position of the shark below and researchers follow in a boat and every minute record the boat's position and distance and bearing to the float [6]. This method worked well for their purposes. The floats were attached to juvenile lemon sharks in the shallows. However, this method will not work for tracking larger sharks that may swim deeper than the cord is long and that migrate over a period of weeks or months. Humans would need to constantly record information on position. This also does not allow for information on the water conditions or behavior underwater. 
Yet another method of recording information on shark behavior underwater is the attaching of a camera to the shark [6]. This method allows for visual recording of shark interactions, but also needs to be recovered. This is problematic as the prototype of the 'tigercam' met its end in the stomach of a tiger shark [6].

Another method recently developed to track large marine predators, while not applied towards shark tracking, could be used to record information on shark behavior underwater. The paper described the creation and deployment of a set of 3 sensor buoys that were used to triangulate the signal received from an acoustic tag [2]. Results provided good information on the positioning of the tag while within the range of the sensors. However, the system operates similar to a stationary acoustic receiver in that once deployed the system records information in the region of interest, but does not actively attempt to pursue a target that appears to be moving beyond the range of the sensors. The sensors must be picked up then redeployed to the new mission area.

\subsection{Shark Tracking}

The goal of this project is to demonstrate how an AUV could accurately track a shark through the water. However, the application for using an AUV to track a tagged shark would be to learn more about how shark's naturally behave in the wild. This means that in order to observe a shark's natural behavior, it cannot be affected by the AUV being in close proximity. Otherwise, only the shark's behavior as it interacted with the AUV could be observed. This is particularly important because sharks are particularly sensitive to electric fields in the water, and the AUV by its own nature gives off electric signals. 
In order to accomplish the goal of this project, several criteria need to be met. First the AUV must maintain within range of the acoustic sensors to get reliable readings from the acoustic fish tag. Second, the AUV must stay outside of the range of the shark's active sensory field. Thus the optimal point for the AUV to have the best chance of maintaining a minimum distance outside the shark's awareness and minimize the chance of losing the shark is a point on the circle characterized with a radius of the hold off distance centered on the shark itself. However, keeping the AUV on this circle at all times is physically impossible. Thus it may be beneficial to track a slightly wider radius around the shark to allow for overshoot of the AUV or slow response to the shark doubling back on itself.

\subsection{What is the range of detection?}

The range of detection of the fish tag depends on several factors. These factors include the distance the receiver can pick up on the signal sent from the tag and local ocean conditions. In the paper "Tracking Large Marine Predators in Three Dimensions: The Real-time Acoustic Tracking System" they found that they could get consistent readings up to $1000 \mathrm{~m}$ away with reliability decreasing from $1000 \mathrm{~m}$ to $2000 \mathrm{~m}$ with no readings at over $2300 \mathrm{~m}$ [2]. However, for the proposed shark tracking system a different acoustic receiver was suggested. Testing has yet to be done to determine the limits of accuracy of the receiver chosen for Calpoly's AUV, so for the current time a similar reliability of the acoustic receiver is assumed. With the acoustic receiver, the further the distance the less reliable the reading is. This is due to factors like reflection and distortion of the signal. Also bearing and direction to the shark are determined by signal strength 
and the time between the receivers hearing the signal. Over distance the signal strength dies and there is a smaller difference in time between when the signal reaches the receivers.

Other factors that affect the accuracy of the reading are water density and salinity of the water. Changes in water density affect how quickly the signal can go from the tag to the receiver, resulting in a different distance estimate. Depending on the type of shark being tracked two additional sources of error must also be taken into account, objects in the water and thermoclines. For tracking Shovelnose and Leopard sharks they like to inhabit shallower waters where things like seaweed or other natural objects could get between the AUV and the shark and thus change how the AUV nears the signal. For Whites, who prefer the more open oceans, objects aren't as much of a consideration as the thermocline is. At the thermocline there is an abrupt change in temperature salinity and thus water density. If the AUV is on the other side of the thermocline from the shark, it may lead to a false distance reading to the shark. Thus as distance increases, the less desirable the condition of the signal.

The signal the AUV receives from the tag will have noise. In order for a shark tracking algorithm to be a feasible solution it must be robust enough that noise in that signal doesn't negatively impact the AUV's ability to follow the shark. This noise could be anywhere on the range of 5 meter standard deviation in distance and 2 degrees standard deviation in angle to 150 meter standard deviation in distance and 30 degrees standard deviation in angle. 


\subsection{Shark swimming behavior}

Not only must the acoustic receiver be kept in range of the tag on the shark, but the chance of losing the shark must be minimized. First the swimming patterns of the shark are looked at to get an idea of how the AUV will have to move to keep up with its target. The particular sharks of interest are Shovelnose Sharks (Rhinobatos productus), Leopard sharks (Triakis semifasciata) and juvenile great White sharks (Carcharodon carcharias).

The first thing looked at is the average speed of the target to make sure that pursuit of the shark is feasible. In the paper, "Aspects of Shark Swimming Performance Determined using a Large Water Tunnel", the critical swimming speeds of several sharks were tested [12]. The sharks tested were Lemon, Leopard, and Mako sharks. The experiment outlined in the paper attempted to find the critical swimming speed for these sharks and compared that to tail beat frequency in order to find the efficiency of the sharks' swimming. The critical swimming speed refers to the maximum sustainable swimming speed for a set period of time, in this case 30 minutes. Of interest to me were those of the Leopard sharks. A total of 18 different Leopard sharks were tested with total lengths ranging from $35 \mathrm{~cm}$ to $121 \mathrm{~cm}$. The average critical swimming speed was $71.14 \mathrm{~cm} / \mathrm{s}$ with a maximum recorded sustainable swimming speed of $96.9 \mathrm{~cm} / \mathrm{s}$ [12].

The swimming speeds of the White shark have been observed in several papers. All the papers showed comparable swimming velocities. The paper, "Movement and Swimming Behavior of White Sharks in Australian Waters", described the tracking of four different White sharks. All four sharks showed similar swimming speeds of 2.5 to $3.1 \mathrm{~km} / \mathrm{h}, 1.2$ to $3.3 \mathrm{~km} / \mathrm{h}, 2.5$ to $3.8 \mathrm{~km} / \mathrm{h}$, and 1.1 to 3.3 $\mathrm{km} / \mathrm{h}$ respectively [5]. Converting from $\mathrm{km} / \mathrm{hr}$ to $\mathrm{m} / \mathrm{s}$ this results in an average speed range of $0.5 \mathrm{~m} / \mathrm{s}$ to $0.94 \mathrm{~m} / \mathrm{s}$. In a paper looking at movement and swim- 
ming behavior of different sharks in La Jolla, a White shark was tracked with an average velocity of $0.8 \mathrm{~m} / \mathrm{s}$ and a max velocity of $1.3 \mathrm{~m} / \mathrm{s}$ [19]. In a paper looking at space utilization and swimming depth of White sharks at South Farallon Islands, four White sharks were tracked with an average speed of $2.3 \mathrm{~km} / \mathrm{h}$ [11]. Converted to $\mathrm{m} / \mathrm{s}$ this yielded an average swimming speed of $0.64 \mathrm{~m} / \mathrm{s}$.

In the paper on White shark migration, where the White sharks were tracked migrating from California waters to Hawaii, results from the PAT tags used to track the sharks recorded an average minimum speed of $88 \pm 14 \mathrm{~km} /$ day and the fastest migration occurred at a minimum speed of $119 \mathrm{~km} /$ day [27]. This yield an average migration speed of at least $1.02 \mathrm{~m} / \mathrm{s} \pm 0.162 \mathrm{~m} / \mathrm{s}$ and a fastest migration speed of at least $1.38 \mathrm{~m} / \mathrm{s}$. This usage of the term minimal speed comes from the method used to track the sharks. When the PAT tag transmits the record of the shark's movements, it has a limited amount of time to transfer a vast amount of data before it loses battery power. Because of this limited time, the data is summarized and excerpts are sent [4]. This yields a number of points and times the shark was there, however it doesn't give information on where the shark swam between the sent points. By taking the distance between the points and the time at which they were recorded, the researcher can say that this is the minimum speed necessary to move from point A to point B. The shark may have swam in a few circles or a longer distance than the linear distance between the two points which would yield a faster swimming speed. By combining the velocities measured by the various studies, an average velocity of $0.7 \mathrm{~m} / \mathrm{s}$ and a fastest observed speed of at least $1.38 \mathrm{~m} / \mathrm{s}$ are found.

There are however several key things to consider about these shark swimming speeds. The age of the shark, particularly in White sharks may influence the swimming speed. These cited studies determine the sharks' swimming speeds by 
averaging over time. The top swimming speed for the sharks in short bursts may far exceed the observed speed in these studies. This however is not as troubling for the proposed controller as it sounds. As long as the shark cannot maintain the hightened burst of speed, if the AUV does not lose the shark the maximum maintainable swimming speeds of the shark is the key number.

The Iver2, the AUV proposed in this thesis has a velocity range of 1-4 knots [21]. At a conversion rate of 1 knot $=0.5144$ meters / second, that is a velocity range of 0.514 to 2.057 meters/second. From the Oceanserver brochure, the Iver2 has a battery life of up to $24 \mathrm{hrs}$ continuous operation at a speed of 2.5 knots (or $1.29 \mathrm{~m} / \mathrm{s}$ ) [21]. Comparing the AUV speeds to those of the proposed sharks to study, the AUV outpaces the Leopard sharks on a time scale of greater than 30 minutes as the greatest sustainable swimming velocity of the Leopard sharks observed was $0.97 \mathrm{~m} / \mathrm{s}$. This makes the Leopard shark a great candidate for testing of the shark tracking program. The White shark however swims much closer to the speed of the AUV. This increases the odds of losing the shark as if it does get ahead of the AUV, it might not be able to catch up. To prevent losing the shark, a robust tracking method is needed as an improper estimate or prediction of the shark's movement might be unrecoverable.

\subsection{What is the range of shark behavior modi- fication?}

When using the AUV to record data on shark's behavior in the wild, the presence of the AUV should not change the shark's behavior. To ensure this, the distance at which the AUV might affect the shark's behavior must be found. 
Sharks have highly specialized senses that they use to interact with their environment. Sharks pick up on sounds, electromagnetic fields, tastes, smells, physical and visual cues to detect things around them. Since the AUV doesn't produce smells in the water such as blood or urine this sense can be ignored. Since the cost of an Iver2 is fifty-thousand dollars[21], the shark should not be allowed to get close enough to taste the AUV. Similarly, if the AUV runs into the shark it is obviously going to change its behavior so the AUV should not want to be in the same spot as the shark. This leaves electroreception, sounds and vision that the shark can use to detect the AUV.

At the range of one meter or greater, the galvanic field generated by the AUV dies off. In a study [9] done by Dr. Douglas Fields, sharks primarily use electroreception in the final phase of their attack on a potential meal to ensure their jaws close on their prey. Seeing how the aim is to keep the AUV from this circumstance, not letting the shark get so close as to use its electroreceptors should be ensured.

Sound is going to be a big factor in the AUV affecting the shark's behavior. Sound carries through water. The sound of the cavitation of the propeller of the AUV will travel for up to $100 \mathrm{ft}$. If the AUV gets too close to the shark, the sound of the propeller may produce a response in the shark's behavior. One thing going for the AUV is that the ocean is noisy. Sharks that swim around the West coast, particularly closer to shore, are going to be used to the sound of propellers from boats and other watercraft in the distance. It will only be at close range that the sharks will respond to the AUV's propeller.

With regards to the sharks seeing the AUV, water visibility or lack thereof will reduce the change of seeing the AUV at a distance. Very rarely is the visibility greater than $100 \mathrm{ft}$, the cavitation distance, in Californian waters. 
Both Shovelnose and Leopard sharks behave similarly. Both sharks inhabit shallower waters and tend to swim on the bottom. They have the tendency to rest on the bottom and mill around over an area of 100 meters. For both of these sharks, the AUV should try to stay greater than 20 meters away from these sharks. White sharks however are more directional in their swimming patterns. They tend to go straight for at least 1 kilometer before turning. They are also more aggressive than the Shovelnose or Leopard sharks and thus require a greater hold off distance of at least 200 meters.

\subsection{Path Following}

In addition to the overall tracking of the shark's GPS location, data collection on the local conditions would be a key feature to include. This feature is something that was considered for the shark tracker. There are several benefits to having the AUV follow the shark's path directly through the water. By following the exact path of the shark and mounting various sensors on the AUV, local ocean conditions can be determined. Information gained by this could include temperature, oxygen levels, salinity or even topological information. It would also follow the shark's path around an object in the water as opposed to attempting to go directly through it. However, an exact path following of the shark has its disadvantages as well; the first and foremost of these being the distinct possibility of losing the shark. For example, if the shark is just milling around, but then swims off in pursuit of prey, the AUV would have to follow the milling around path before going after the shark in which time, the AUV might lose the shark. 
Also in order to follow the shark's path exactly, a good deal of the battery may be used to execute some of the tight loops the shark makes resulting in decreased mission time.

Due to these concerns, exact following of the shark's path was made a secondary mission objective. This meant that following the exact path of the shark would be beneficial if and only if the shark could not be lost in the process.

\subsection{Objectives}

AUVs have an arsenal of sensors capable of being deployed for recording data in the underwater environment. By using an AUV as a mobile acoustic tag reader, this eliminates the problem of needing many acoustic readers. By using an AUV that can track and follow the path of the shark through the water the local conditions like temperature, depth and water composition can be recorded. By having the autonomous logic tracking the shark, it can be ensured the complete record of data can be analyzed later. The benefits of the use of an AUV compared to the human recording the information is localized information under the water, and constant data collection. Also it allows information to be recorded without needing to lure the sharks with promises of prey and record information at depths and in the open ocean. While expensive, the AUV is also expendable, and eliminated the risk of putting divers in the water with the sharks. By attaching a camera to the AUV, shark behavior can be recorded without having to attach anything directly to the shark. By demonstrating the tracking of an object through the water, the controller could be used on many other species 
of marine life, including sea turtles, migratory whales or even commercially to record divers without putting a cameraman at risk.

\subsection{How the proposed method will advance AUV research}

By designing a controller and demonstrating that the tracking of a shark through the water is feasible and offering an optimal solution, I will not only advance knowledge of sharks, but also explore new uses of AUVs. I believe that the potential of AUVs has yet to be exploited and that this project may lay the foundation for the use of AUVs to further the knowledge of the vast incredible oceans. 


\section{Chapter 2}

\section{Problem Statement}

To assess the performance of the controller a cost function is needed to represent the problem. To do this, the goals and constraints of the problem must be mathematically defined. First, to ensure the shark doesn't swim outside the range of the acoustic sensors, the AUV should minimize the distance to the shark. Second, in order to obtain as much data on the path that the shark is swimming

through the water, the AUV should minimize the distance to the shark's previous trajectory through the water. Finally, the constraint of the range at which the AUV's presence modifies the shark's behavior must be added.

\subsection{Cost Function}

The position of the robot can be described by Equation (2.1). In this definition, $x_{A U V}$ and $y_{A U V}$ are variables that refer to the AUV's position, and $\theta_{A U V}$ refers to the direction that the AUV is pointed. The position of the shark can be defined in a similar manner as seen in Equation (2.2). Our control elements can 
be described as Equation (2.3). The $v_{A U V}$ element represents the desired velocity of the AUV and the $\omega_{A U V}$ element represents the angular velocity of the AUV.

$$
\begin{aligned}
\hat{X}_{A U V, t} & =\left[x_{A U V}, y_{A U V}, \theta_{A U V}\right]_{t} \\
\hat{X}_{\text {shark }, t} & =\left[x_{\text {shark }}, y_{\text {shark }}, \theta_{\text {shark }}\right]_{t} \\
U_{t} & =\left[v_{A U V}, \omega_{A U V}\right]_{t}
\end{aligned}
$$

The cost of tracking the shark can be defined as Equation (2.4). This is the summation of the distance from the target over the time period analyzed. The target is the location on the hold off circle specified by the Desired Point Planner.

The cost of following the shark's trajectory can be defined as Equation (2.5). Where $\Delta$ can be defined as seen in Equation (2.6) and $\bar{v}_{\text {shark }}$ is Equation (2.7). $\bar{v}_{\text {shark }}$ is the average velocity of the shark from the last recorded position outside the hold off radius to the shark's current position. $\Delta$ is the time between the last recorded shark position outside the hold off radius and the shark's current reading. This is used to represent the time since the shark's previous path is outside the minimum distance the AUV must maintain from the shark. This cost function is similar to the one above, but instead of calculating the distance to the target, it looks at the distance to the path the shark has taken through the water over the given time period.

Combining the two cost functions, the overall cost function can be determined to be Equation (2.8). $J_{\text {total }}$ defines the cost of following the target point and the cost of the distance from the shark's previous path through the water. 


$$
\begin{gathered}
J_{\text {tracking }}=\sum_{t=0}^{t_{\text {max }}}\left(\left(x_{\text {target }, t}-x_{A U V, t}\right)^{2}+\left(y_{\text {target }, t}-y_{A U V, t}\right)^{2}\right)^{\frac{1}{2}} \\
J_{\text {trajectory }}=\sum_{t=0}^{t_{\max }}\left(\left(x_{\text {shark }, t-\Delta}-x_{A U V, t}\right)^{2}+\left(y_{\text {shark }, t-\Delta}-y_{A U V, t}\right)^{2}\right)^{\frac{1}{2}} \\
\Delta=r_{\text {holdoff }} / \bar{v}_{\text {shark }} \\
\bar{v}_{\text {shark }}=\left(\sum_{t-\Delta}^{t} v_{\text {shark }, t}\right) / \Delta \\
J_{\text {total }}=J_{\text {tracking }}+J_{\text {trajectory }}
\end{gathered}
$$

\subsection{Constraints}

This simulation also had to operate under several constraint equations. First, since this is a model of a physical system, The AUV is constrained to the kinematic equations of motion seen in Equations $(2.9,2.10,2.11)$.

$$
\begin{gathered}
x_{t}=x_{t-1}+\Delta t v_{t} \cos \left(\theta_{t-1}\right) \\
y_{t}=y_{t-1}+\Delta t v_{t} \sin \left(\theta_{t-1}\right) \\
\theta_{t}=\theta_{t-1}+\Delta t \omega_{t}
\end{gathered}
$$


The response of the AUV was limited in velocity and acceleration modeled after the real world limits of the Iver2. The Iver2, the AUV proposed in this thesis has a max velocity of 4 knots [21]. At a conversion rate of 1 knot $=0.5144$ meters / second, that is a max velocity of 2.057 meters/second. The angular velocity of the AUV was also limited. The Iver2 has a max turn radius of 3 meters. At a max velocity of roughly 2 meters/second, it can complete a full circle of $6 \pi$ meters in $3 \pi$ seconds. Converting to radians, the Iver2 has a maximum angular velocity of roughly 0.66 radians/second. Taking data recorded from testing of the Iver2 in the ocean and throwing out statisical outliers, a maximum acceleration of 1.10 $\mathrm{m} / \mathrm{s}^{2}$ was observed. Equations $(2.12,2.13$ and 2.14) were used to constraint the simulated AUV response to that of the Iver2.

$$
\begin{aligned}
& v_{t} \leq v_{\max } \\
& \omega_{t} \leq \omega_{\max } \\
& a_{t} \leq a_{\max }
\end{aligned}
$$

To ensure the AUV does not modify the shark's behavior, the AUV was further constrained by Equation (2.15). To ensure the AUV does not lose the shark, Equation (2.16) was used to make sure the shark does not swim outside the range of the AUV's sensors.

$$
\left(\left(x_{\text {shark }, t}-x_{A U V, t}\right)^{2}+\left(y_{\text {shark }, t}-y_{A U V, t}\right)^{2}\right)^{\frac{1}{2}} \geq r_{\text {holdoff }}
$$




$$
\left(\left(x_{\text {shark }, t}-x_{A U V, t}\right)^{2}+\left(y_{\text {shark }, t}-y_{A U V, t}\right)^{2}\right)^{\frac{1}{2}} \leq r_{\text {sensorrange }}
$$

\subsection{Assumptions}

Several assumptions were made in this simulation. The main assumption made is the kinematic response of the AUV. This simulation assumes a basic first order system. Momentum and drag of the AUV are ignored. However, the acceleration of the AUV is limited to the AUV's actual acceleration in the water. Another assumption made is that the AUV is tracking the shark in open water or within an area where it will not encounter obstacles in its path. The initial tests of the simulation assume no noise in the signal from the shark, however later tests explore the effect of noise. When the second AUV is added to the simulation, unlimited communication between the 2 AUVs is assumed.

\subsection{Optimal solution}

By combining the two mathematical interpretations of the constraints, an optimal solution to target in the execution of the project can be found. This optimum solution is: $\min J\left(\hat{X}_{A U V, t}\right)$ on $t=0 \ldots t_{\max }$ subject to $U_{t}$. This is subject to the constraints listed above.

The objective of the proposed controller is to minimize $J_{\text {total }}$ for the range of the data set. While the goal is to minimize the cost function over the entire time of the test, in application the AUV cannot look ahead to future known points on the shark's path. Since in actuality the AUV has very little ability to predict the shark's future position, it must use some method of estimating the shark's motion 
and / or attempt to minimize the cost function at each time step in attempt to minimize the total cost function. 


\section{Chapter 3}

\section{Shark Tracking Controller}

\subsection{Controller Block Diagram}

The controller created to track a tagged shark implemented in this project can be described using a controller block diagram as seen in Figure 3.1. The inputs to the control loop are shown to the left. The range and bearing to the shark are given by the acoustic receiver. For the Iver sensors, depth, bearing and GPS location can be read. The Iver uses these to estimate its location. The main three blocks of the controller diagram concerning this project were the Shark State Estimator, Desired Point Planner, and Point tracker blocks. The Shark State Estimator gives a limited prediction of the shark's future path. The Desired Point Planner attempts to minimize the cost functions at the current time step subject to the path weighting. 


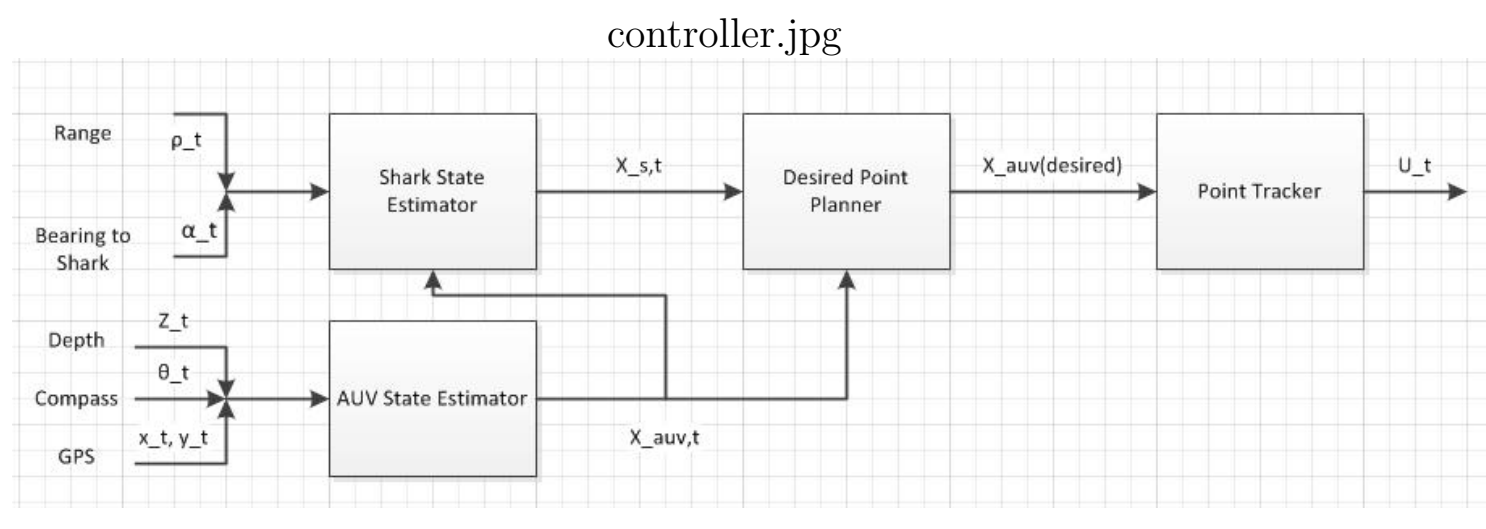

Figure 3.1: Shark Controller Block Diagram.

\subsection{Shark State Estimator}

The Shark State Estimator uses the current AUV state estimation and the distance and bearing to shark to estimate the location of the shark. The purpose of the Shark State Estimator is to convert the discreet signal from the shark tag to a semi-analog representation that the Desired Point Planner can use. This means whenever the AUV wants to update its desired point, it has an estimate of the location of the shark, even if it did not just receive a signal from the shark tag. There are also a number of factors that can introduce error in this measurement. Due to the nature of the acoustic receiver, the distance and bearing to the shark are not discrete and thus can represent a number of different points covering a small area. Thus the exact position of the shark is not known at any point in time. Therefore to estimate the actual position and heading of the shark, a particle filter was implemented.

A particle filter is a method of taking a collection of particles (samples of the distribution with different weightings) to estimate the actual state of the tracked variable. In this case, each particle represents the possible location and movement vector of the tracked tagged shark. The particle filter uses many 
particles that all represent a possible location of where the target could be to statistically determine where the target actually is.

The Particle filter is described below in Psuedocode.

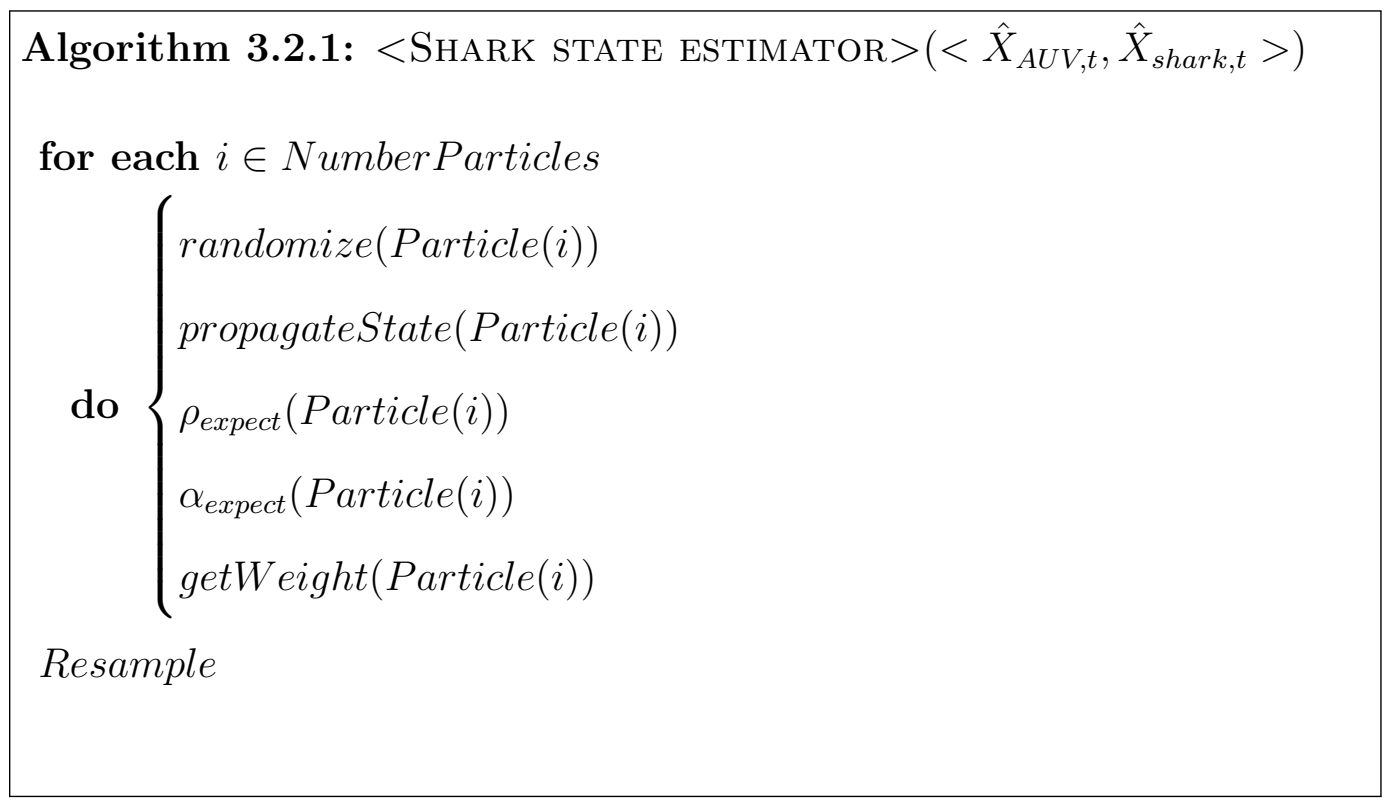

Each particle is created with initial $x, y, \theta$, velocity and angular velocity at the first known shark position. From here a small amount of randomness is added to the velocity and angular velocity of each particle. Then each particle is moved forward in time as the simulation progresses. Due to the randomness added to each particle, the particle cloud disperses along possible vectors the shark could take.

The probability density function is used to determine the weighting of each particle as seen in Equations 3.1 and 3.2. In these equations, $\sigma$ is the standard deviation of the angles and distances from the AUV to the particles. In this case the $\sigma$ values of 5 meters and 2 degrees were used. In the first equation, $\theta_{\text {auvtoshark }}$ is the measured angle to the shark signal and $\alpha_{\text {expect }}$ is the angle expected if this particle is at the angle from the AUV as the shark. Similarly, in equation 3.2, dist fromshark $_{\text {is }}$ the measured distance to the shark signal and $\rho_{\text {expect }}$ is the 
distance expected if this particle is at the distance from the AUV as the shark.

$$
\begin{gathered}
g_{\alpha}=\left(\left(2 \pi \sigma_{\alpha}^{2}\right)^{-0.5}\right) \exp \left(\left(-\left(\alpha_{\text {expect }}-\theta_{\text {auvtoshark }}\right)^{2}\right) /\left(2 \sigma_{\alpha}^{2}\right)\right) \\
g_{\rho}=\left(\left(2 \pi \sigma_{\rho}^{2}\right)^{-0.5}\right) \exp \left(\left(-\left(\rho_{\text {expect }}-\text { dist }_{\text {fromshark }}\right)^{2}\right) /\left(2 \sigma_{\rho}^{2}\right)\right) \\
g_{\text {particle }}=g_{\rho} g_{\alpha}
\end{gathered}
$$

The weighting combines the distance and angular weights into a single number. This is done by multiplying Equations 3.1 and 3.2 together as seen in Equation 3.3. How the weighting works can be seen by looking at Figure 3.2. A number of different particles are shown as red Xs. Angles between the AUV and these particles are shown in green. Particle A has both a high $g_{\alpha}$ and $g_{\rho}$ weighting as it has a similar angle and distance from the AUV to the shark. Particle B has a high $g_{\alpha}$ but lower $g_{\rho}$ weighting as it has a similar angle but different distance from the AUV to the shark. Particle $\mathrm{C}$ has a lower $g_{\alpha}$ but higher $g_{\rho}$ weighting as it has a different angle but similar distance from the AUV to the shark. Particle D has both a low $g_{\alpha}$ and $g_{\rho}$ weighting as it has a dissimilar angle and distance from the AUV to the shark. Particle E has the worst $g_{\alpha}$ and $g_{\rho}$ weighting as it has a very different angle and distance from the AUV to the shark. It has the worst chance of being reselected during the resampling process. Particle A has the highest chance of being reselected. Both Particles B and C have a decent chance of being reselected, while Particle D has a lower chance of reselection.

Next a re-sampling occurs. In this re-sampling, particles that have a higher weight are chosen more often than those with a lower weight. This new set of 


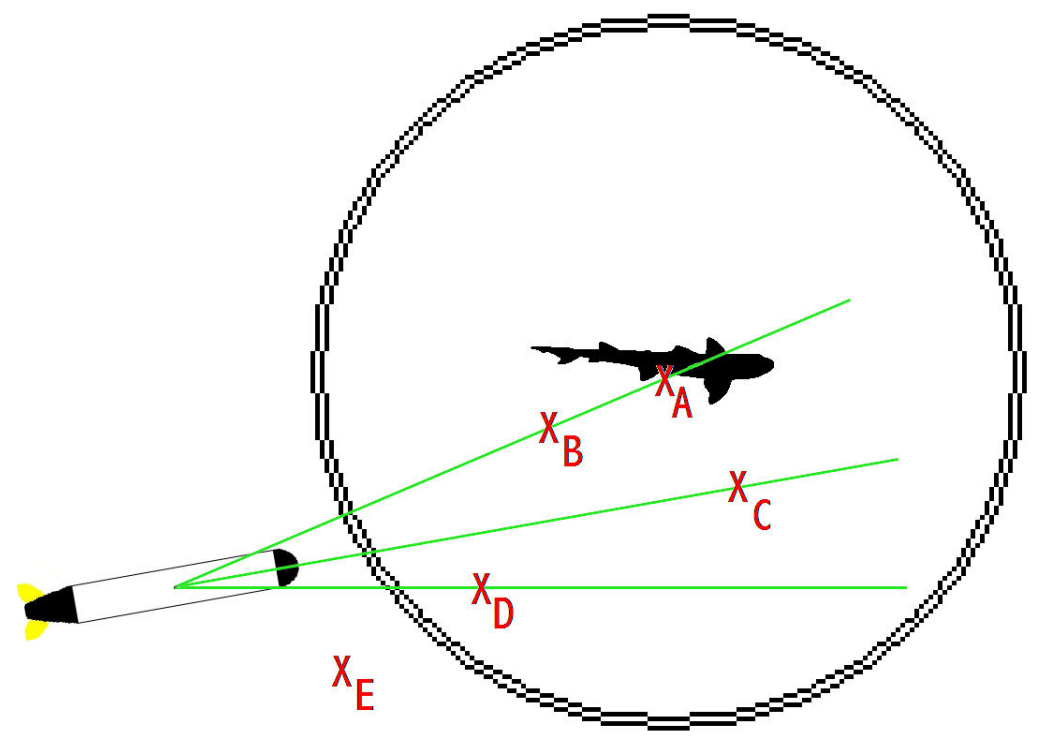

Figure 3.2: Diagram of Particle Weightings

particles is then again passed through the particle filter the next time the Shark State Estimator is used. Thus particles that better represent the actual reading of the shark are propagated and those that are less characteristic of the actual reading die off. By taking the weighted average of the particles that could possibly represent the actual position of the shark, the shark's position can be reasonably predicted.

The shark state estimate is calculated as the weighted average of all the particles. This statte estimate allows for the AUV to attempt to locate the shark in between signals from the acoustic tag and gives is a reasonable estimate of where the shark may be if the AUV loses the shark. 


\subsection{Desired Point Planner}

The Desired Point Planner control block takes the current state estimates of the shark and the AUV and determines where the AUV should be to minimize the cost function. This target point is defined as Equation 3.4. The closest place on that circle to the AUV would be the quickest point on that circle to track. However the AUV may want to follow the shark's path through the water to record information on the local conditions that the shark is actually swimming through. However, the AUV can't just go to any previous path point as it still must maintain a minimum distance from the target shark. So to follow the previous path of the shark the AUV must target the most recent point that is safe to go to.

$$
\hat{X}_{\text {target }, t}=\left[x_{\text {target }}, y_{\text {target }}, \theta_{\text {target }}\right]_{t}
$$

This feature was added to the proposed controller through the use of a simple while loop. Since the AUV has a record of where the shark was and what time it was there it has the shark's path saved to memory. Utilizing a while loop, the AUV steps backwards sequentially through the previously recorded points. For each point, the distance from that point to the shark's current position is calculated. This is found by the following equation. $x_{s p}=x(t-i l o o p), y_{s p}=y(t-i l o o p)$, and $\sqrt{\left(x_{s p}-x_{s}\right)^{2}+\left(y_{s p}-y_{s}\right)^{2}}>=c_{\text {holdoffdist }}+c_{\text {holdoffbuff }}$ If that distance is greater than the hold off distance the while loop is exited and set a flag to let the controller know that a previous path point was found that is safe to go to. Integrated into the while loop is a counter to avoid getting stuck in an infinite loop. If a safe previous path point is unable to be located within a number of iterations, the loop is exited and the flag indicating a previous path point was 
found is kept false.

If a safe point on the shark's path is known, the AUV can then be directed to go there as it still meets the criteria of an optimum point. That is, greater than the hold off distance, but it is also as close as possible to that hold off distance to minimize the chance of losing the shark. For a visualization of angles see figure 3.6. From here there are two possible points on the circle that describes the optimal positioning of the AUV; which does the AUV choose? To deal with this problem, a variable was built in to tell the AUV the weighting of which point it should target. This path weighting is a variable on the range of $[0,1]$ with 0 being weighted entirely to following the most direct path to the shark and 1 being weighted entirely to targeting a previous point on the shark's path if one is available.

If the value of the weighting variable falls between the extremes the AUV will track a point that falls between the direct point on the circle and the place the shark's path crossed the circle. Since the weighting variable can fall on any value between 0 and 1 representing the extremes, the possible track points could be described as the line that crosses through the two points. This causes a problem though. For any line segment that passes between any two points on the circle, all points on that line segment will fall within the circle. This is a problem because the AUV should not enter that circle. Thus the weighting variable should correspond to the points on the arc length between the two known points.

To accomplish this some trigonometry is needed to find the localized $x, y$ corresponding to the desired point. Currently the $x, y$ values of the AUV position are known, the shark and the place the path crosses the hold off circle. The angles and distances from the AUV and path point to the shark can be found. Since both share the same termination point (the shark), the angle between 


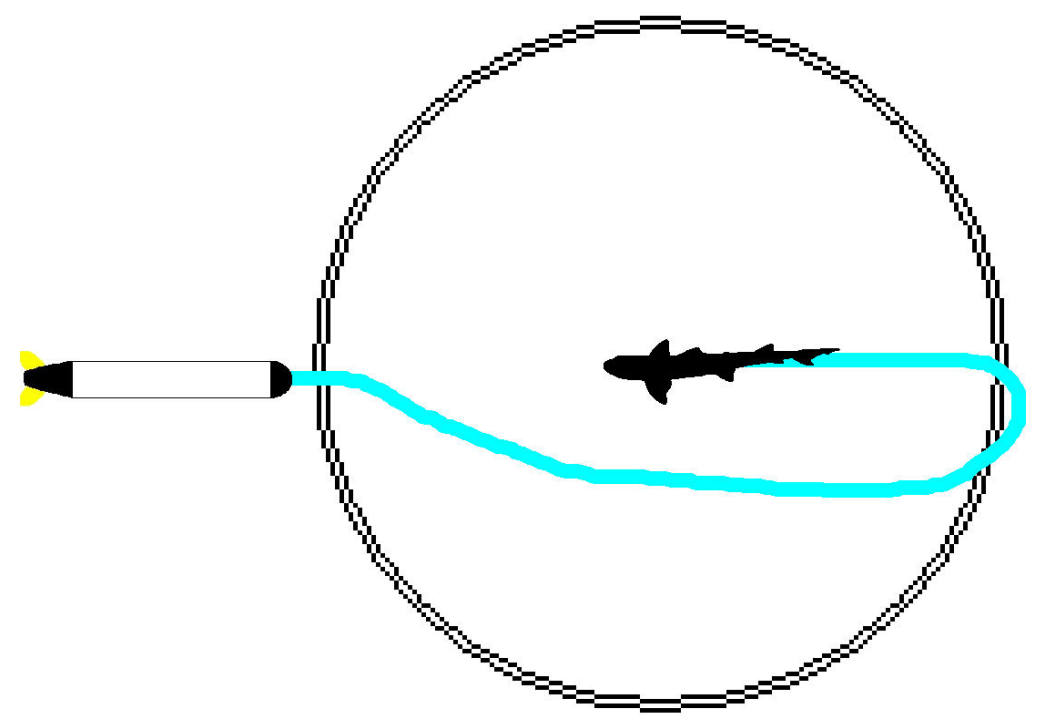

Figure 3.3: Diagram of Shark Doubling Back

them can be found. This angle difference is calculated by thet $a_{\text {sharkpathtoAUV }}=$ thet $a_{\text {tosharkpath }}-$ thet $a_{\text {toshark }}$ This value must then be checked to ensure that it is the concave angle of the two. However one more check must be applied before the AUV can use this angle. If the angle between the two points is greater than 90 degrees then the AUV could potentially attempt to track a point that causes it to cross into the hold of area, and if close to 180 degrees could cause the AUV to cross the shark's path if not collide with it. See Figure 3.3. As this could potentially modify the shark's behavior, this condition is avoided by limiting the angle to being less than pi/2 and greater than -pi/2.

The formula for arc length is as follows. Arclength $=$ RadiusCentralAngle ${ }_{\text {rad }}$ Since the radius is constant regardless of the weighting and is linear, if it were desired to apply some factor to the arc length (the weighting variable) it follows that it could be applied to the central angle. Thus the path weighting is mul- 
tiplied to the interior angle formed by the direct and path points then find the point on the circle that lies on that angle. This can be found by using Equations 3.5, 3.6, and 3.7. The result is a weighting factor that gives a point on the arc between the two points that is a valid point to track as it satisfies maintaining the minimum distance from the shark, but minimizes the distance from that circle.

By running the simulation for several different data sets for several different path weightings, a path weighting can be determined that further minimizes the cost function for that particular shark's behavior.

$$
\begin{gathered}
\theta_{\text {target }}=\theta_{\text {toshark }}+(\text { pathweighting }) \theta_{\text {sptoAUV }} \\
x_{\text {target }}=x_{s}-\left(\left(c_{\text {holdoffdist }}+c_{\text {holdoffbuff }}\right) \cos \left(\theta_{\text {target }}\right)\right) \\
y_{\text {target }}=y_{s}-\left(\left(c_{\text {holdoffdist }}+c_{\text {holdoffbuff } f}\right) \sin \left(\theta_{\text {target }}\right)\right)
\end{gathered}
$$

\subsection{Point Tracker}

The Point tracker control block takes the desired location of the AUV to follow the shark and returns the necessary motor speed and angular velocity to get the AUV to that point. The simplest form of controller is a proportional controller. In this case, a gain multiplied by the distance the AUV is from the shark position to determine the velocity the AUV should use to approach the target. The directional control is achieved in a similar manner. Another gain is multiplied to the angle between the shark and the AUV to determine the desired turn 
speed of the AUV. A third gain is used to turn the AUV to a desired orientation when it reaches its target destination.

Using direct proportional control will result in the most direct path between the AUV and the shark. However, a modified form of proportional control must be used as there is a minimum distance the AUV can get from the shark. To rectify this, instead of tracking the shark directly, the distance and angle from the AUV to the shark is calculated then it is extended by the hold off distance from the shark along the line that connects the shark and the AUV. This is the point that the proportional controller tracks. This point is the closest point to the AUV that is on the circle that describes the optimal tracking distance needed from the shark. Using this method is also useful in implementing the path following functionality described later.

In order to use proportional control, the error factors, gains, and control components need to be defined. The control components are the elements the AUV can control to reduce the error. In this case, these are velocity and angular velocity and can be defined by Equation 2.3. The error components error ${ }_{t}$ are easily defined as the difference between $\hat{X}_{A U V, t}$ (equation 2.1 ) and $\hat{X}_{\text {target, } t}$ (equation 3.4 ). So that leaves equation 3.8, where the error is described as equation 3.9.

$$
\begin{gathered}
\left|\begin{array}{c}
v \\
w
\end{array}\right|=\text { Kerror }_{t} \\
\text { error }_{t}=\hat{X}_{A U V, t}-\hat{X}_{\text {target }, t}
\end{gathered}
$$

From here the $\mathrm{K}$ matrix must be characterized. To do this a coordinate transform is used to get from $\hat{X}_{A U V, t}$ to $\hat{X}_{\text {target, } t}$ as seen in "An Introduction to 
Autonomous Mobile Robots" [1]. This is seen in Equations 3.10,3.11,3.12. The distance and bearing to the target are the obvious choices for the $\rho$ distance and $\alpha$ angles. That leaves the $\beta$ angle. This angle is the angle that represents the final orientation of the AUV. For this controller, this angle was set to match the angle the shark is heading. This allows for the AUV to quickly respond in case the shark takes off.

This method works best for angles of $\alpha$ between $\pi / 2$ and $-\pi / 2$. For values outside this range, it is faster for the AUV to go in reverse. This changes the sign on $\rho$ and how $\alpha$ is found. This is shown in Equations 3.13,3.14,3.15. This redefines the goal as driving the new error components $(\rho, \alpha$ and $\beta)$ to 0 . The control matrix was defined by using Equations 3.16,3.17,3.18. This gives the control equations 3.193 .20 .

$$
\begin{gathered}
\rho=\sqrt{\left(x_{\text {target }}-x_{A U V}\right)^{2}+\left(y_{\text {target }}-y_{A U V}\right)^{2}} \\
\alpha=-\theta_{A U V}+\operatorname{atan} 2\left(\left(y_{\text {target }}-y_{A U V}\right),\left(x_{\text {target }}-x_{A U V}\right)\right) \\
\beta=-\theta_{A U V}-\alpha \\
\rho=-\sqrt{\left(x_{\text {target }}-x_{A U V}\right)^{2}+\left(y_{\text {target }}-y_{A U V}\right)^{2}} \\
\alpha=-\theta_{A U V}+\operatorname{atan} 2\left(-\left(y_{\text {target }}-y_{A U V}\right),-\left(x_{\text {target }}-x_{A U V}\right)\right) \\
\beta=-\theta_{A U V}-\alpha
\end{gathered}
$$




$$
\begin{aligned}
& U_{t}=\left[v_{A U V}, \omega_{A U V}\right]_{t} \\
& v_{A U V}=k_{\rho}\left(\text { dist }_{\text {totarget }}\right) \\
& \omega_{A U V}=k_{\alpha}\left(\text { theta }_{\text {diff }}\right)+k_{\beta}(\beta) \\
& v_{A U V}=k_{\rho} \rho \\
& \omega_{A U V}=k_{\alpha} \alpha+k_{\beta} \beta
\end{aligned}
$$

In summation, the velocity desired then is the error (or distance) from the AUV to the target point. The desired omega is a combination of the two different angular gains. The first gain is multiplied to the difference between the AUV's current bearing and the bearing to the shark from the AUV. The second gain is multiplied by the difference between the AUV's current bearing and the desired bearing when the AUV reaches the tracked point.

\subsection{Determining of Gains}

Before the shark tracker could function properly, the gains of the proportional control needed to be adjusted. There are a total of three gains that needed to be tuned as outlined in the proportional controller section of this paper.

To determine for what gains the controller would remain stable, the coordinate 
transform was again used to calculate out the new kinematics as seen in [1]. Substituting in Equation 3.19, linearizing and using the small angle assumption yields the results in Equation 3.21. Taking the determinate and solving for Eigen values yields Equation 3.22. The controller will then be stable if $k_{\rho}>0, k_{\beta}<0$, and $k_{\alpha}-k_{\rho}>0$.

$$
\begin{gathered}
{\left[\begin{array}{c}
\dot{\rho} \\
\dot{\alpha} \\
\dot{\beta}
\end{array}\right]=\left[\begin{array}{ccc}
-k_{\rho} & 0 & 0 \\
0 & -\left(-k_{\alpha}-k_{\rho}\right) & -k_{\beta} \\
0 & -k_{\rho} & 0
\end{array}\right]\left[\begin{array}{l}
\rho \\
\alpha \\
\beta
\end{array}\right]} \\
\left(\Lambda+k_{\rho}\right)\left(\Lambda^{2}+\Lambda\left(k_{\alpha}-k_{\rho}\right)-k_{\rho} k_{\beta}\right)=0
\end{gathered}
$$

Working from here, several simulations were run on different test cases to determine a good set of gain to make the system respond as desired. For tuning proportional controllers, the quickest response to inputs without excessive overshoot is desired. Another consideration while adjusting the gains is that the higher the output, the faster speed is desired and thus the higher the power consumption to propel the AUV to that speed. So if a combination of smaller gains can closely approximate the response of a set of higher gains, the lower gains would be more beneficial to the mission of tracking the shark for as long as possible. This of course only holds if the AUV doesn't lose the shark more while using the lower gains.

With this in mind, the simulation was run for several different sets of data. Each run the gains were modified and the average distance to the shark recorded the AUV exhibited. The simulations were also watched for any evidence of overshoot that negatively affected the AUV. This was seen when the AUV had trouble smoothly tracking the target point, allowing for jumps in the target's position. 
It would oscillate quickly back and forth or not be able to turn fast enough for the speed gain to arrive at a desired point.

To determine a good set of gains, the method of successive approximation was used to find where the average distance to the shark decreased. Starting with gains of 0.1 and incrementing by 0.2 , the average distance to the shark for the same data set was observed. When this value peaked, then smaller and smaller increments were used until the improvement in average distance to the shark was minimal. If oscillation was observed, indicating too high of a gain, the gains were modified until the oscillation was no longer observed. Using this procedure the gains of $K_{\rho}=0.4, K_{\alpha}=1.25$, and $K_{\beta}=-0.05$ were chosen.

\subsection{The Second AUV}

The addition of a second AUV would provide many benefits to an automated shark tracking system. The key aspect being increased accuracy in location measurements. But having 2 AUVs following a shark in the exact same manner would only result in getting in each other's way and no additional data would be acquired. Therefore, the second AUV needs to follow the shark differently than the first. Having the second AUV allows the first AUV to follow the shark at depth while maintaining the accuracy in its position through GPS communication.

The orientation of the two AUVs relative to the shark should allow for the most information capture possible to justify the cost of the second AUV. The first AUV is using a particle filter to estimate the actual location of the shark. With the signal received from the tag, the AUV is able to determine the angle to the shark fairly accurately, but distance is less accurate. If the second AUV 


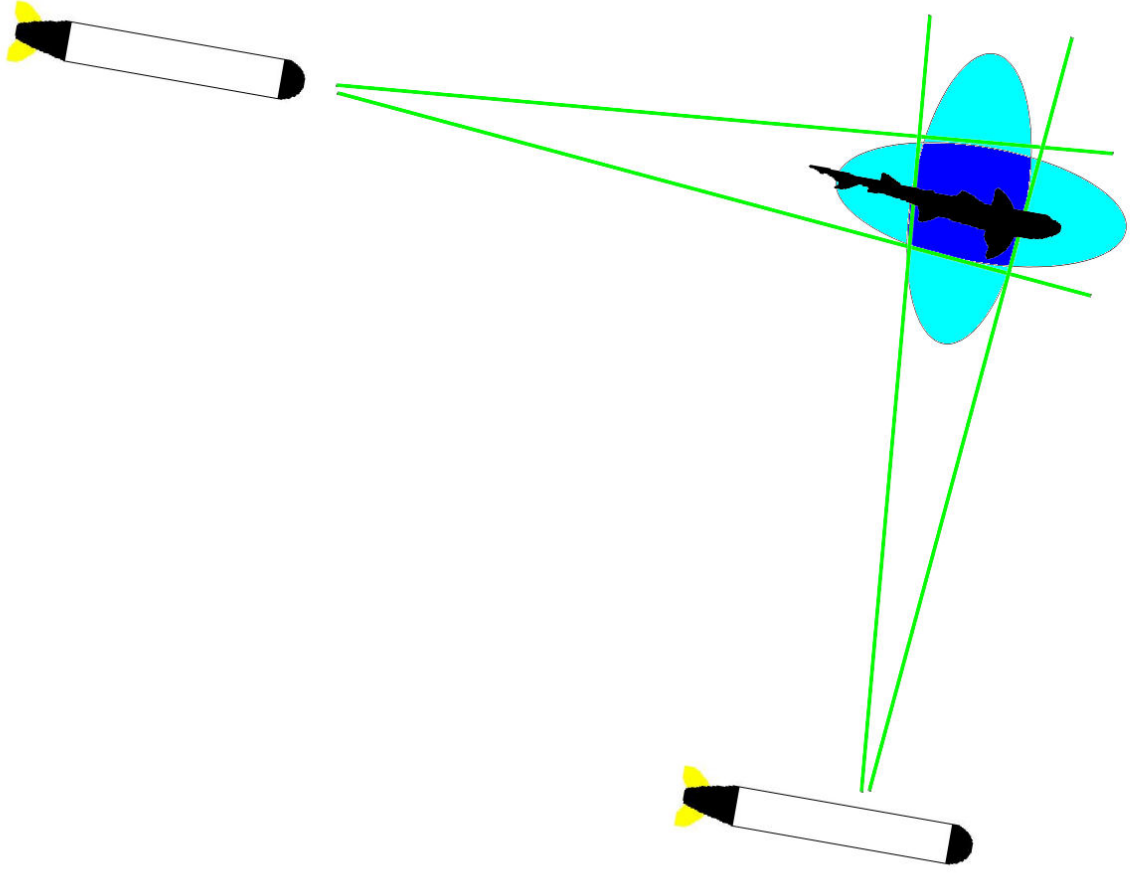

Figure 3.4: Multiple AUV tracking benefit.

is also keeping track of the position of the shark with it's own particle filter, it could communicate this data to the first AUV. Since the angle is fairly accurate, the AUVs want the most difference in this aspect to reduce the error in distance. This concept can be seen in figure 3.4, where the particle clouds (depicted in light blue) of the two AUVs are overlaid. Because the shark belongs to both sets of particles, both areas are reduced (to the dark blue) and the shark's position is more accurately known. Thus the second AUV should attempt to navigate perpendicular to the first AUV and at the surface while the first AUV follows the shark's path and navigates at the same depth as the shark to further increase the resolution in the $z$ dimension. 


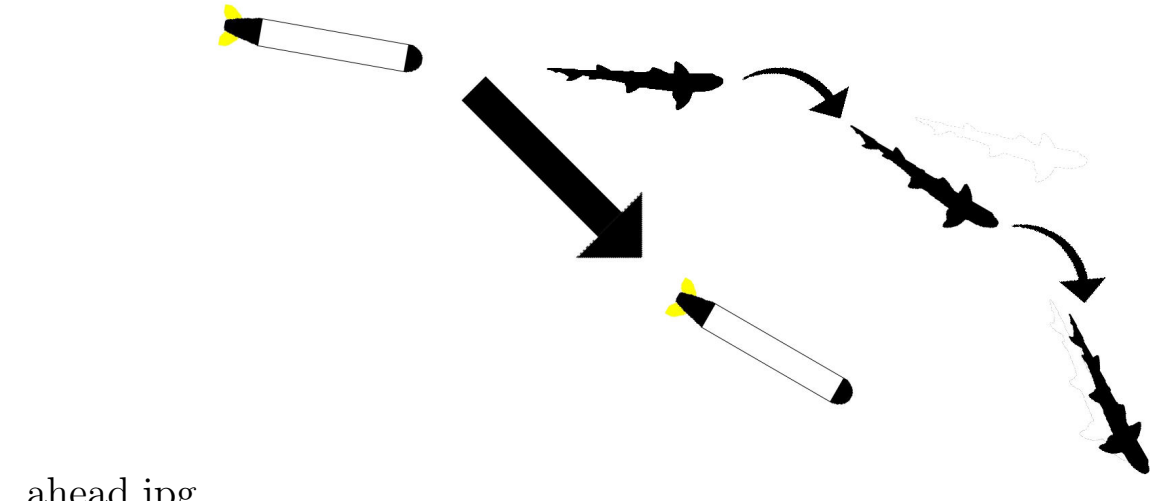

Figure 3.5: Multiple AUV tracking benefit.

\subsection{Shark Position Prediction to reduce Cost}

In addition to the particle filter, another method of predicting the shark's future location could reduce the cost of tracking the shark. The concept being if the shark is swimming a sweeping curve, the AUV could move to cut the corner and reduce the battery consumed by the longer path. This concept is illustrated in figure 3.5 .

The shark's current linear and angular velocity are taken and extrapolated forward in time to predict where the shark will be if it continues on its current path. The AUV then uses distance over time to determine the velocity needed to end up in the optimal position to follow the shark at that future point in time. A very minimal path weighting is applied so that the AUV is slightly inclined to follow the shark's path through the water reducing the $J_{t r a j}$. The further into the future the AUV attempts to predict, the more it will try to cut the corner of the shark's path, however, the greater the potential for error in that guess. 


\subsection{Signal Noise}

A major concern for designing a feasible shark tracking algorithm is how the system responds to noise. The acoustic tag detection system has fairly good angular accuracy, but the accuracy of the distance measurements is much less precise. The shark positioning data used to test this shark tracking controller was recorded with an acoustic tag detector and thus already has some noise built into it. However, for the purposes of testing this controller, the recorded positions are considered to be the actual shark's position and thus to test the reaction to signal noise against a noiseless signal, additional noise must generated.

Noise is random error of a certain magnitude. To generate noise, a normally distributed pseudorandom number generator was used. This random number then was multiplied by the standard deviation of the angular accuracy of the acoustic tag detector. This noise was then added to the actual angle from the AUV to the signal. The process was repeated, generating another random number, this time multiplied by the standard deviation of the signal distance. This noise was added to the signal distance. The following five different noise levels were tested. Noise levels tested were [5m 2deg],[20m 5deg],[50m 15deg],,[100m 20deg] and [150m 30deg]. The first number represents the standard deviation in the distance to the shark and the second refers to the standard deviation in the angle to the shark. 


\subsection{Code Execution Summary}

First, the proposed controller checks if there are any previously recorded positions of the shark that fall outside the total hold off distance. If so, it saves the most recent point that the shark was seen at that it outside the hold off area. The localized $\mathrm{x}$ and $\mathrm{y}$ values of this point are saved to variables for later use. If the search for a previous path point is unsuccessful, the flag for the previous path point is kept false.

Next the distance and angle to the shark is calculated. The distance from the AUV to the shark is found by using Pythagorean's theorem. The angle from the AUV to the shark can be found by using the atan 2 function which takes a change in $\mathrm{x}$ value and a change in $\mathrm{y}$ value and returns the angle between the two. The difference between the shark's position in Cartesian co-ordinates and the AUV's position is passed into the atan2 function to return the angle from the AUV to the shark.

Next if a previous path point was found, denoted by the point found flag, then the AUV uses the atan2 function again to determine the angle from the shark path to the shark. If a previous point was not found, then the AUV sets the theta to shark path variable to the same value as the theta to shark variable. Next the angle created by the AUV, shark and previous path point is calculated (see figure 3.6). By drawing a set of parallel lines cut by the transversal line between the AUV and the shark and another parallel line at the previous path point, the alternate interior angle theorem can be used to show that AUV to shark path angle is equivalent to AUV to shark angle plus the shark to shark path angle. Thus the following formula is found describing the angle between the AUV and previous path point: $t$ thet $a_{\text {sptoAUV }}=$ thet $a_{\text {tosharkpath }}-$ thet $a_{t o_{s} h a r k}$. This value is then checked to ensure that it is the concave angle of the two. Finally, this angle 


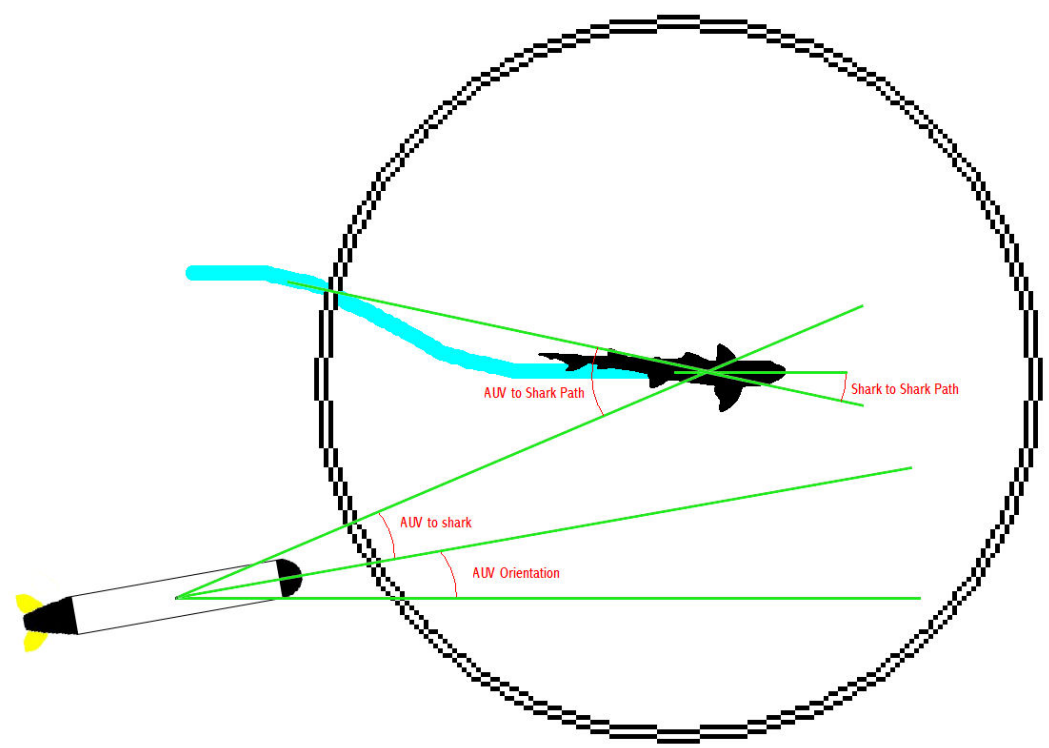

Figure 3.6: Diagram of Shark Angles

is limited to being less than $\pi / 2$ and greater than $-\pi / 2$.

The next step of the proposed shark tracker function applies the weighting of the shark's previous path to the point to track. This is done by calculating the angle created from the point the controller will to the shark. This angle is equal to the angle from the AUV to the shark plus the weighting factor multiplied to the angle between the previous path point and the AUV. The $x$ and $y$ values of the target point to track towards is then back calculated from the shark position and the hold off distance desired. This is seen in Equation 3.5. At this point, the code has a point that it can track using solely proportional control.

The distance between the AUV and the target point is then calculated by again using Pythagorean's theorem as seen in Equation 3.23. This distance is the error of the controller. The angle to this point is then calculated using the atan2 function as seen in Equation 3.24. By taking the difference between the 
AUV's current bearing and the angle to the tracked point, the error in the bearing of the AUV is found. However, this point must be checked to ensure that the difference angle is in the correct quadrant.

$$
\begin{gathered}
\text { dist } t_{\text {totarget }}=\sqrt{\left(x_{\text {target }}-x_{A U V}\right)^{2}+\left(y_{\text {target }}-y_{A U V}\right)^{2}} \\
\text { theta } a_{\text {totarget }}=\operatorname{atan} 2\left(\left(y_{\text {target }}-y_{A U V}\right),\left(x_{\text {target }}-x_{A U V}\right)\right)
\end{gathered}
$$

At this point the AUV must check the magnitude of this angle. If the absolute value of the angle is greater than $\pi / 2$ then it would be faster for the AUV to go in reverse than to circle around by going forward. The final desired bearing of the AUV can be described by: $\beta=$ theta $_{s}-$ thet $_{A U V}($ actualtime -1$)-$ thet $_{\text {diff }}$. This will orient the robot in the same direction as the shark is heading, allowing it to respond quickly in case the shark suddenly speeds up. At this point all the error terms of the controller can be defined. The error is passed into the control equations 3.163 .173 .18 and the desired speed and angular speed are calculated. If the desired speed or angular speed exceed the max speed of the Iver, they are capped at the maximums. 


\section{Chapter 4}

\section{Implementation}

The simulation code for this thesis was written in Matlab. The simulation was run off a PC and relevant data was recorded and captured in Matlab.

\subsection{Effective Controller Characteristics}

Success or failure of the shark tracker is judged on several factors. The primary factors are that it meets the constraints outlined in the problem statement. The first factor to be judged is the ability of the tracker to keep the shark in range. If the controller cannot keep the shark in range, then it must have a method to reacquire the target. An effective controller will have minimal shark losses and be able to recover if it loses the shark for a period of time. A shark loss is considered to be the shark exceeding the maximum range of the acoustic sensors.

The second factor to judge is that the AUV maintains a minimum distance

from the shark. A successful controller will minimize overshoot into the shark's 
personal radius. An effective controller will stay close to the radius of the shark's personal space within reason.

There are several secondary criteria on which the controller may also be judged. A feature beneficial to an effective tracker is the ability to follow the shark's path through the water. This factor will be judged in the difference between the AUV's path and the shark's path through the water. The introduction of noise to the signal from the tag should not significantly impact the performance of the controller. Another feature beneficial to a good tracking algorithm is a method of predicting where the shark will be in between signal readings. This is in case the AUV loses the shark it has a method to reacquire the target. The ability to utilize a second AUV would be another good feature.

\subsection{Data sets}

In order to test the tracking algorithm, a simulated shark was needed for the simulated Iver2 to follow. For this simulated shark to accurately measure the reliability of the proposed tracking algorithm, it must behave like a real shark. In order to ensure this, the simulated shark would be based on actual GPS data of a shark swimming.

"The data set used in this work was obtained by Dr. Chris Lowe in 2008 using a VemCo tagging system installed at Bolsa Chica Ecological Reserve in Southern California. It consists of latitude and longitude data from one Shovelnose shark, and can be seen in Figure 4.1. The shark was tagged with an acoustic transmitter that was then used in conjunction with static receivers to triangulate the shark's 


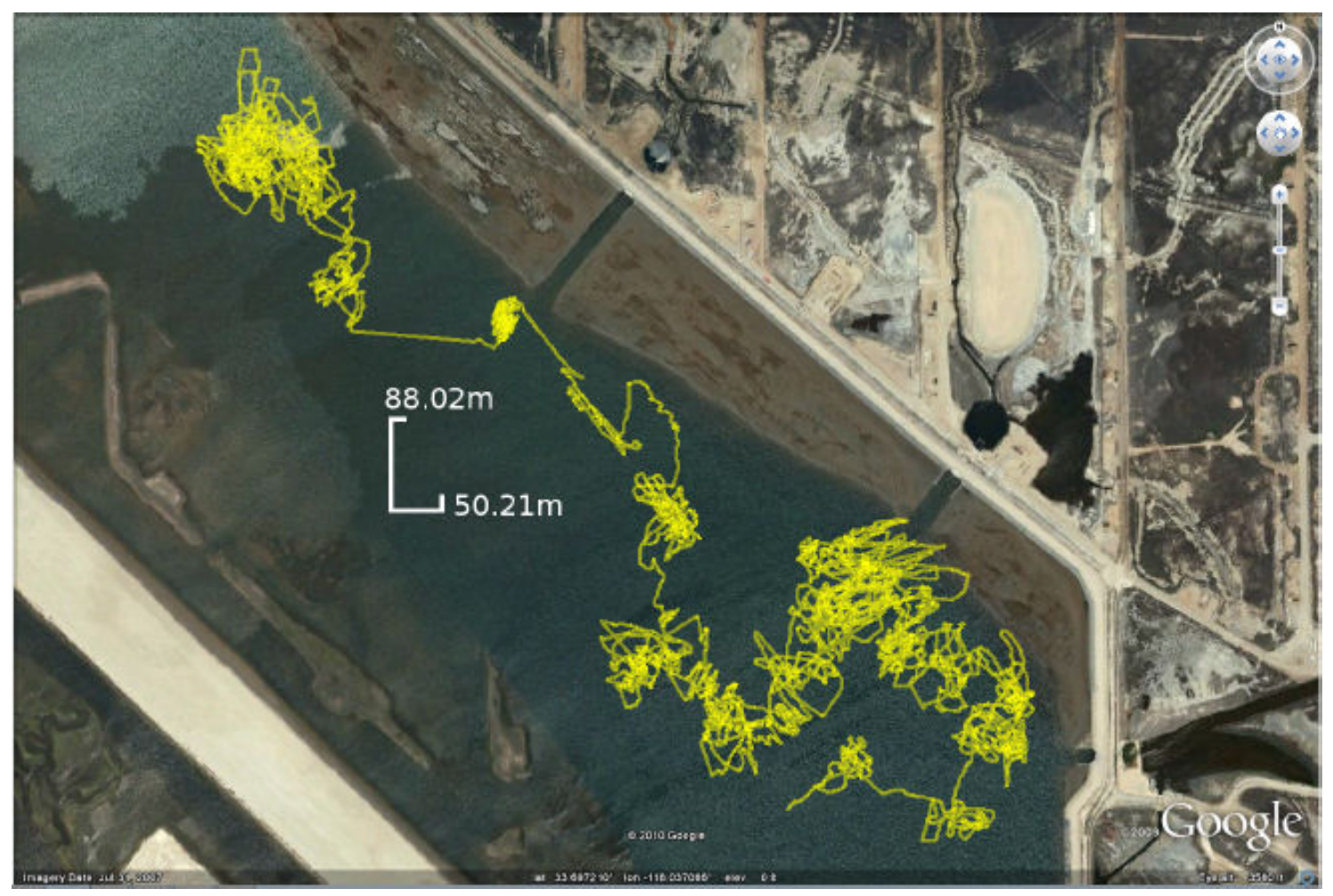

Figure 4.1: Shovelnose trajectory over 24 hours.

positions. Each latitude and longitude measurement pair was time-stamped to the second" [28]. The second set of data is also from Dr. Chris Lowe. This data set records the motion of a White shark for a period of roughly two and a half hours and can be seen in Figure 4.2 .

For each point recorded, the longitude and latitude were converted to Cartesian coordinates localized to the area. Timestamps were subtracted to yield the change in time from the previous time step to the current one. Using $x, y$ and $d t$, several other factors about the shark's movement could be calculated, such as velocity, angular orientation and angular velocity. However, since the AUV will only be able to read distance and direction from its current location, factors such as velocity and orientation are again calculated by the shark tracking algorithm 


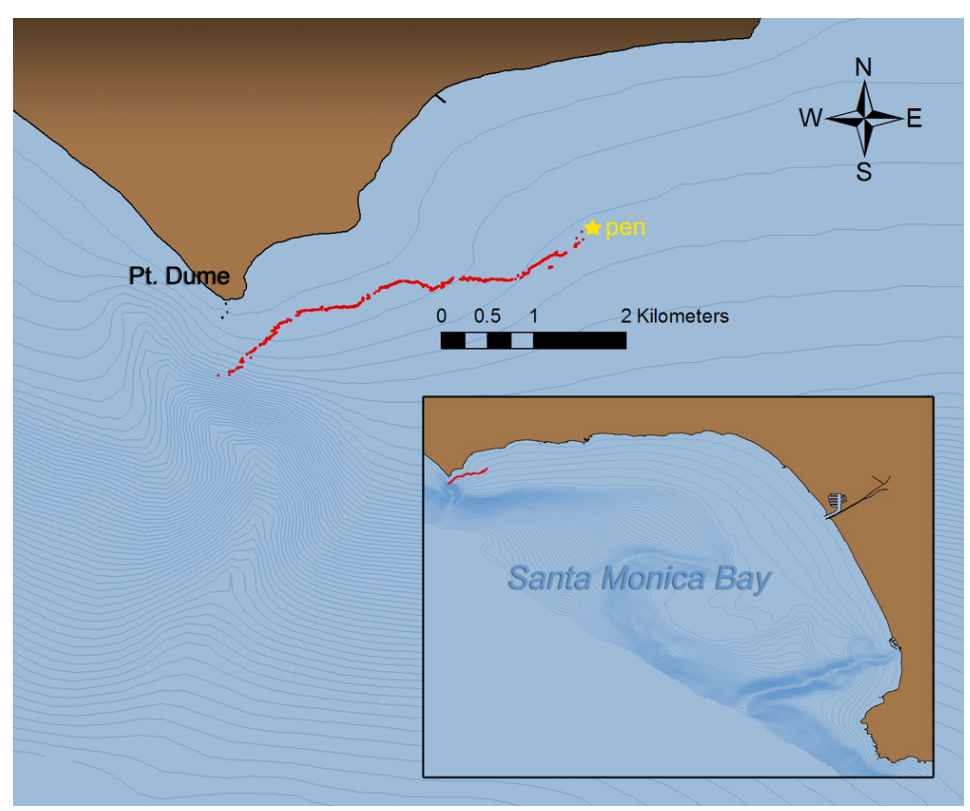

Figure 4.2: Shovelnose trajectory over 24 hours.

as explained earlier in the paper.

As a whole, the data set was difficult to visualize due to the small area and high number of data points. In order to better understand how the shark tracker responded to the input data, several groups of data points were taken from the set. These smaller data sets were then used to test the response of the shark tracker on an individual and case by case basis. They varied in length and figure to elicit different responses from the tracking code.

Several of the data sets can be seen in Figures 4.3, 4.4, 4.5, 4.6, 4.7, 4.8 and 4.9. A quick breakdown of the data sets can be seen in table 4.1.

For each the simulation, the set of data points was identified by changing the starting data point (saved in the variable startStep) and the number of data 


\begin{tabular}{|l|l|l|l|l|l|l|}
\hline $\begin{array}{l}\text { Data } \\
\text { Set }\end{array}$ & $\begin{array}{l}\text { Shark } \\
\text { Species }\end{array}$ & $\begin{array}{l}\text { Starting } \\
\text { Point }\end{array}$ & $\begin{array}{l}\# \\
\text { Points }\end{array}$ & $\begin{array}{l}\text { Total Time } \\
(\text { hh:mm:ss })\end{array}$ & $\begin{array}{l}\text { Distance } \\
\text { Swam (m) }\end{array}$ & Area (m) \\
\hline 1 & Shovelnose & 12100 & 600 & $13: 51$ & 863.065 & $80 \times 90$ \\
\hline 2 & Shovelnose & 12990 & 625 & $15: 35$ & 534.274 & $70 \times 70$ \\
\hline 3 & Shovelnose & 19000 & 1200 & $39: 08$ & 2130.760 & $60 \times 80$ \\
\hline 4 & Shovelnose & 34000 & 800 & $26: 31$ & 2315.977 & $80 \times 120$ \\
\hline 5 & White & 65 & 365 & $34: 02$ & 12277.389 & $1200 \times 600$ \\
\hline 6 & Shovelnose & 37800 & 1700 & $57: 14$ & 3718.900 & $140 \times 120$ \\
\hline 7 & White & 60 & 1140 & $1: 59: 18$ & 42800.743 & $3000 \times 1500$ \\
\hline
\end{tabular}

Table 4.1: Summary of Data Sets

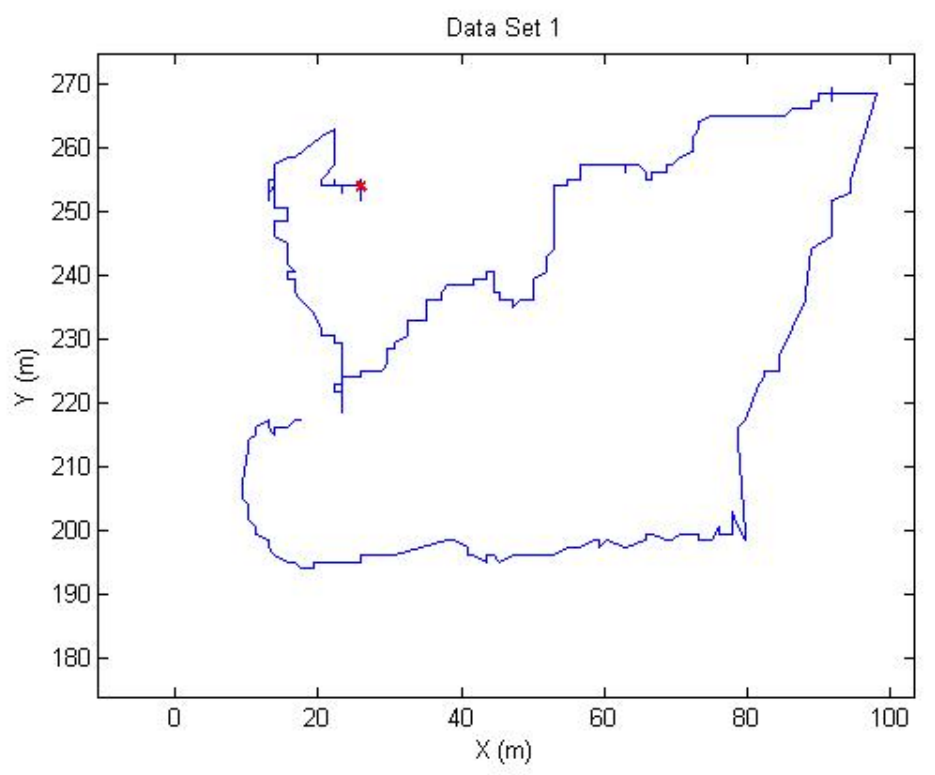

Figure 4.3: Data Set 1. 


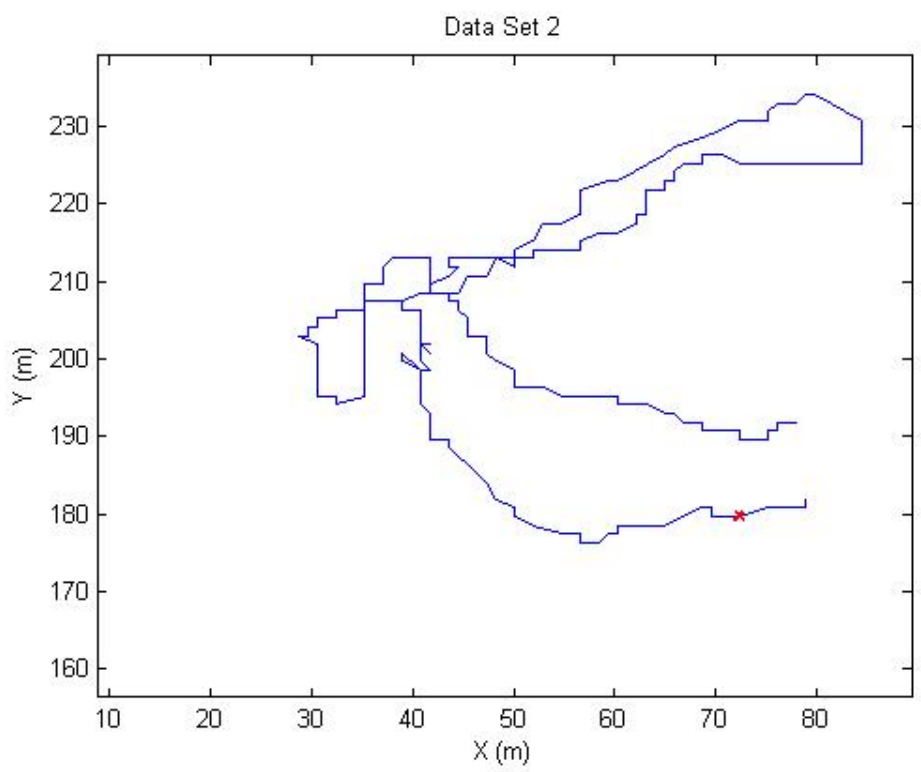

Figure 4.4: Data Set 2.

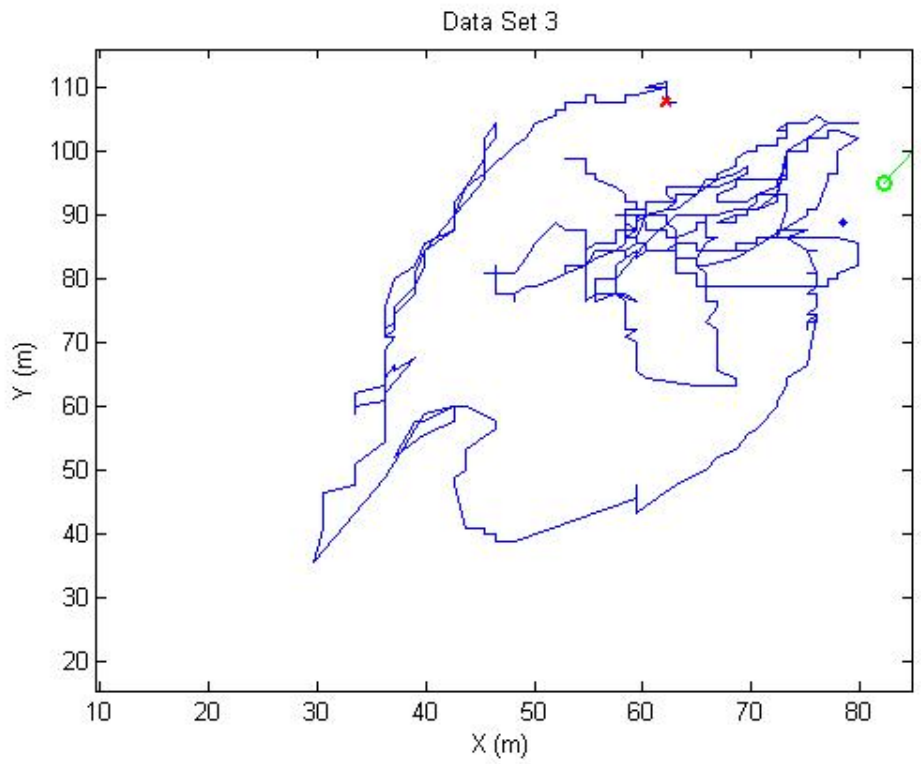

Figure 4.5: Data Set 3. 


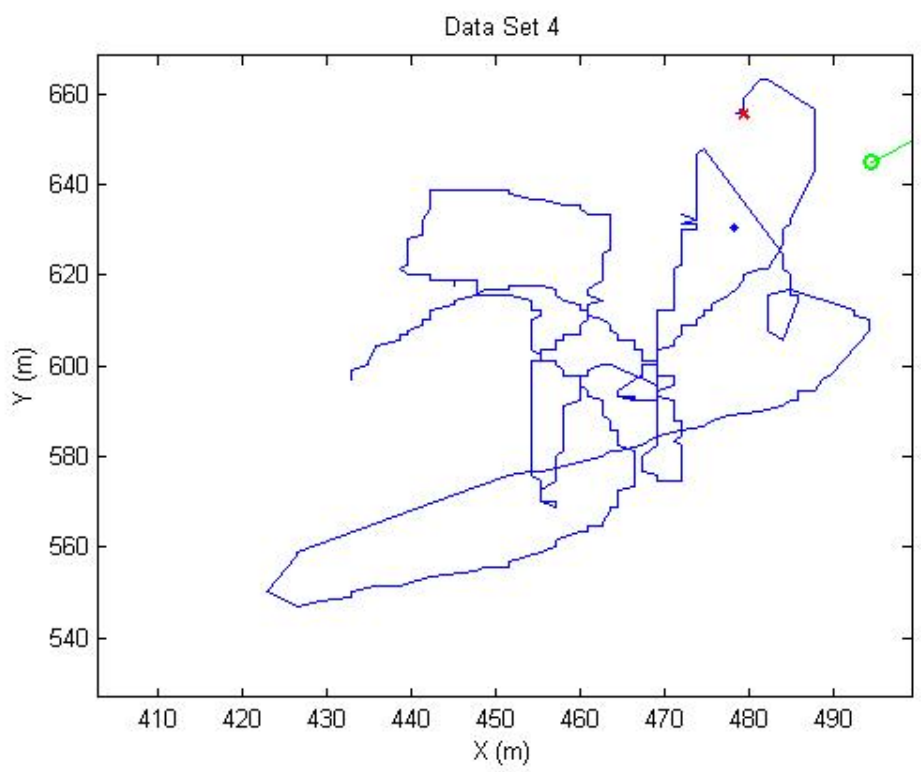

Figure 4.6: Data Set 4.

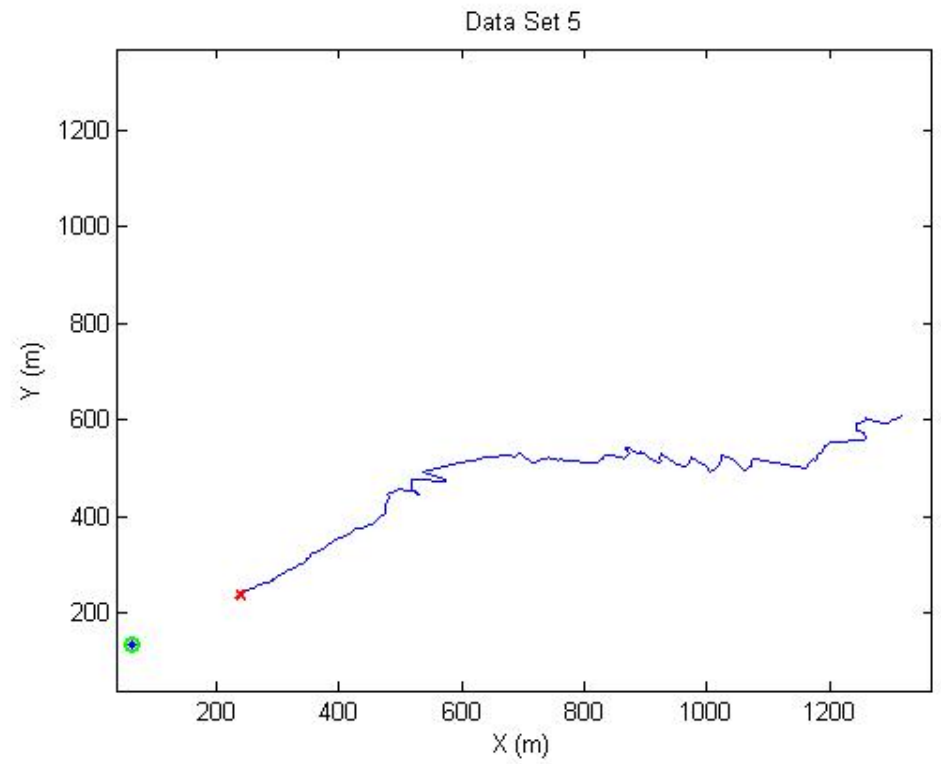

Figure 4.7: Data Set 5. 


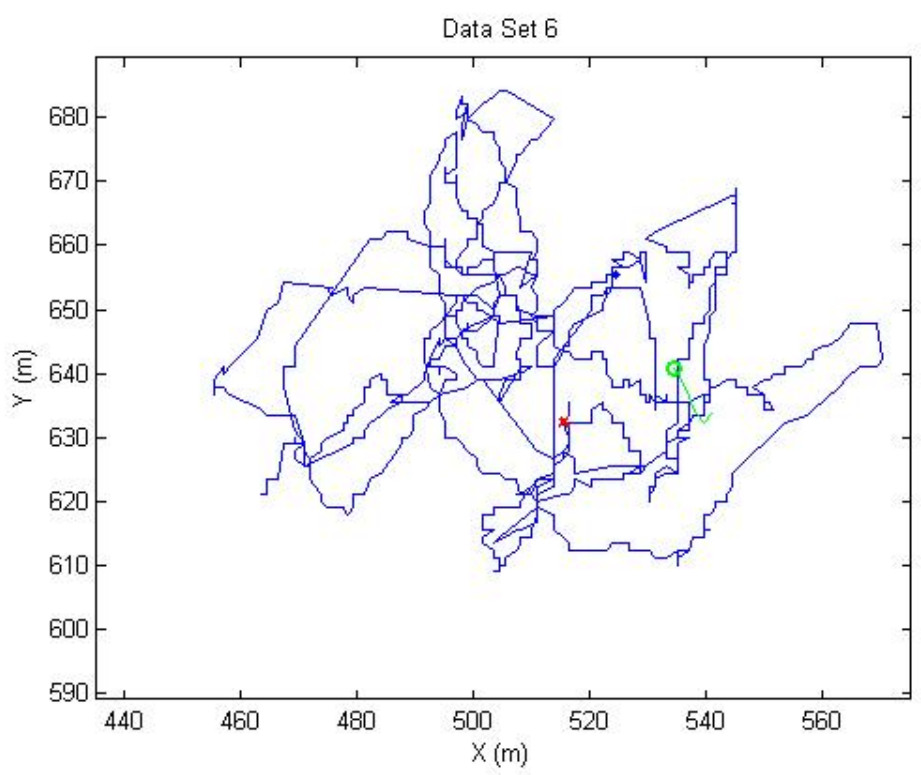

Figure 4.8: Data Set 6.

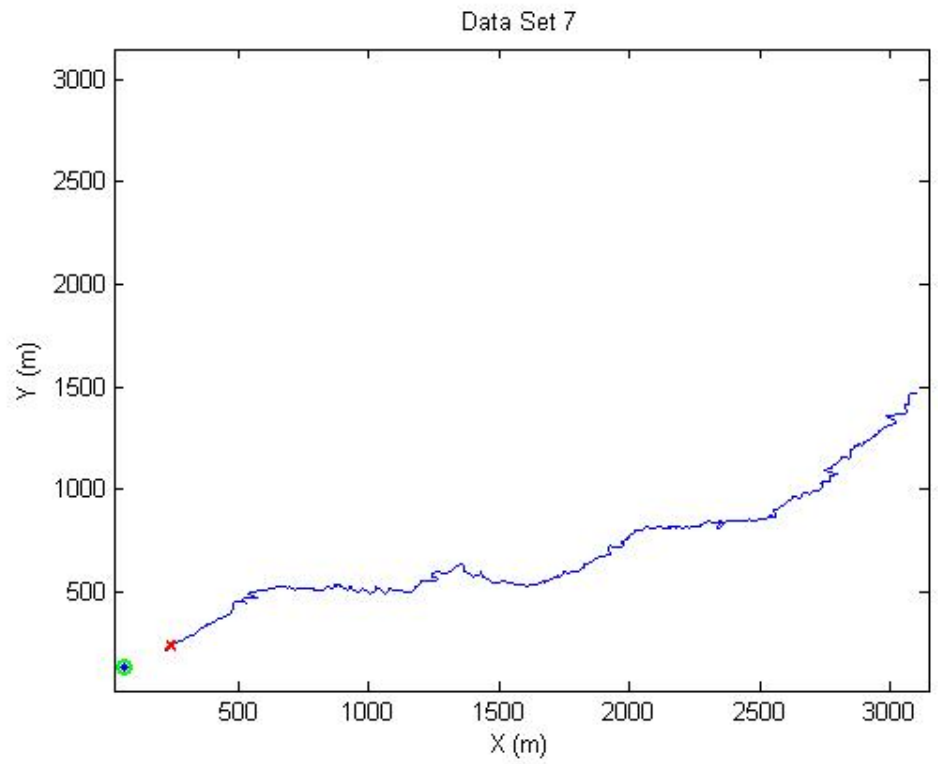

Figure 4.9: Data Set 7. 
points desired to simulate (saved in the variable numTimeSteps). The rate at which the graph of the shark's and AUV's positions is updated is saved in the variable timeStepSize. Getting the timing of the simulation reliable was needed to accurately simulate the shark's and AUV's movements. To accomplish this, the simulator was run on one timing scale. At every step of timeStepsize, the AUV would execute its tracking logic and update its position and propagate the particles if a particle filter was used. It would also increment another timer that would then be compared to the dt until the next shark reading was recorded. Once this counter exceeded that dt value, the shark step would be incremented, resulting in the shark being 'seen' by the AUV at the next position in the data set. If the new step was equal to the endStep of the simulation i.e. the startStep +numTimeSteps, then the simulation ends and displays the output graphs desired. By using this method, the AUV and shark would be updated on different timescales to ensure a realistic simulation.

\subsection{Ocean and Simulation similarities and dif- ferences}

There are a number of similarities and differences between the code that ran in Matlab to simulate the AUV and its responses to the code to be used in the real water tests. First and foremost, the logic and code has to be ported from Matlab to C Sharp, the language that the Iver2 AUV is currently running off. Several files and the methods to read and write to them will be created to input and output data from the Iver2 during the ocean test. The hydrophones would be setup

and attached to the Iver2 in some configuration that optimized the accuracy of 
data gathered. The hydrophones detect the signal emitted from an underwater fish tag. This signal is amplified and isolated from the background noise by each hydrophone. Knowing the orientation of the hydrophones and the time between the signal reaching each hydrophone, direction and distance the signal emanated from can be determined, giving the controller distance and direction to the shark. An example of how this might be done for the Iver2 platform can be found in the Calpoly Senior Project, Ultrasonic Shark-tag Locator System for IVER2 AUV [10].

In the Matlab simulation, the $x, y$ position of the Iver2 was calculated from the velocity, angular velocity and time step size. In the actual ocean test, the $x, y$ of the Iver2 was calculated by the Iver2. Since this controller only runs at the surface, GPS functionality will be available to better know the Iver2's position.

In the Matlab simulation of the Iver2 operation, the outputs of the shark tracker were the velocity and angular velocity of the Iver2. For the ocean test however, the only functions to control the Iver2's movement were a motor gain with a range of 0-255 and a fin orientation angle again with a range of 0-255. In both cases a gain of 128 represents neutral. For velocity 0 represents full reverse and 255 equals full forward. For the angle, 0 steers full right and 255 full left. The tracking module was modified to output desired velocity and the desired AUV heading to the target point. The difference between the desired heading and the AUV's actual heading becomes the angular error. This error will then need to be converted from radians to degrees and the angular gain was converted from radians to degrees. The result of the angular error and the angular gain would be multiplied and added to 128 to determine the desired yawFin angle. Desired motor speed was passed into the following function to convert from desired speed in meters per second to a motor value. This first must be changed to from meter 
per second to knots by dividing by 0.5144 . This speed in knots $\left(v_{\text {desired }}\right)$ is then passed into formula 4.1 to determine the motor gain $\left(k_{\text {motor }}\right)$. In this formula, $c_{1}=0.9658, c_{2}=5.6050, c_{3}=35.3502$ and $c_{4}=123.9276$.

$$
k_{\text {motor }}=c_{1} v_{\text {desired }}^{3}-c_{2} v_{\text {desired }}^{2}+c_{3} v_{\text {desired }}+c_{4}
$$




\section{Chapter 5}

\section{Results}

Seven different test cases were decided upon for the testing of the shark tracking controller simulation. First the accuracy of the particle filter will be analyzed. Second, a number of different data sets will be analyzed using various weighting values to determine what the best weighting is for tracking the different sharks. Third, the affects of different weightings on a single data set will be looked at. Fourth, the affect of noise on the signal will be explored. Fifth, the benefits of the addition of a second AUV to the controller will be examined. Next, basic prediction of the shark's future movements will be used to attempt to reduce the cost. Lastly, the combined particle filter, path planner and point tracker will be tested using the optimal weighting and longer data sets to show that the shark tracking controller functions as desired. 


\subsection{Particle Filter Accuracy}

In order to track the shark between readings an accurate particle filter is needed to estimate the shark state at the current point in time. For this test two different particle filters were used. The first was a basic Gaussian particle filter. The second particle filter used was the particle filter developed by Alex Xydes that uses an estimate of the shark's behavior pattern to get a more reliable estimate of what the shark will do next [28].

For this test case data set 1 was used. Each particle filter used 500 particles to estimate the current state of the shark. The simulation was run using an equal number of particles per filter to yield more comparable results. From these sets of particles, a weighted average was taken to represent the location that each particle filter estimated that the shark was. Alex's particle filter first took a weighted average of the particles in each behavior state, representing the location of the shark for each behavior. Then the behaviors were weighted based on the shark's current actions. The weighted average of the behavior estimated locations was

then used to represent the estimated location of the shark [28]. The estimates of the shark's current state were then compared to the GPS data of where the shark was recorded at that point in time. The distance between the estimated shark and the recorded shark was then calculated using Pythagorean's theorem to determine the error associated with the particle filter. This shows a measure of the accuracy of each particle filter.

The graph of the error in each particle filter over the time of the simulation is shown in Figure 5.1. The y-axis of the graph shows in meters the distance from the particle filter shark to the recorded shark. The x-axis displays the time in 


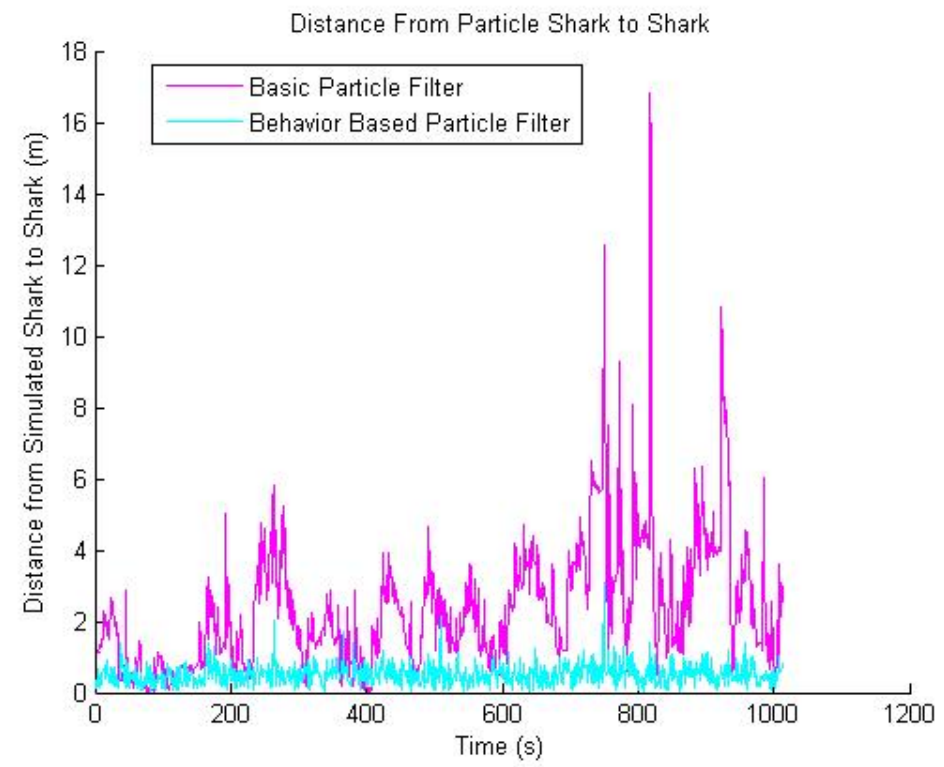

Figure 5.1: Particle Filter Error.

seconds into the simulation that the error was calculated at. The Magenta line shows the error associated with the basic Gaussian particle filter. The Cyan line shows the error associated with the behavior weighted particle filter.

The other relevant data to assessing the accuracy of the particle filters is the standard deviation of all the particles at each time step. The larger the standard deviation, the less precise the particle filter is. Precision is important because it allows the AUV to narrow the possible area the shark could occupy. The graph of the standard deviation of the particles of each filter is seen in Figure 5.2. The $\mathrm{y}$-axis of the graph displays the standard deviation in meters. The $\mathrm{x}$-axis of the graph displays the time in seconds. The Magenta line again represents the standard deviation of the basic Gaussian particle filter, and the Cyan line represents the behavior weighted particle filter. 


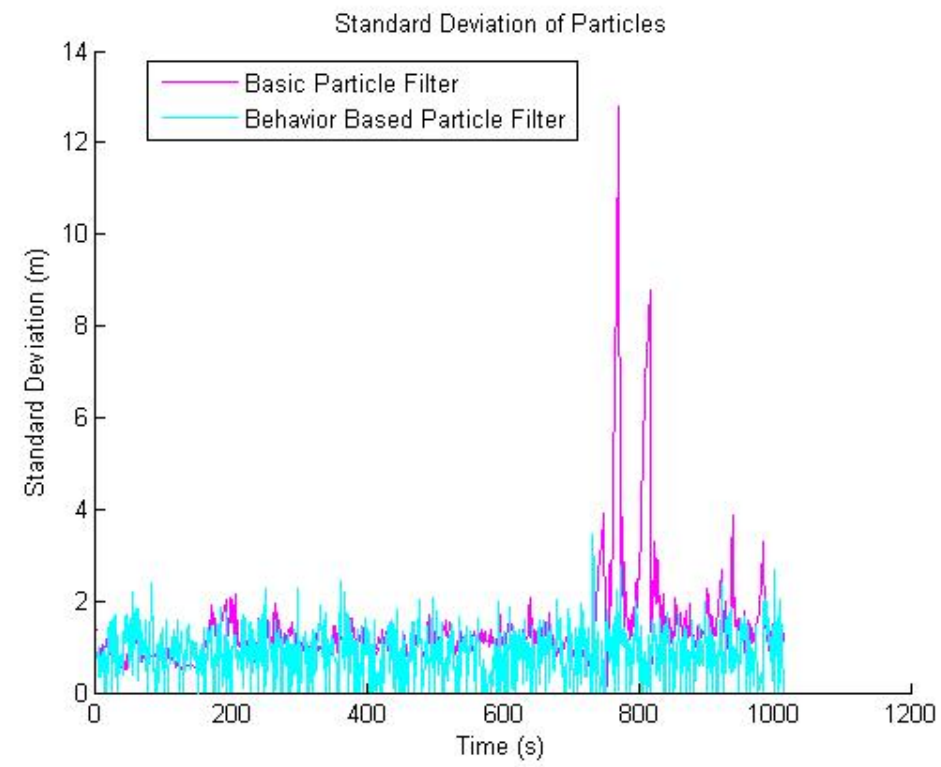

\section{Figure 5.2: Standard Deviation of Particle Filter Error.}

\subsection{Path Weighting}

For different path weightings, the AUV will responds differently. Just how noticeable are the different path weightings? For this test case, data set 4 was used. Three different weightings were applied to the shark tracking controller. These weights were $[0,0.5,1]$. Two different aspects of the change in weighting were looked at. These were the path the AUV took through the water in pursuit of the shark and the costs associated with each time step.

The simulation of the shark tracking controller was run three times, one for each different weighting. The trajectories of the AUV during each trial were recorded and then overlaid on the same graph to visualize the differences caused by the different weightings. The resulting graph can be seen in Figure 5.3. The $\mathrm{x}$-axis of this graph shows the localized $\mathrm{x}$ coordinate of the shark or AUV in meters. The y-axis shows the localized y coordinate of the shark or AUV in meters. The Black line shows the shark's path through the water. The Red line represents 


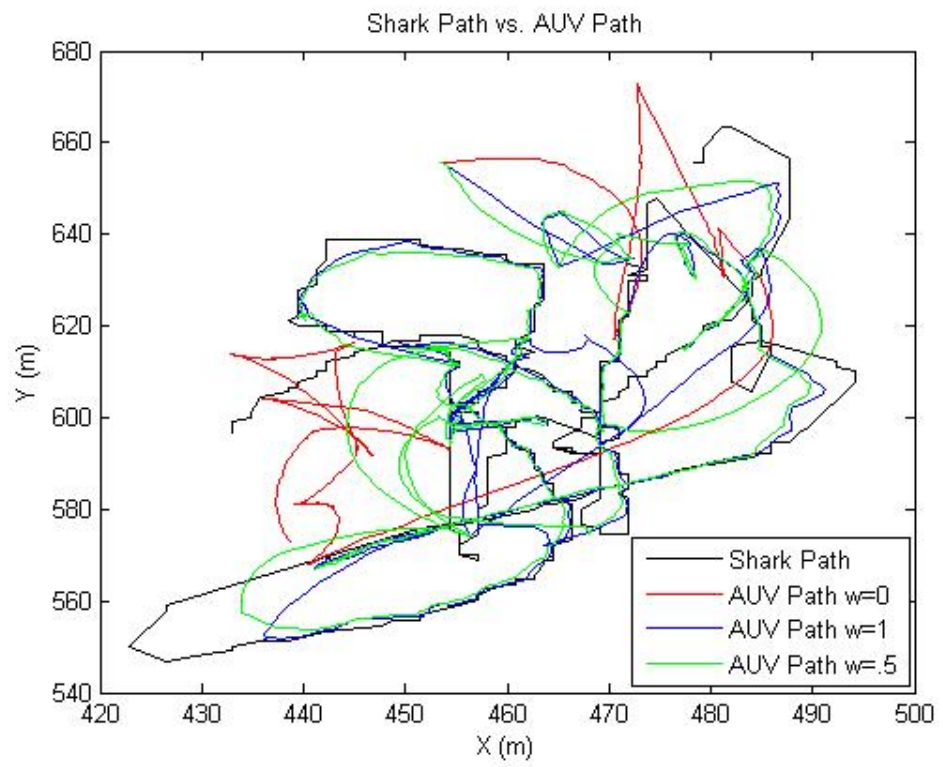

\section{Figure 5.3: Plot of the shark path vs. AUV path for three different path weightings.}

the AUV's path when the simulation was run with a weighting of 0 . The Green line represents the AUV's path when the simulation was run with a weighting of 0.5. The Blue line represents the AUV's path when the simulation was run with a weighting of 1 .

The cost functions associated with the various path weightings were then analyzed. The graphs of the cost functions can be seen in the following figures. Figure 5.4 shows the cost functions with a weighting of 0 . Figure 5.5 shows the cost functions with a weighting of 0.5 . Figure 5.6 shows the cost functions with a weighting of 1 . The $y$-axis shows the value of the cost. The $\mathrm{x}$-axis shows the time in the simulation in seconds. In each graph, the Red line shows the cost of tracking the shark, the Blue line shows the cost of following the trajectory of the shark, and the Green line shows the total cost of tracking the shark and its 


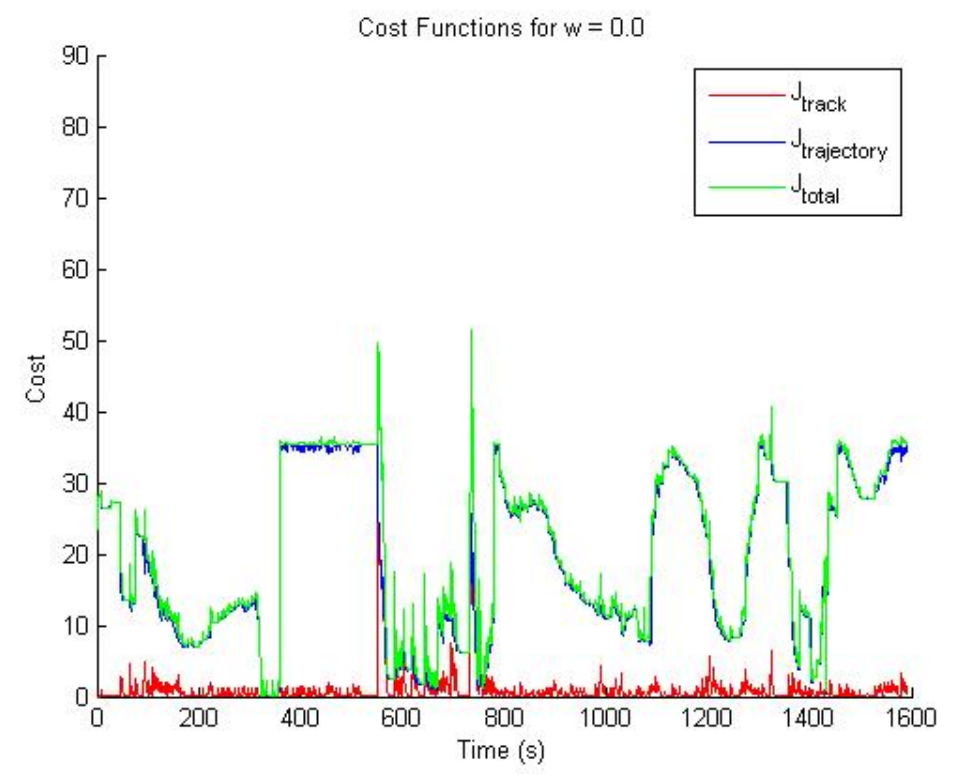

Figure 5.4: Cost Functions over the time of the trial for Data Set 4 with a path weight of 0 .

trajectory.

\subsection{Optimal Path Weighting}

The purpose of this second path weighting test case was to determine the optimal value of the weighting of the shark path for the different sharks. As shown in the prior test case, different values of weightings yield different results. Since the weighting must be chosen before the simulation can be run an optimal weighting must be chosen prior to the AUV being sent on the mission.

This test case not only ran different weightings, but ran the weightings for several different data sets. The chosen weightings were $\mathrm{w}=[0,0.25,0.5,0.75$, 1 ]. The data sets used in this test were sets 1-5. The metric used to measure how well each weighting worked were the cost functions. Each data set was run 


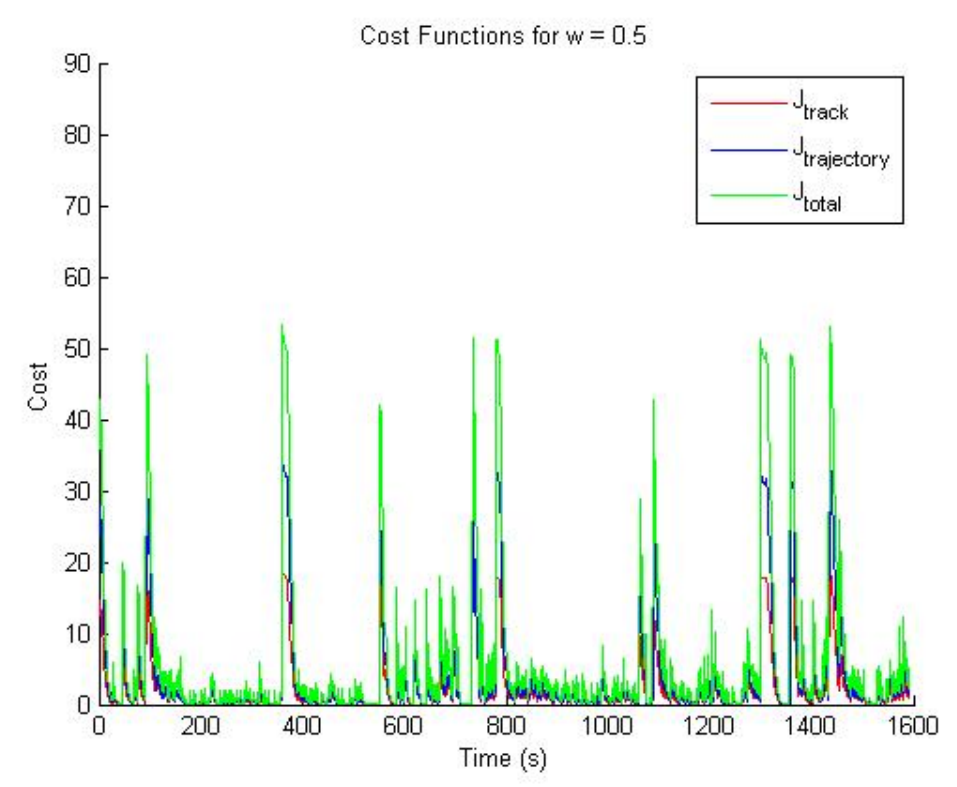

Figure 5.5: Cost Functions over the time of the trial for Data Set 4 with a path weight of 0.5 .

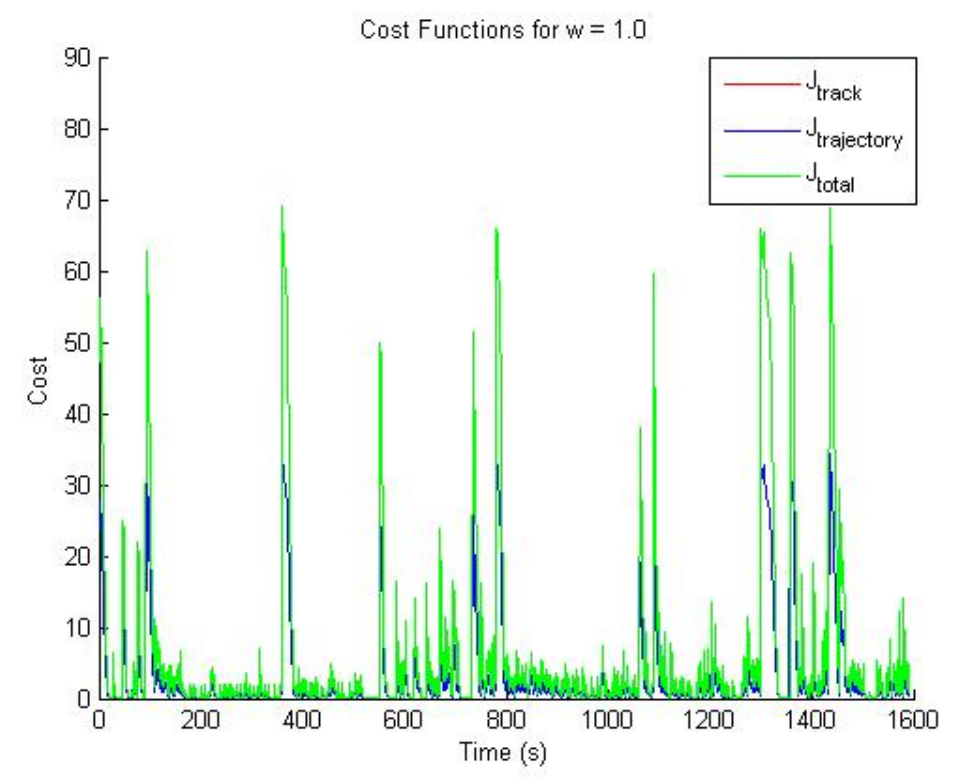

Figure 5.6: Cost Functions over the time of the trial for Data Set 4 with a path weight of 1 . 
through the simulator a total of five times, once for each possible weighting. The costs associated with each weight were graphed next to each other. It should be noted that data sets 1-4 are based on Shovelnose shark GPS data and data set 5 is based on White shark GPS data. Because each species of shark has its own swimming behavior, different weightings may be warranted.

The graphs of the data sets and weightings can be seen in Figures 5.75 .8 5.95 .10 and 5.11. The y-axis of the graphs shows the cost. Grouped along the $\mathrm{x}$-axis are the different weightings. For each weighting, the three different costs (tracking, trajectory and total) were plotted. The Blue bar shows the cost of tracking the shark, the Green bar shows the cost of tracking the trajectory of the shark, and the Red bar shows the total cost of tracking the shark and its trajectory.

The complete results can be seen in Table 5.1. In this table, key factors from the trials are shown. These include total cost functions over the data set, cost functions averaged over the time of the trial, the maximum costs of each, and finally minimum, maximum and average distance from the shark. As the different species of shark have different swimming behaviors, different weights could possibly yield better results for one shark species over another. To better interpret the results the various weightings have across several Data Sets, the results were averaged over Data Sets 1-4 (the Shovelnose data) and Data Sets 1-5 (both White and Shovelnose data sets). This can be seen in Table 5.2. Looking at the results from running the simulation over four different Shovelnose Shark data sets and a White Shark data set, the effects of different weights can be generalized for each shark.

The total cost columns display the total costs over the time of the trial, these 


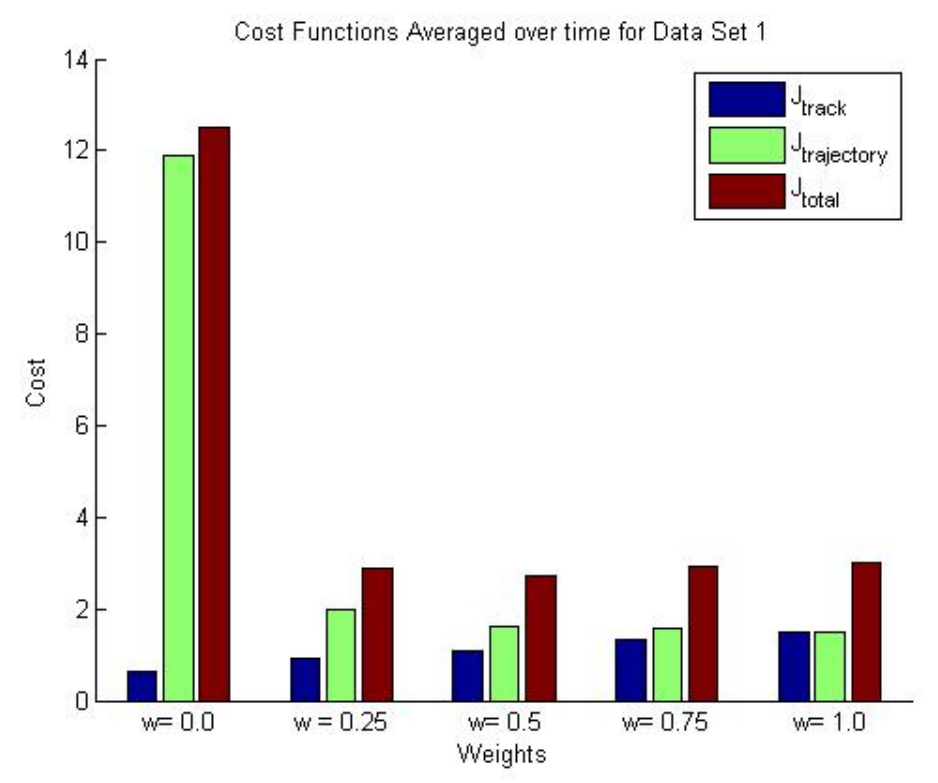

Figure 5.7: Cost Functions over the time of the trial for Data Set 1 with various path weightings.

columns show how the costs vary with the path weighting factor, but since all the data sets are different lengths, the more informative columns are the cost functions averaged over time. These can be compared across various data sets. The lower the cost values the better. The maximum values of the cost functions tell which weightings result in the highest costs at different points in time. Again, the smaller the max values the better. The final sets of numbers extracted from the trials are the minimum, maximum, and average distance to the shark. The minimum distance to the shark should be the closest value to the hold off distance without going under it. The maximum distance to the shark should be as small as possible. The average distance should be as close to the hold off distance as possible. 


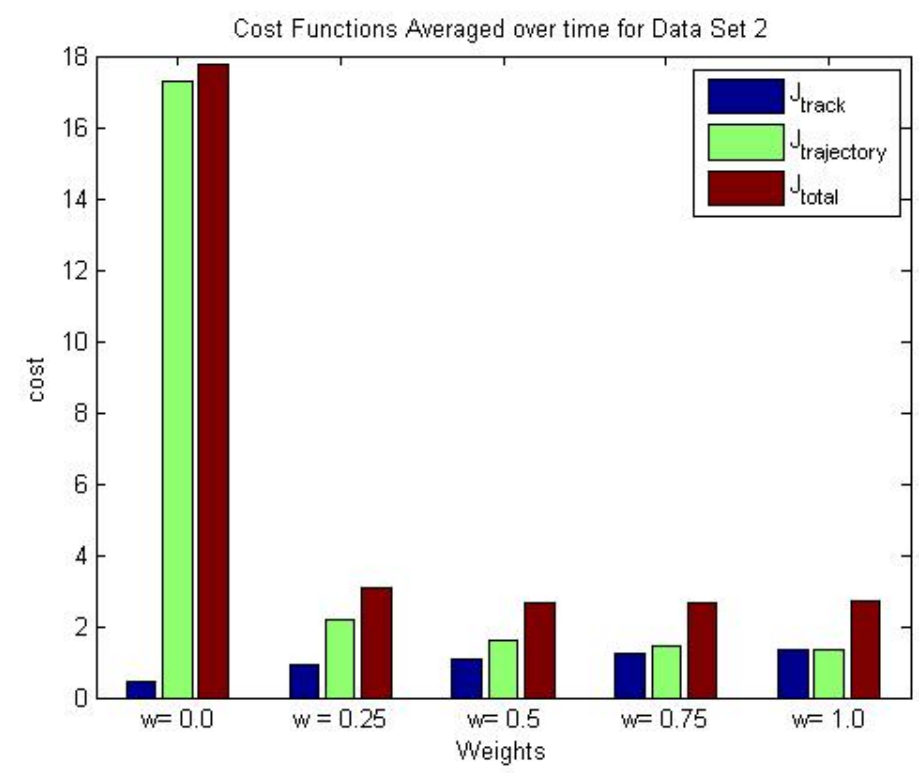

Figure 5.8: Cost Functions over the time of the trial for Data Set 2 with various path weightings.

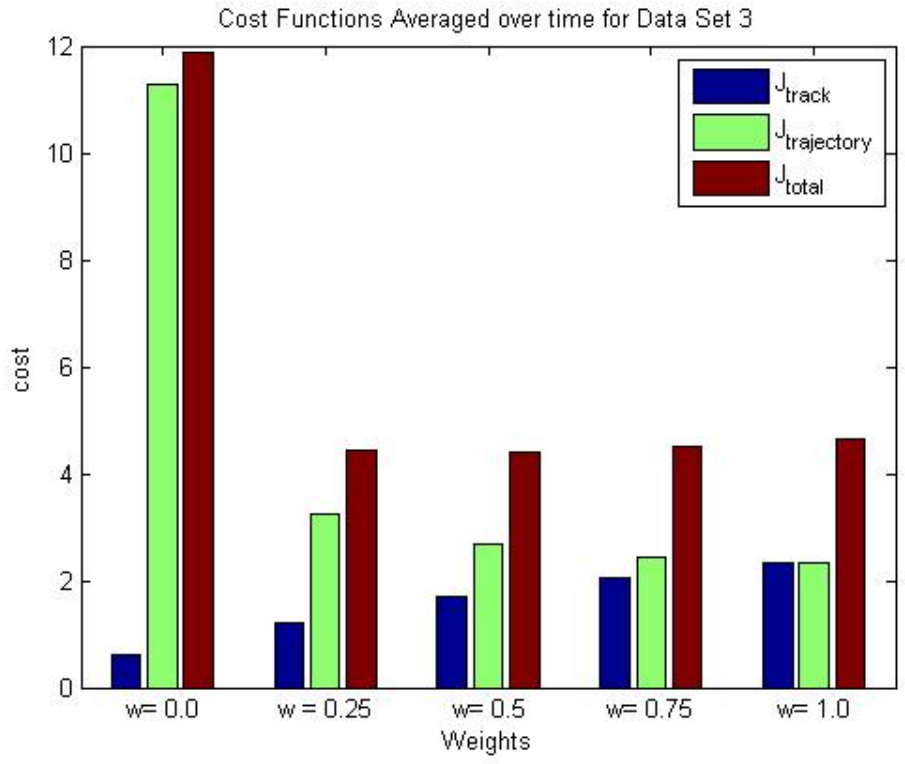

Figure 5.9: Cost Functions over the time of the trial for Data Set 3 with various path weightings. 


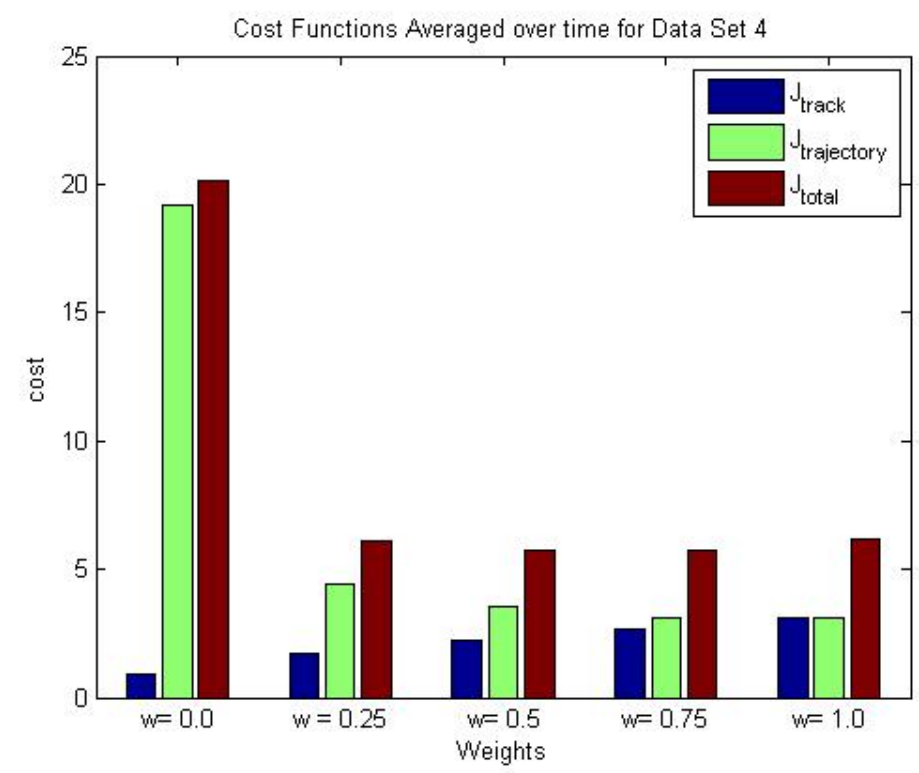

Figure 5.10: Cost Functions over the time of the trial for Data Set 4 with various path weightings.

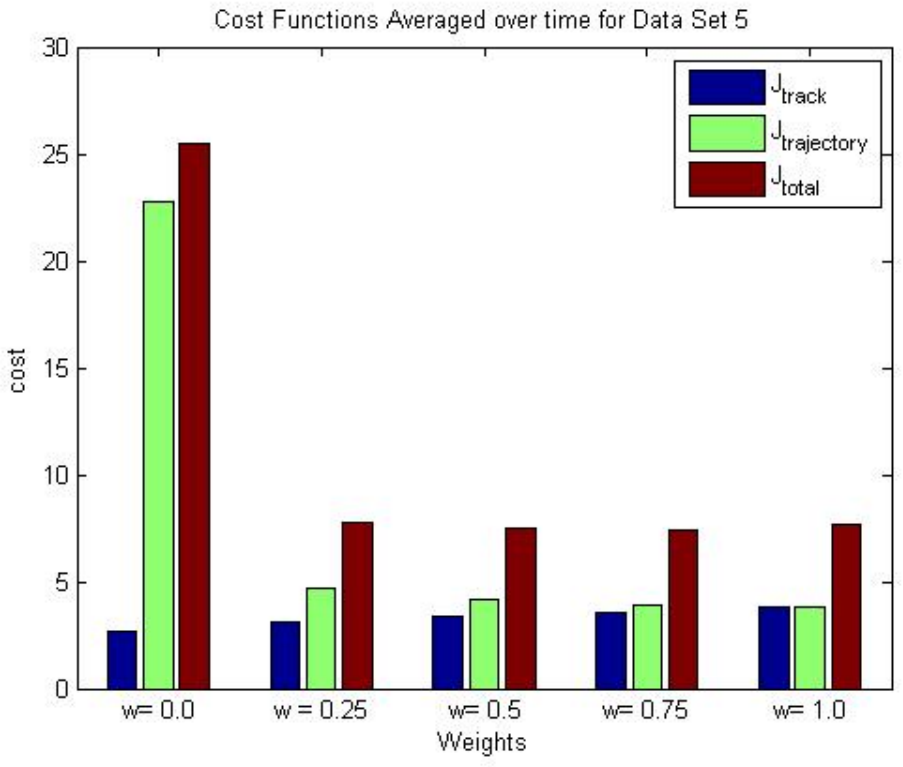

Figure 5.11: Cost Functions over the time of the trial for Data Set 5 with various path weightings. 


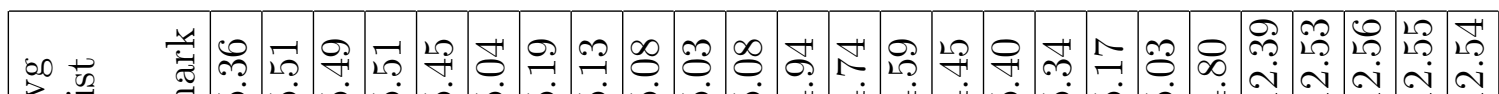

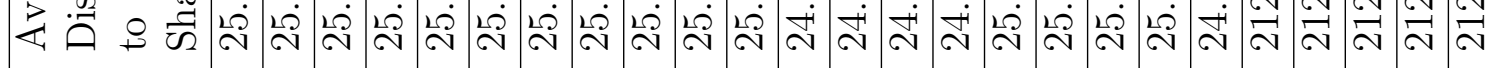

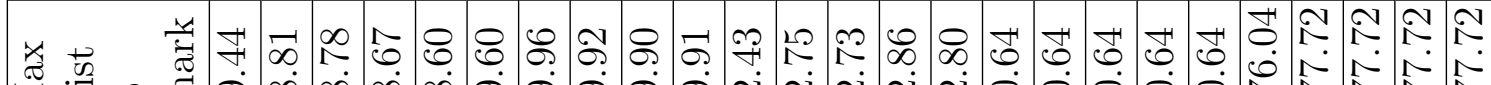

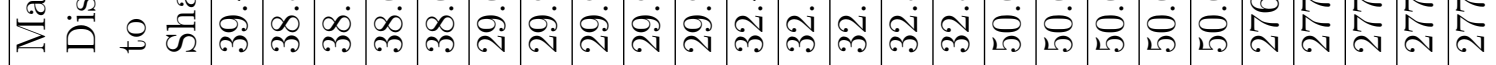

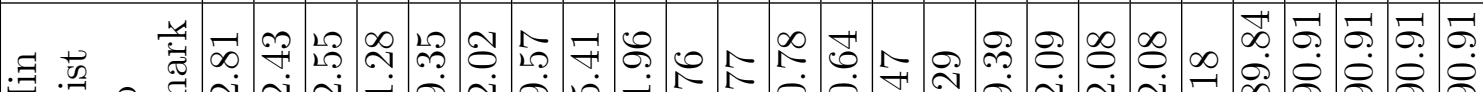

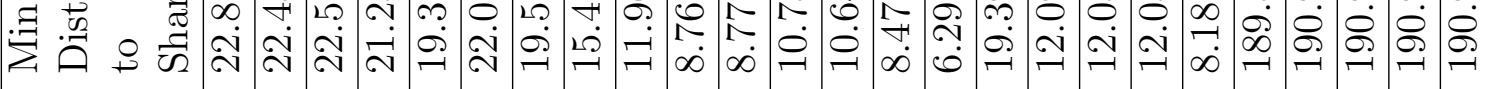

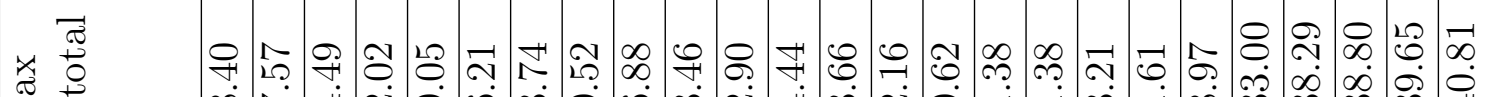

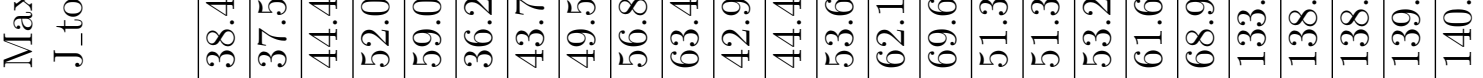

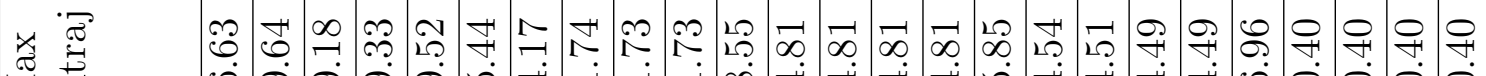

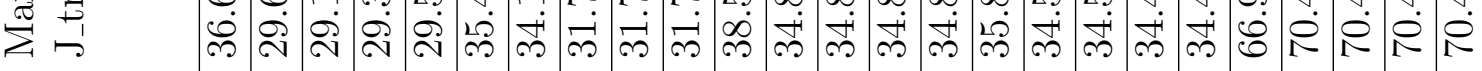

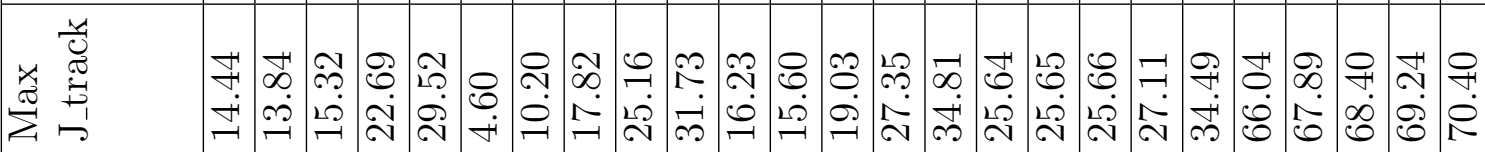

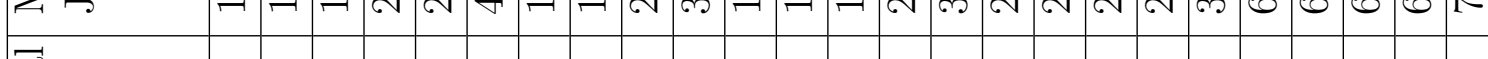

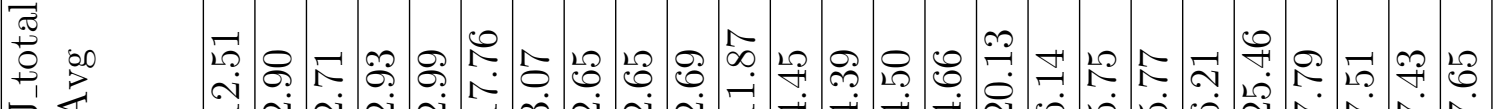

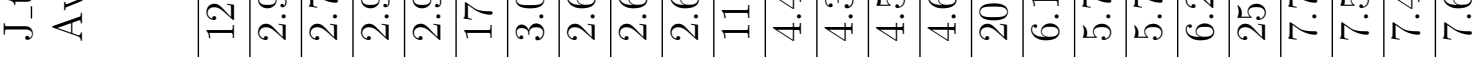

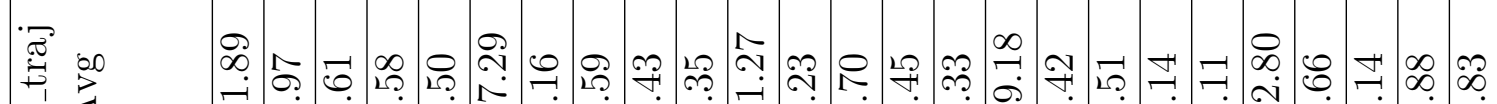

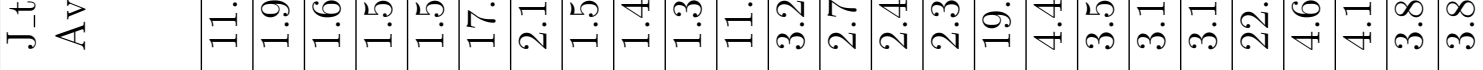

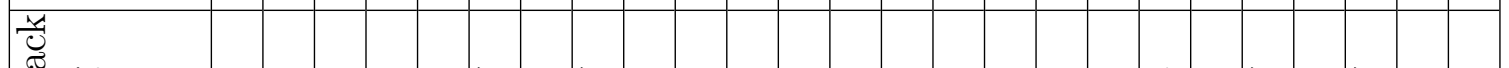

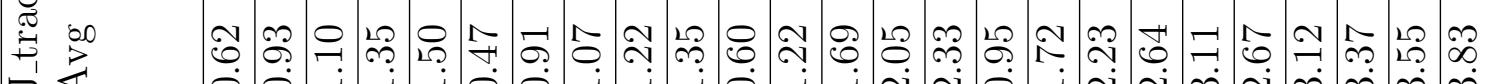

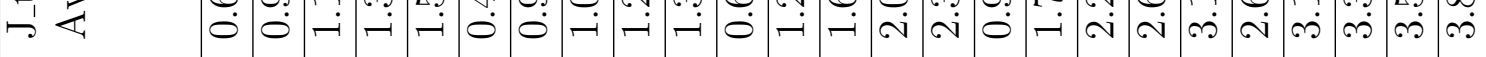

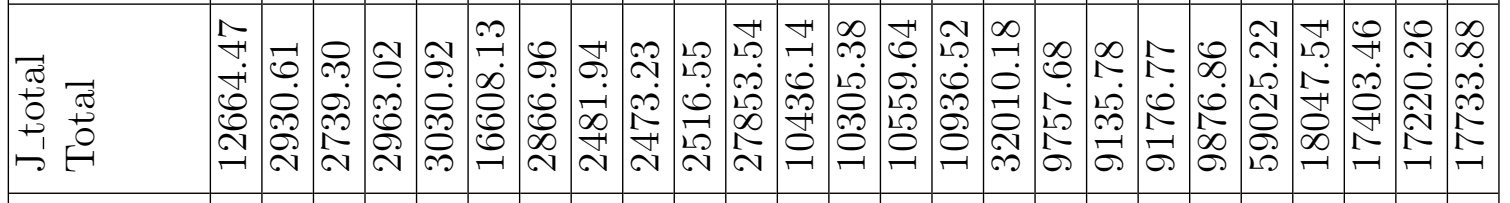

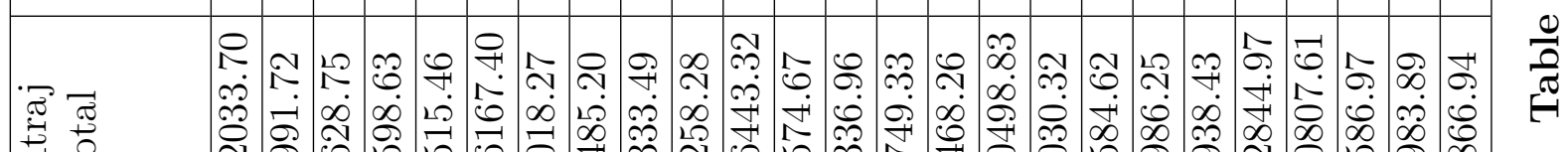
H

\begin{tabular}{|c|c|c|c|c|c|c|c|c|c|c|c|c|c|c|c|c|c|c|c|c|c|c|c|c|}
\hline 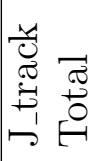 & 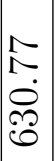 & $\begin{array}{l}\mathscr{D} \\
\infty \\
\infty \\
\infty \\
\infty\end{array}$ & 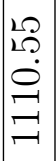 & 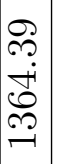 & 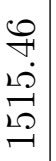 & 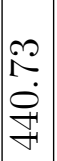 & $\begin{array}{l}\dot{\theta} \\
\dot{0} \\
\infty \\
+ \\
\infty\end{array}$ & $\mid \begin{array}{l}\overrightarrow{1} \\
\dot{8} \\
\mathscr{\Omega}\end{array}$ & 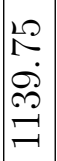 & 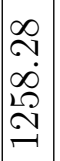 & 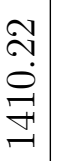 & 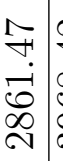 & 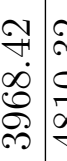 & & 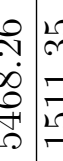 & 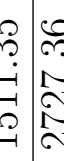 & 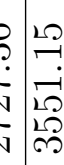 & 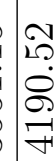 & $\mid \begin{array}{c}\mathscr{P} \\
\dot{\infty} \\
\infty \\
\mathscr{F} \\
\stackrel{+}{*}\end{array}$ & 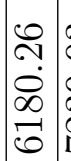 & 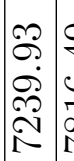 & 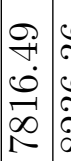 & 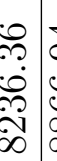 & $\begin{array}{l}5 \\
5 \\
6 \\
0 \\
\infty \\
\infty\end{array}$ \\
\hline 3 & $\begin{array}{l}8 \\
0 \\
0\end{array}$ & \begin{tabular}{l}
$\stackrel{2}{0}$ \\
$\stackrel{0}{0}$ \\
\hdashline
\end{tabular} & $\begin{array}{c}0 \\
\stackrel{1}{0} \\
0\end{array}$ & $\begin{array}{l}120 \\
\stackrel{2}{2} \\
0\end{array}$ & $\underset{-}{8}$ & $\begin{array}{l}8 \\
0 \\
0\end{array}$ & $\begin{array}{l}\stackrel{L}{2} \\
\stackrel{0}{O}\end{array}$ & $\begin{array}{c}0 \\
2 \\
0 \\
0 \\
0\end{array}$ & $\begin{array}{l}20 \\
\stackrel{2}{0} \\
\dot{0}\end{array}$ & $\begin{array}{l}8 \\
\\
\end{array}$ & \begin{tabular}{l}
8 \\
\hdashline \\
0
\end{tabular} & \begin{tabular}{l|l}
$\stackrel{2}{2}$ \\
$\stackrel{0}{0}$ \\
\hdashline
\end{tabular} & & & & & 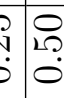 & $\stackrel{12}{\stackrel{2}{2}}$ & $\underset{-}{8}$ & $\begin{array}{l}8 \\
0 \\
0\end{array}$ & 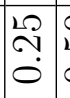 & $\mid$\begin{tabular}{c|c}
0 \\
2 \\
0 \\
0
\end{tabular} & 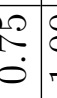 & \\
\hline 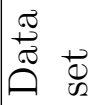 & $\neg$ & $\neg$ & -1 & $\neg$ & $\neg$ & $\sim$ & $\sim$ & $\sim$ & N & $\sim$ & $\infty$ & $\infty$ & $\infty$ & $\infty \sigma$ & $m=$ & $+\nabla$ & + & $\mid$ & $F$ & ג ס1 & ג & L 20 & תמ & o \\
\hline
\end{tabular}




\begin{tabular}{|c|c|c|c|c|c|c|c|c|c|c|}
\hline 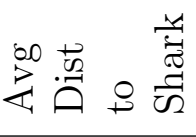 & 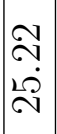 & $\mid \begin{array}{c}\stackrel{L}{\sim} \\
\stackrel{2}{2} \\
\stackrel{2}{\sim}\end{array}$ & 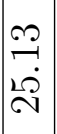 & 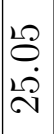 & $\left|\begin{array}{c}\mathscr{O} \\
\stackrel{+}{+} \\
\sim\end{array}\right|$ & $\begin{array}{l}0 \\
0 \\
\dot{1} \\
0\end{array}$ & $\begin{array}{l}尺 \\
i \\
i v \\
0\end{array}$ & 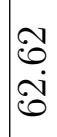 & $\begin{array}{l}20 \\
20 \\
ن] \\
0 \\
0\end{array}$ & \\
\hline 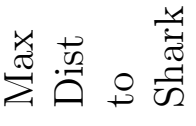 & $\begin{array}{c}\infty \\
0 \\
\infty \\
\infty \\
\infty\end{array}$ & $\begin{array}{c}\overrightarrow{1} \\
\infty \\
\infty \\
\infty\end{array}$ & $\begin{array}{c}\Upsilon \\
0 \\
\infty \\
\infty \\
\infty\end{array}$ & $\begin{array}{c}\mathcal{D} \\
\dot{b} \\
\infty \\
\infty \\
\infty\end{array}$ & 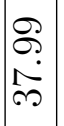 & $\begin{array}{l}\mathscr{m} \\
\ddot{b} \\
2 \dot{\infty} \\
\infty\end{array}$ & $\begin{array}{l}\infty \\
0 \\
1 \\
\infty \\
\infty\end{array}$ & $\begin{array}{l}0 \\
2 \\
10 \\
\infty\end{array}$ & $\begin{array}{l}0 \\
2 \\
20 \\
\infty\end{array}$ & $\begin{array}{l}2 \\
\infty \\
\infty \\
\infty\end{array}$ \\
\hline 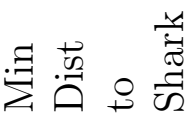 & $\mid \begin{array}{l}2 \\
\sim \\
\infty \\
\infty \\
-1 \\
-1\end{array}$ & 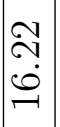 & $\mid \begin{array}{c}1 \\
-1 \\
\dot{2} \\
-1 \\
-1\end{array}$ & 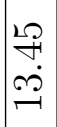 & $\mid$\begin{tabular}{l}
$\overrightarrow{0}$ \\
$\dot{0}$ \\
\hdashline
\end{tabular} & $\begin{array}{l}1 \\
20 \\
ن \\
i \\
20\end{array}$ & $\begin{array}{c}0 \\
\stackrel{0}{-1} \\
\dot{20}\end{array}$ & $\begin{array}{l}\text { Oे } \\
\ddot{0} \\
\stackrel{0}{0}\end{array}$ & $\begin{array}{l}\overrightarrow{1} \\
0 \\
\infty \\
+ \\
+1\end{array}$ & P \\
\hline 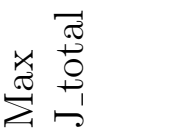 & $\left|\begin{array}{c}\stackrel{\sim}{\sim} \\
\stackrel{\sim}{\forall}\end{array}\right|$ & $\left|\begin{array}{c}\stackrel{2}{ } \\
\dot{f} \\
\dot{H}\end{array}\right|$ & 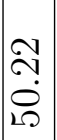 & $\begin{array}{l}1 \\
-1 \\
\infty \\
20 \\
20\end{array}$ & & & $\begin{array}{c}8 \\
8 \\
\dot{0} \\
0\end{array}$ & $\frac{\overrightarrow{0}}{0}$ & $\begin{array}{l}0 \\
\stackrel{1}{1} \\
\stackrel{+}{N}\end{array}$ & 文 \\
\hline 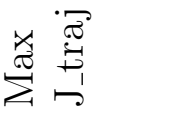 & $\left|\begin{array}{l}1 \\
0 \\
0 \\
0 \\
ن\end{array}\right|$ & 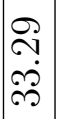 & $\begin{array}{l}0 \\
0 \\
20 \\
\text { กิ }\end{array}$ & 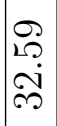 & $\mid \begin{array}{l}\overrightarrow{0} \\
\text { Oें } \\
\approx\end{array}$ & $\begin{array}{l}\mathscr{g} \\
\ddot{0} \\
\dot{y}\end{array}$ & $\stackrel{ }{\check{0}}$ & $\stackrel{m}{\dddot{2}}$ & $\stackrel{20}{\stackrel{1}{0}}$ & $\underset{\overbrace{}}{\stackrel{0}{0}}$ \\
\hline 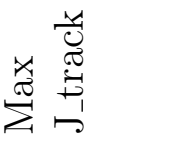 & 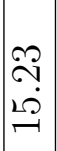 & 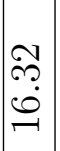 & 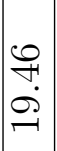 & $\begin{array}{l}\infty \\
2 ? \\
20 \\
\sim \\
\sim\end{array}$ & 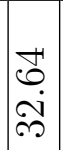 & 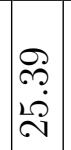 & $\left|\begin{array}{l}\Re \\
0 \\
\dot{0} \\
\sim\end{array}\right|$ & 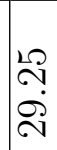 & $\underset{m}{m}$ & $\stackrel{\rho}{\stackrel{0}{0}}$ \\
\hline 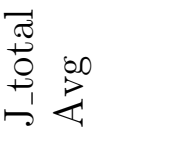 & $\mid \begin{array}{ll}1 \\
100 \\
100 \\
-1 \\
-1\end{array}$ & $\underset{+}{\stackrel{\vec{f}}{+}}$ & $\mid \begin{array}{l}\alpha \\
\infty \\
\infty \\
\infty\end{array}$ & $\begin{array}{l}0 \\
8 \\
\infty \\
\infty\end{array}$ & $\underset{\square}{\not}$ & 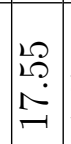 & $\begin{array}{l}\infty \\
\infty \\
\dot{+}\end{array}$ & 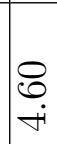 & $\begin{array}{l}2 \Omega \\
0 \\
\dot{\gamma}\end{array}$ & $\underset{+}{\infty}$ \\
\hline 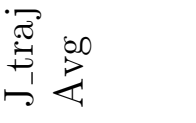 & $\mid \begin{array}{l}\vec{\sigma} \\
\overrightarrow{+}\end{array}$ & $\begin{array}{l}\vec{S} \\
\vec{\sigma} \\
\dot{N}\end{array}$ & $\mid \begin{array}{l}\stackrel{2}{\infty} \\
\sim \\
\sim \\
\sim\end{array}$ & $\underset{\sim 20}{\stackrel{20}{\sim}}$ & $\begin{array}{c}\hat{O} \\
\stackrel{1}{*}\end{array}$ & 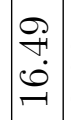 & 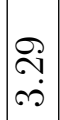 & $\stackrel{\Gamma}{\sim}$ & $\begin{array}{l}\stackrel{\rho}{+} \\
\text { ণ }\end{array}$ & $\underset{\stackrel{\sim}{*}}{\stackrel{\sim}{*}}$ \\
\hline 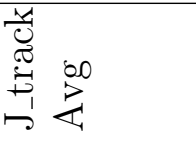 & $\mid \begin{array}{l}0 \\
\ddot{0} \\
\dot{0}\end{array}$ & $\stackrel{\Omega}{\stackrel{\leftrightarrow}{\rightleftharpoons}}$ & 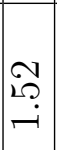 & $\begin{array}{l}\vec{\infty} \\
-i \\
-i\end{array}$ & $\begin{array}{l}\hat{D} \\
\text { id }\end{array}$ & $\begin{array}{c}0 \\
0 \\
-i\end{array} \mid$ & 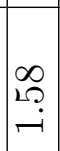 & م. & $\stackrel{0}{\underset{\sim}{\sim}}$ & $\underset{\sim}{\stackrel{\sim}{\sim}}$ \\
\hline 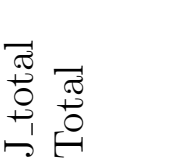 & 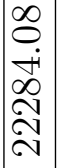 & 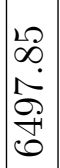 & $\left|\begin{array}{c}0 \\
0 \\
10 \\
0 \\
6 \\
0\end{array}\right|$ & $\begin{array}{c}0 \\
-1 \\
2 \dot{2} \\
2 \\
0 \\
0\end{array}$ & 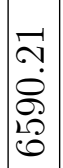 & 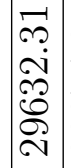 & $\begin{array}{l}\Omega \\
N \\
N \\
0 \\
\infty \\
\infty\end{array}$ & $\begin{array}{l}\sim \\
\stackrel{\sim}{\infty} \\
\stackrel{\infty}{\not} \\
\infty\end{array}$ & $\begin{array}{l}\infty \\
20 \\
\infty \\
1 \\
\infty \\
\infty\end{array}$ & $\begin{array}{l}\infty \\
\infty \\
\infty \\
\infty \\
\infty \\
\infty\end{array}$ \\
\hline F & $\begin{array}{l}\not \\
\infty \\
\dot{\infty} \\
\infty \\
\sim \\
\stackrel{\sim}{N} \\
\vec{N}\end{array}$ & 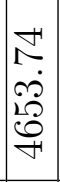 & $\begin{array}{l}\infty \\
\infty \\
\infty \\
\infty \\
1 \infty \\
\infty \\
\infty\end{array}$ & 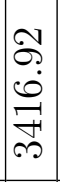 & 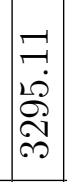 & 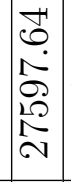 & $\begin{array}{l}\mathcal{i} \\
i \\
\dot{1} \\
\infty \\
\infty \\
1 \\
10\end{array}$ & 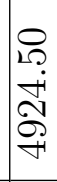 & 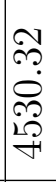 & 華 \\
\hline 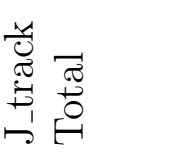 & 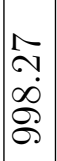 & $\begin{array}{l}0 \\
\stackrel{-}{+} \\
\underset{+1}{\infty} \\
\infty \\
-1\end{array}$ & 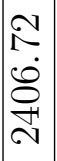 & $\begin{array}{c}\overrightarrow{1} \\
\sim \\
0 \\
0 \\
N \\
\infty \\
\sim \\
N\end{array}$ & 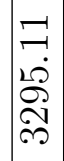 & 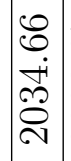 & 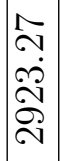 & 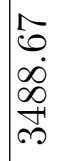 & 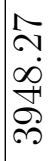 & 芦 \\
\hline$F$ & $\begin{array}{l}8 \\
0 \\
0\end{array}$ & 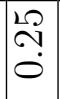 & 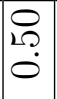 & $\begin{array}{l}20 \\
12 \\
0 \\
0\end{array}$ & $\underset{8}{8}$ & $\begin{array}{l}8 \\
0 \\
\dot{0}\end{array}$ & 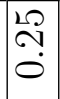 & $\begin{array}{l}0 \\
10 \\
0 \\
0\end{array}$ & $\stackrel{12}{12}$ & $\underset{8}{8}$ \\
\hline 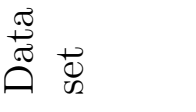 & $\stackrel{1}{-1}$ & $\stackrel{+}{-1}$ & $\stackrel{+}{+}$ & $\stackrel{F}{-1}$ & $\stackrel{-}{-1}$ & $\left(\begin{array}{l}2 \\
1 \\
-1\end{array} \mid\right.$ & 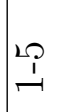 & $\stackrel{20}{1}$ & $\stackrel{2}{1}$ & $\stackrel{\substack{p \\
-1}}{-1}$ \\
\hline
\end{tabular}




\subsection{Addition of a Second AUV}

This test is to show the benefit of the implementation of a second AUV. Path and distance from shark will be determined for a data set from both White and Shovelnosed sharks to ensure optimal positioning. Next error and standard deviation of the particle filter will be analyzed to characterize any benefit derived from the second AUV.

The path and distance from the shark of the second AUV was recorded using data sets 1 and 5. This was to ensure that the second AUV behaved correctly for both the smaller circular pattern of the Shovelnose and the longer linear pattern of the White. The path of the secondary AUV is shown in figures 5.12 and 5.15. The shark path is in black and AUV paths are in green (primary) and blue (secondary). The distance from the shark is shown in figures 5.13 and 5.14. The Magenta line represents the primary $\mathrm{AUV}^{\prime} \mathrm{s}$ distance from the shark, whereas the cyan line represents the secondary $\mathrm{AUV}^{\prime}$ s distance from the shark.

The data set used to characterize the benefit from the particle filter stand point was the same as in the particle filter accuracy test, data set 1 . Both accu-

racy and standard deviation of the particles were tested for the single AUV and the two AUVs working together. The basic particle filter was used for this test as it was the less accurate and precise of the two. This will clearly show any benefits from using a second AUV to communicate information on the shark's position. The comparison of the accuracy is shown in figure 5.16. The distance in meters between the particle shark and the actual shark is shown in red for the single AUV and blue for the two AUVs. The comparison of the standard deviation of the particles for each case can be seen in figure 5.17. The standard deviation of the 
AUV Path Test for Data Set 1.jpg

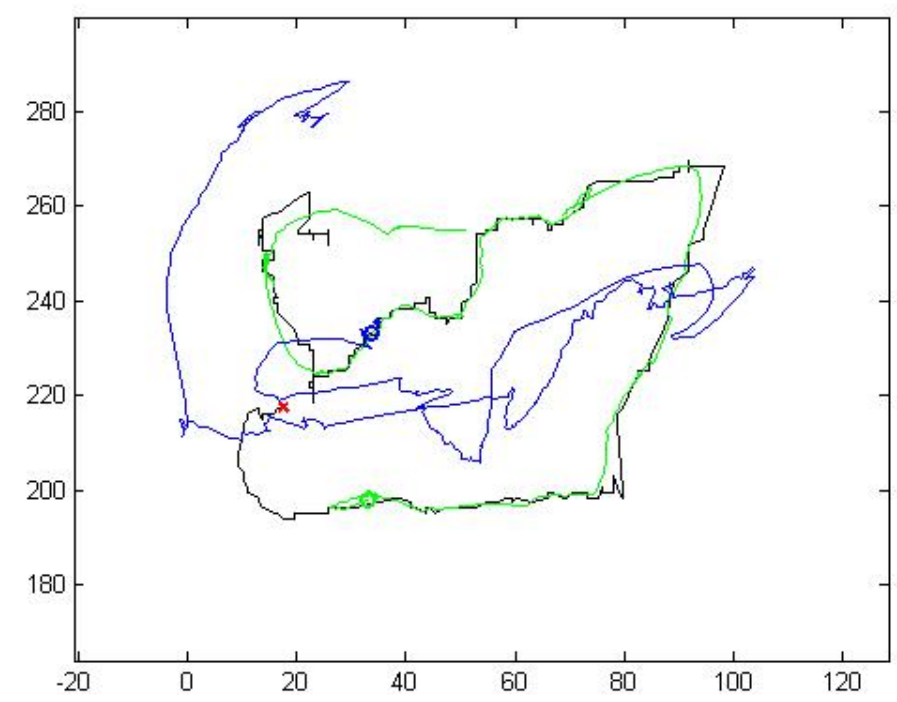

Figure 5.12: Path of Second AUV for Data Set 1.

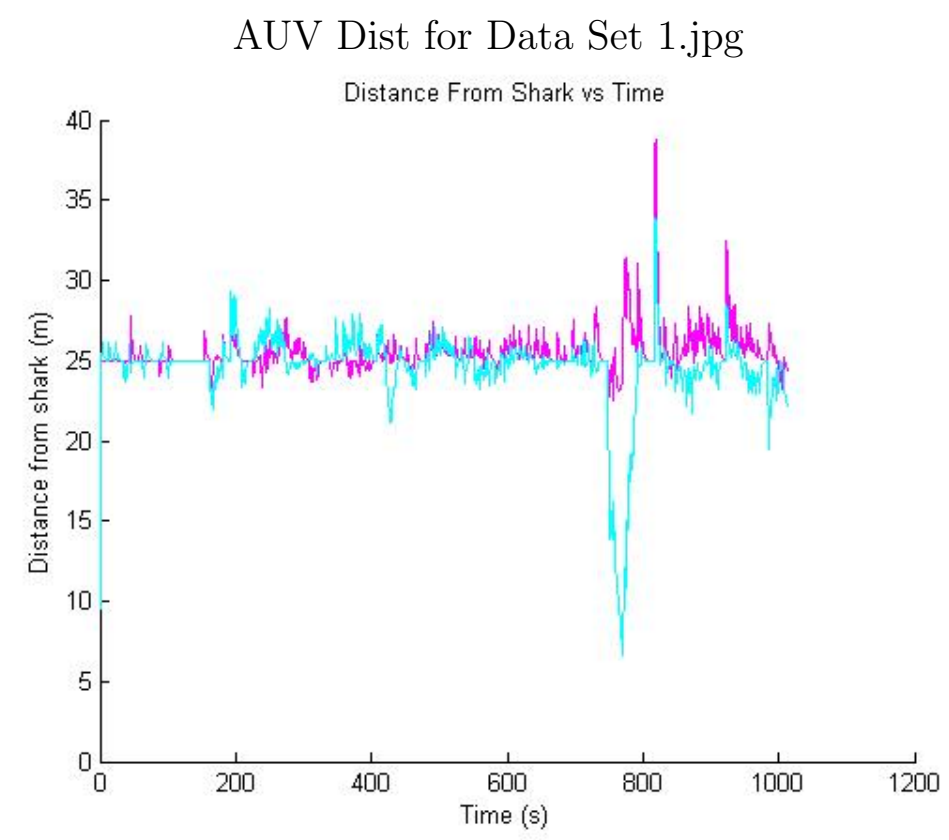

Figure 5.13: Path of Second AUV for Data Set 1. 


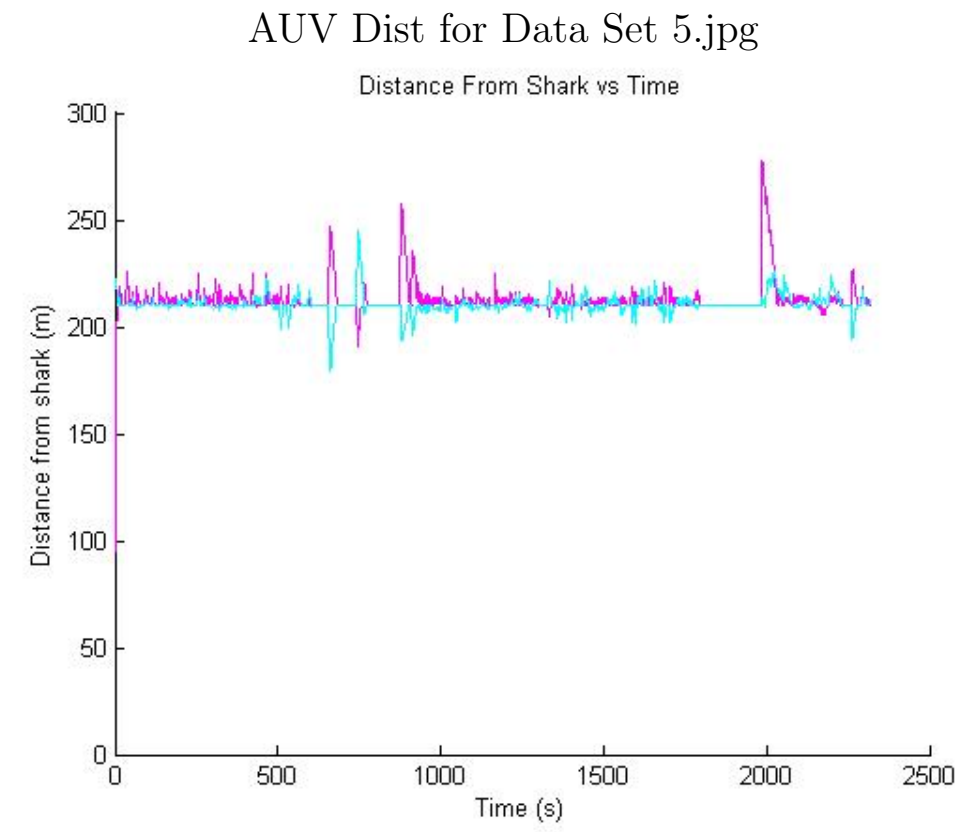

Figure 5.14: Distance from Shark of Second AUV for Data Set 5.

AUV Path Test for Data Set 5.jpg

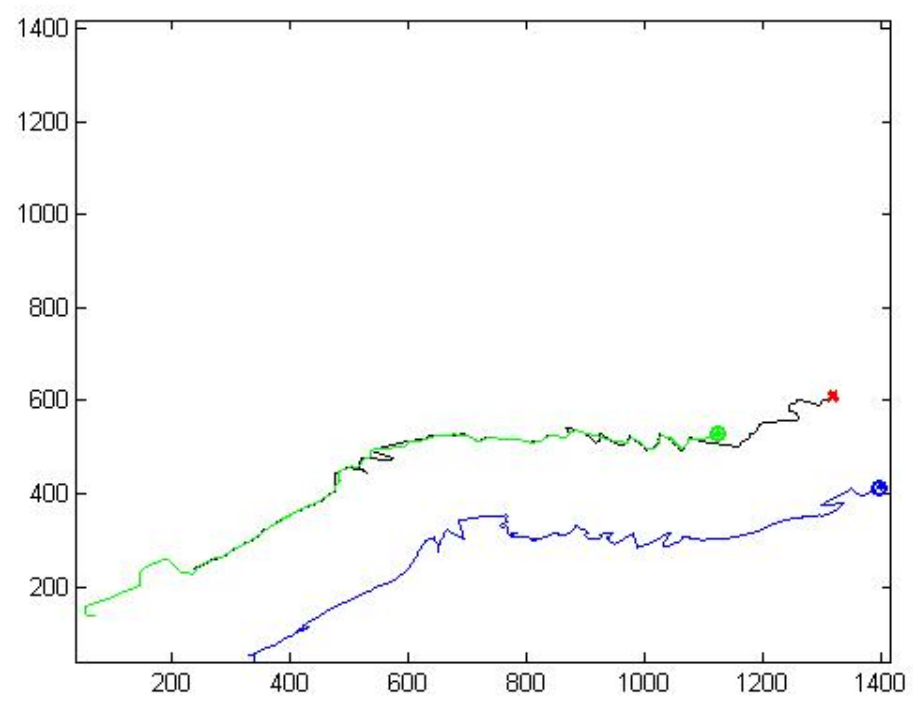

Figure 5.15: Path of Second AUV for Data Set 5. 


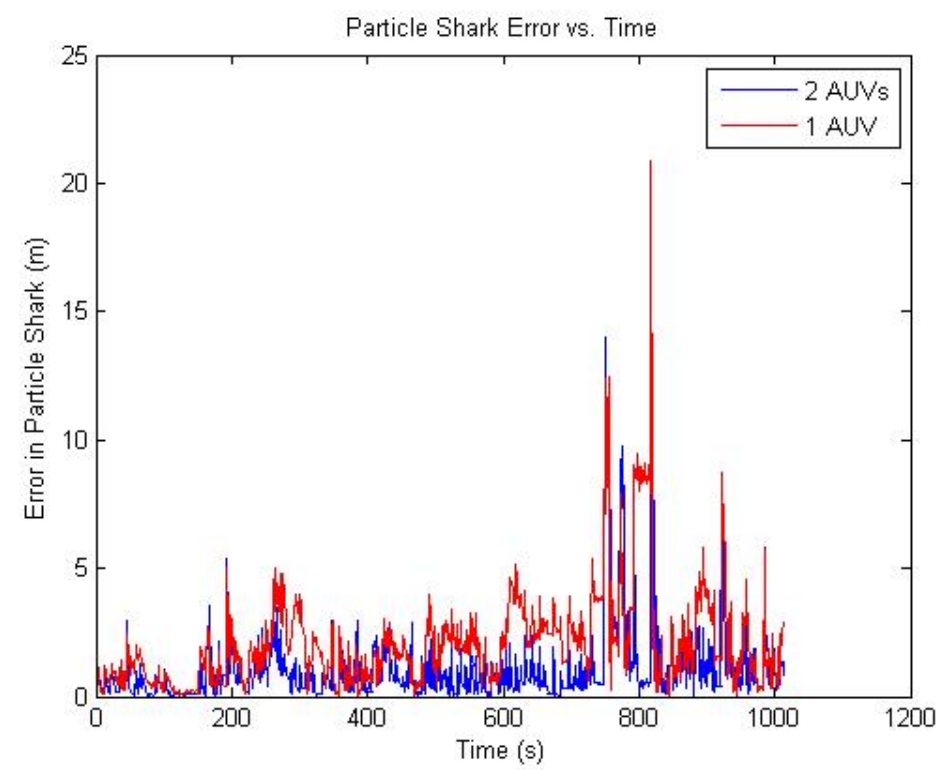

Figure 5.16: Comparison of Particle Filter Accuracy for Multiple AUVs.

particle filter for a single AUV is shown in red and the two AUVs is shown in blue.

\subsection{Future Planning}

The purpose of this test is to look at the effect prediction of the shark's path has on the cost of tracking the shark, as well as the accuracy of that prediction. First, the accuracy of the prediction will be shown for several different prediction times. Next the effect on the cost function will be looked at.

The data set used for this test was data set 2. The simulation was run for the prediction times of $\mathrm{t}=[0,1,3,5,7,10,15,20,25,30]$. For each prediction time, the total cost of following the shark as well as the accuracy of the prediction were recorded. The error was averaged over the time of the test to provide a measure of the accuracy of the prediction method. 


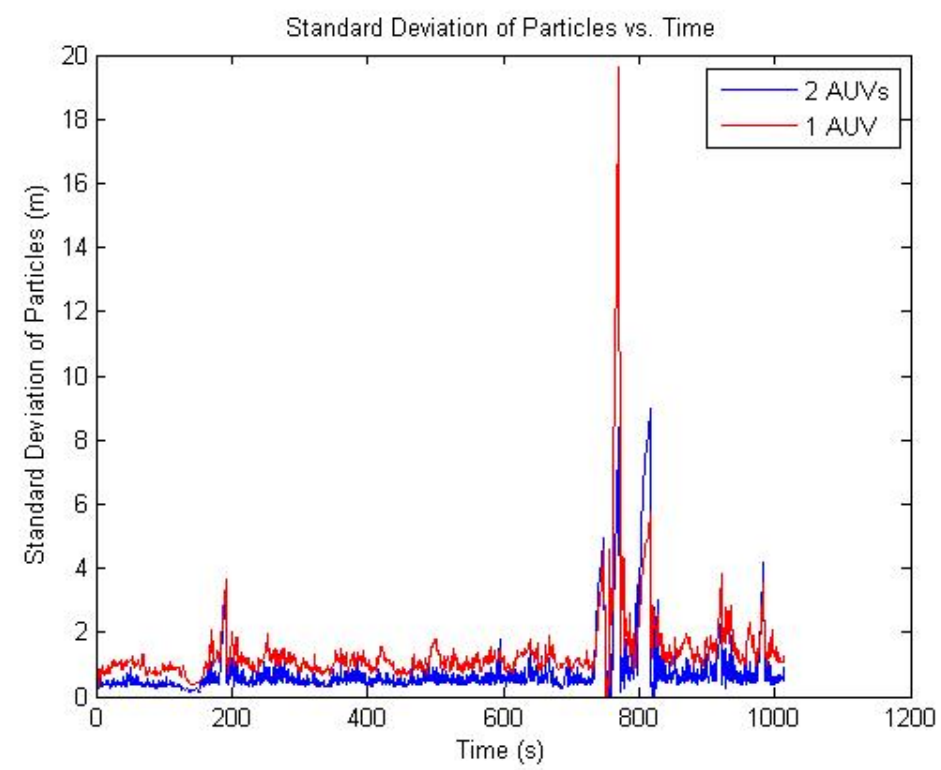

\section{Figure 5.17: Comparison of Particle Filter Standard Deviation for Mul- tiple AUVs.}

The average error in the prediction of the shark's future position vs. the time in seconds looked ahead is shown in figure 5.18. The Cost benefit associated with the prediction time is also shown in Figure 5.18. To visualize the cost benefit versus the error of the prediction, the two were overlaid. The blue line is the average cost and the red line is the average error in meters of the prediction. For this figure, the total cost was averaged over the time of the trial. This shows the associated cost and error with each prediction window.

The test was repeated for the White shark data set 5 to see if the future planning offered similar results for different shark species. The same time increments were used as in the Shovelnose shark data test. The average error in the prediction of the shark's future position vs. the time in seconds looked ahead is shown in figure 5.19. The Cost benefit associated with the prediction time is also shown in Figure 5.19. The two were again overlaid for comparison. The blue line is the average cost and the red line is the average error in meters of the 


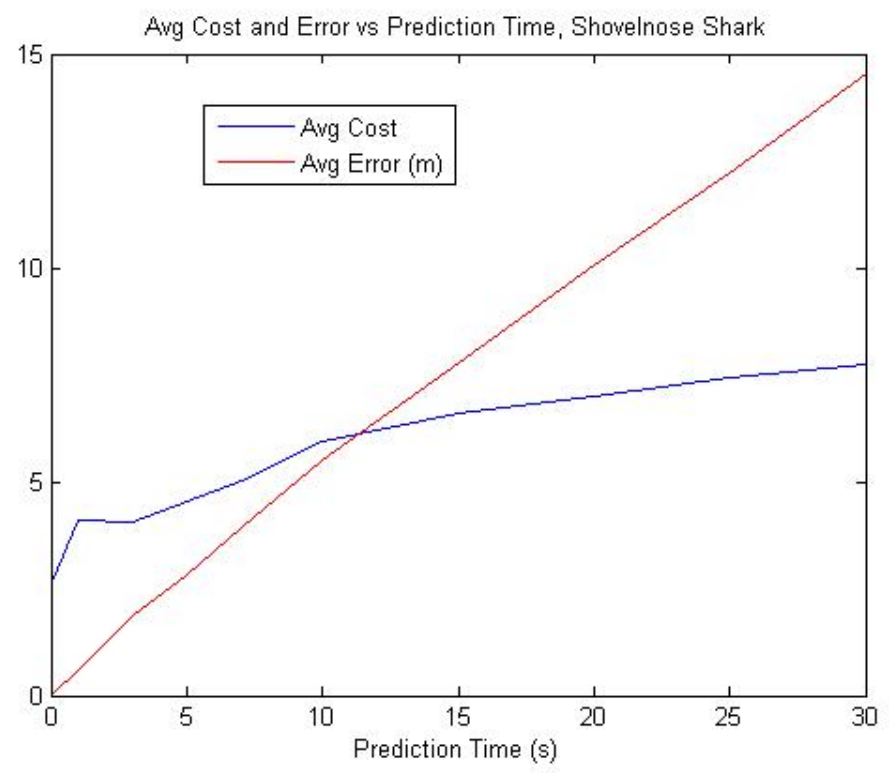

Figure 5.18: Avg Cost and Error vs Prediction Time, Shovelnose Shark prediction.

\subsection{Noise}

The purpose of this test is to look at the effect noise in the reading of the relative shark position could have on the AUV's tracking of the shark. For this test, data sets 4 and 5 were used. The following five different noise levels were tested. Noise levels tested were [5m 2deg],[20m 5deg],[50m 15deg],[100m 20deg] and $[150 \mathrm{~m} 30 \mathrm{deg}]$. The first number represents the standard deviation in the distance to the shark and the second refers to the standard deviation in the angle to the shark. A test run with no noise was also included to serve as a baseline. The goal of this test is to determine how detrimental noise is to the AUV's tracking.

Figure 5.20 shows a bar graph of the cost functions for the various noise levels for data set 4 . Figure 5.21 shows a bar graph of the cost functions for the various 


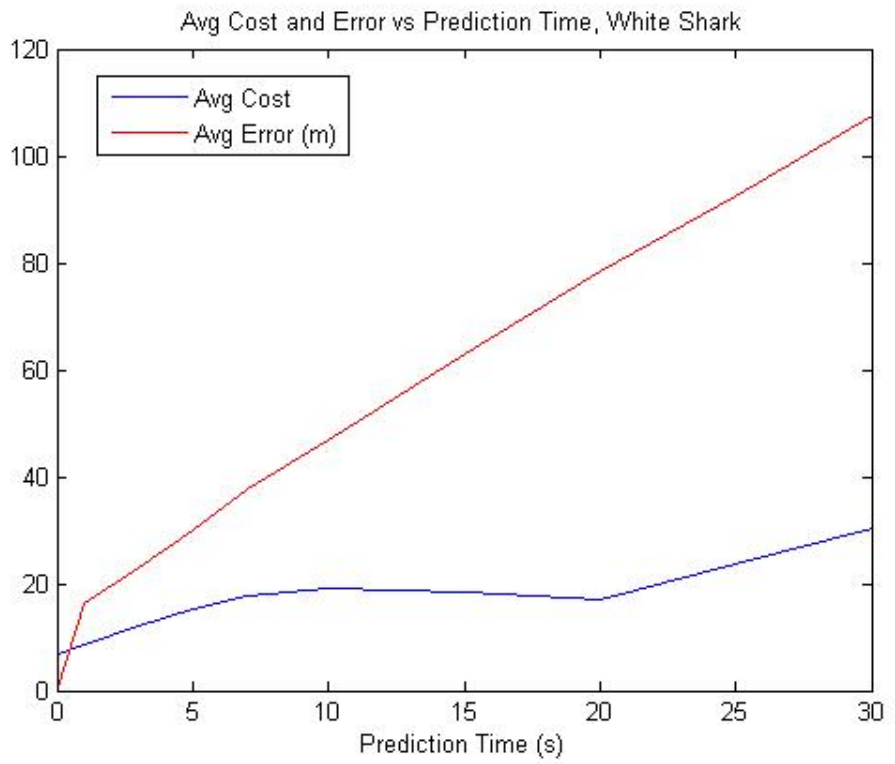

Figure 5.19: Avg Cost and Error vs Prediction Time, White Shark

noise levels for data set $5 . J_{\text {track }}$ is shown in blue. $J_{\text {traj }}$ is shown in green. $J_{\text {total }}$ is shown in red. Table 5.3 shows the numerical values of the cost functions and distances from the shark for both data sets.

\subsection{Combined Test of Methods}

The final test case was the test of the combined shark tracking controller. This test is meant to show what is the best response the AUV can accomplish given the various levels of noise. This test takes the basic gaussian particle filter seen in test case 1 and the use of a secondary AUV as shown in test case 4 to improve the estimation of the shark's actual location despite noise in the signal. The optimal weighting found in test case 3 is used by the controller to calculate the desired location of the AUV. Like test case 6, this test was run on both shark 


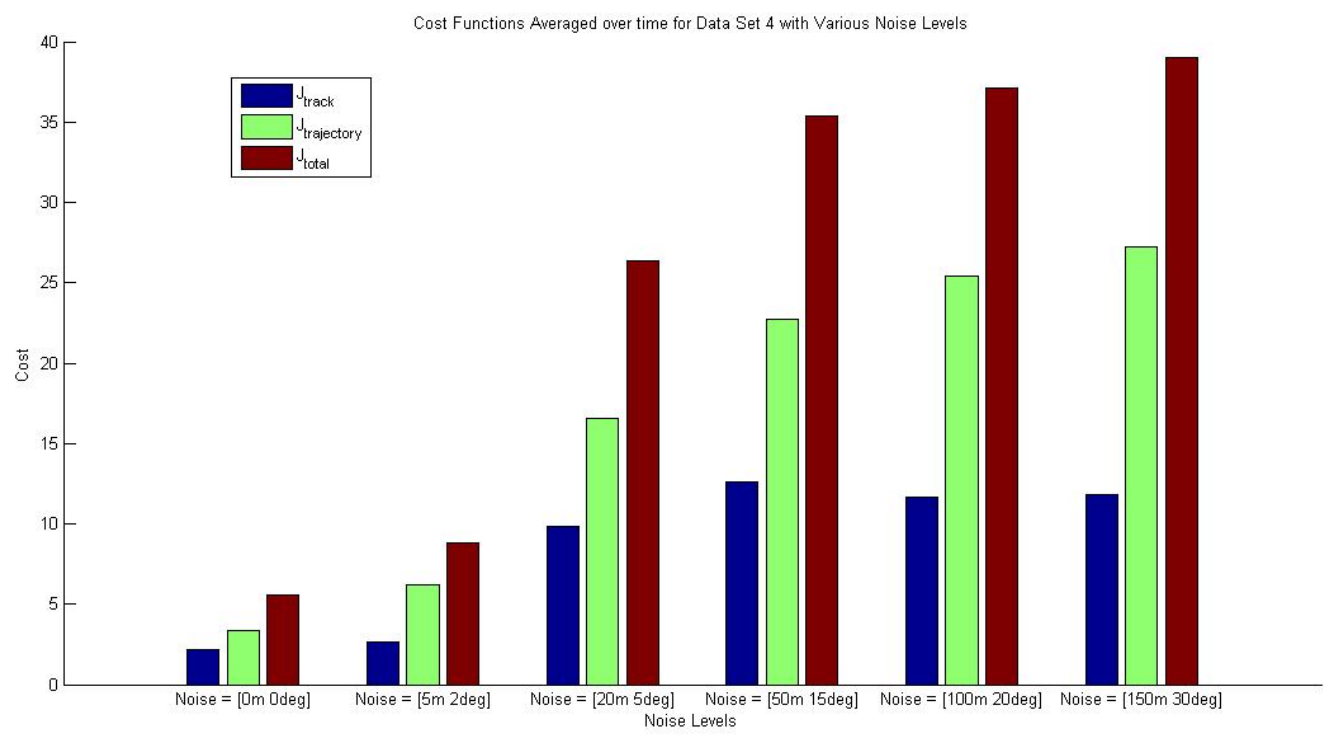

Figure 5.20: Cost Functions over the time of the trial for Data Set 4 for various Noise Levels.

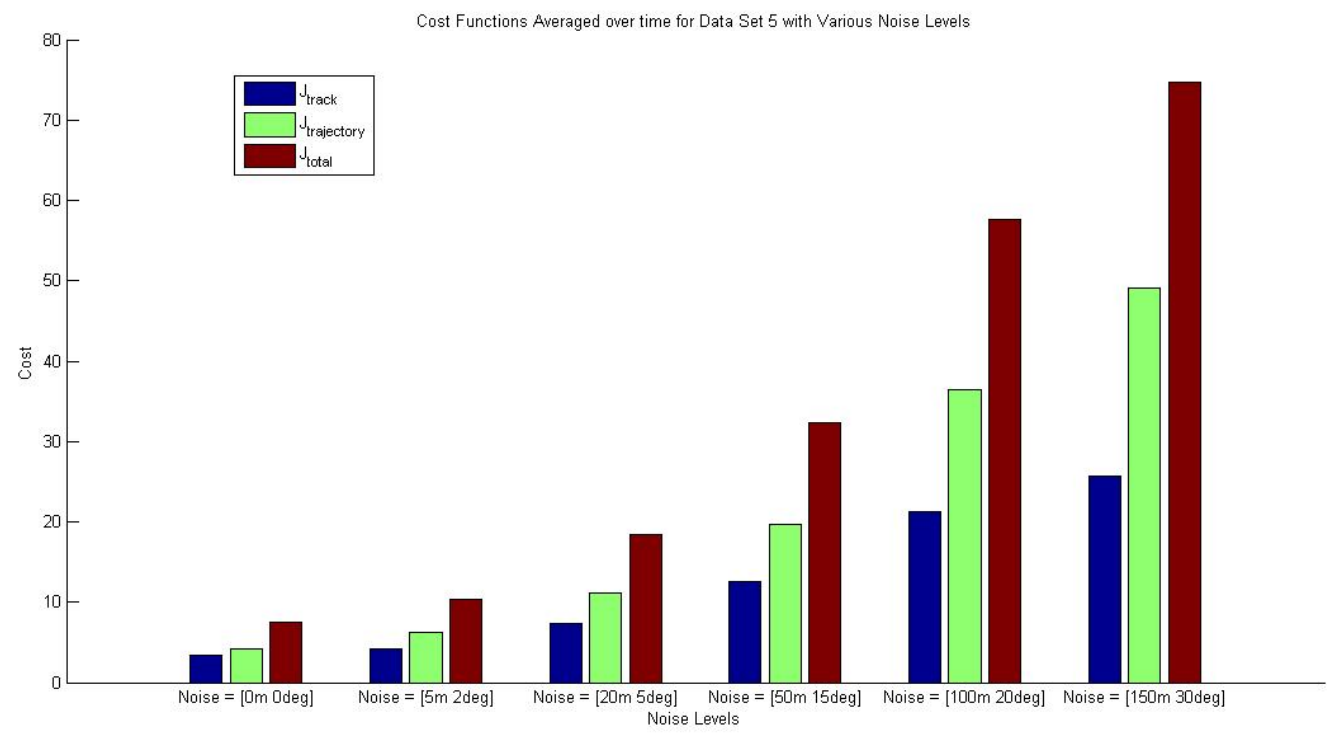

Figure 5.21: Cost Functions over the time of the trial for Data Set 5 for various Noise Levels. 


\begin{tabular}{|c|c|c|c|c|c|c|c|c|c|c|c|c|c|}
\hline 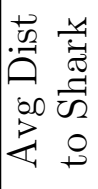 & $\stackrel{10}{10}$ & $\begin{array}{l}0 \\
0 \\
20 \\
\end{array}$ & $\begin{array}{l}1 \\
2 \\
2\end{array}$ & & 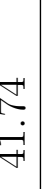 & 昂 & 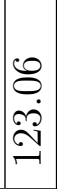 & 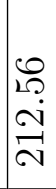 & $\begin{array}{l}2 \Omega \\
\infty \\
\stackrel{\alpha}{A} \\
\stackrel{N}{N}\end{array}$ & $\begin{array}{l}\mathscr{\Omega} \\
\stackrel{\Omega}{+} \\
\stackrel{\sim}{N}\end{array}$ & $\mid \begin{array}{l}\infty \\
\stackrel{\infty}{2} \\
\stackrel{\sim}{\sim} \\
\stackrel{\sim}{N}\end{array}$ & 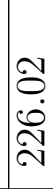 & 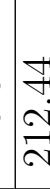 \\
\hline 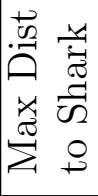 & $\begin{array}{l}+1 \\
0 \\
0 \\
20\end{array}$ & $\begin{array}{l}尺 \\
i \\
i \stackrel{0}{\circ}\end{array}$ & $\left\{\begin{array}{l}a \\
a \\
\mathfrak{c} \\
\mathfrak{c}\end{array}\right.$ & & مִ & $\begin{array}{l}\vec{\sigma} \\
\dot{\rho} \\
\dot{\rho}\end{array}$ & 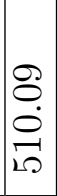 & 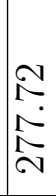 & 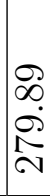 & 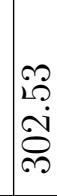 & $\begin{array}{l}\mathcal{O} \\
\stackrel{0}{0} \\
\stackrel{N}{\infty} \\
\infty\end{array}$ & $\begin{array}{l}10 \\
19 \\
0 \\
0 \\
10 \\
10\end{array}$ & 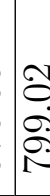 \\
\hline 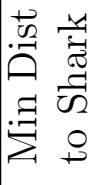 & \begin{tabular}{l}
$\infty$ \\
0 \\
\multirow{1}{*}{} \\
-1
\end{tabular} & ? & e & $\begin{array}{l}N \\
\dot{D} \\
\dot{D}\end{array}$ & : & \begin{tabular}{l}
\multirow{0}{0}{} \\
0 \\
$\dot{0}$
\end{tabular} & $\begin{array}{l}\overrightarrow{0} \\
0 \\
0\end{array}$ & $\begin{array}{l}\vec{\sigma} \\
\dot{\Omega} \\
\stackrel{-}{-}\end{array}$ & 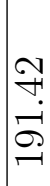 & 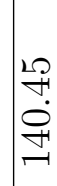 & $\begin{array}{l}\infty \\
\infty \\
\infty \\
\infty \\
+\end{array}$ & مَ & î. \\
\hline 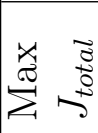 & 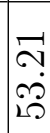 & $\mid \begin{array}{l}\mathcal{O} \\
\mathcal{O} \\
\text { iิ }\end{array}$ & $\begin{array}{l}1 \\
1 \\
i\end{array}$ & ¿ & مُ & $\begin{array}{l}\infty \\
\stackrel{\infty}{+} \\
\dot{\infty}\end{array}$ & 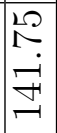 & $\begin{array}{l}\infty \\
\infty \\
\infty \\
\infty \\
-1 \\
-1\end{array}$ & 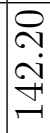 & $\begin{array}{l}\mathscr{2} \\
\infty \\
\mathscr{\infty} \\
\mathscr{N} \\
-1\end{array}$ & $\begin{array}{l}\vec{\sigma} \\
\dot{\rho} \\
\tilde{N}\end{array}$ & $\underset{\substack{f \\
\infty}}{F}$ & F \\
\hline 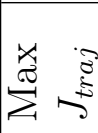 & में & $\stackrel{v}{v}$ & $\int_{7}^{5}$ & tip & مُ & $\begin{array}{l}\stackrel{+}{N} \\
\stackrel{1}{2} \\
\Sigma\end{array}$ & $\begin{array}{l}\stackrel{1}{2} \\
\stackrel{2}{2} \\
\infty \\
\infty\end{array}$ & $\stackrel{\rho}{\stackrel{P}{1}}$ & $\begin{array}{l}\stackrel{0}{0} \\
\mathfrak{N}\end{array}$ & $\begin{array}{l}\text { î } \\
100 \\
0\end{array}$ & \begin{tabular}{l}
$\partial$ \\
$\infty$ \\
$\stackrel{\Delta}{N}$ \\
\multirow{N}{*}{}
\end{tabular} & 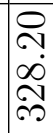 & $\begin{array}{l}8 \\
0 \\
\infty \\
\infty \\
\sim\end{array}$ \\
\hline 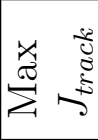 & $\begin{array}{l}0 \\
\stackrel{0}{0} \\
\stackrel{\rho}{N} \\
\sim\end{array}$ & & $\frac{b}{a}$ & 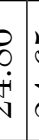 & مُ & $\begin{array}{l}\vec{D} \\
\stackrel{+}{*} \\
\stackrel{\sim}{N}\end{array}$ & $\mid \begin{array}{l}0 \\
120 \\
0 \\
10 \\
10\end{array}$ & $\begin{array}{l}0 \\
\stackrel{7}{1} \\
\dot{0} \\
0\end{array}$ & $\begin{array}{l}0 \\
0 \\
0 \\
0\end{array}$ & $\begin{array}{l}\not{F} \\
\dot{B}\end{array}$ & $\begin{array}{l}20 \\
20 \\
0 \\
0 \\
0\end{array}$ & N & $\begin{array}{l}\dddot{\infty} \\
\infty \\
0 \\
\sigma\end{array}$ \\
\hline 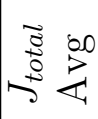 & $\begin{array}{l}0 \\
25 \\
20 \\
0.0\end{array}$ & $\begin{array}{l}10 \\
\infty \\
\infty\end{array}$ & 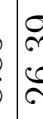 & $\begin{array}{l}\dot{b}^{2} \\
\dot{v}\end{array}$ & مُ & $\underset{\infty}{\stackrel{m}{\sim}}$ & $\begin{array}{l}\infty \\
\dot{\infty} \\
\dot{\infty}\end{array}$ & in & ?ִ & $\begin{array}{l}0 \\
\stackrel{0}{1} \\
\infty \\
\infty\end{array}$ & 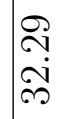 & & $\frac{i}{i}$ \\
\hline 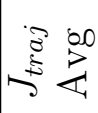 & $\begin{array}{l}\text { Oे } \\
\infty \\
\infty\end{array}$ & $\infty$ & $\begin{array}{l}\text { if } \\
\text { ce }\end{array}$ & 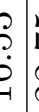 & مै & 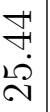 & $\begin{array}{l}\stackrel{N}{N} \\
\stackrel{N}{*}\end{array}$ & $\stackrel{\rightleftarrows}{\rightleftarrows}$ & $\begin{array}{l}\stackrel{N}{~} \\
\qquad\end{array}$ & $\stackrel{m}{\rightleftharpoons}$ & 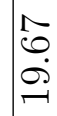 & $\begin{array}{l}\mathscr{P} \\
\dot{\leftrightarrow} \\
\dot{m}\end{array}$ & 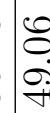 \\
\hline 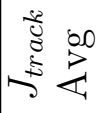 & 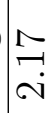 & to. & 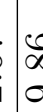 & $\begin{array}{l}1 \\
0 \\
\end{array}$ & בֶ. & 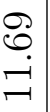 & 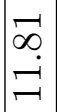 & $\begin{array}{l}N \\
\infty \\
\infty\end{array}$ & $\underset{+}{ت}$ & ח & 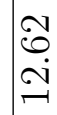 & $\underset{\sim}{\stackrel{\sim}{\sim}}$ & $\begin{array}{l}\overrightarrow{0} \\
\stackrel{0}{2}\end{array}$ \\
\hline 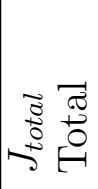 & 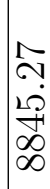 & $\stackrel{\varrho}{\ell}$ & $: \begin{array}{l}8 \\
1 \\
b \\
b\end{array}$ & 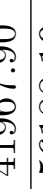 & $\begin{array}{c}0 \\
\infty \\
\infty \\
\infty \\
0 \\
0 \\
0 \\
10\end{array}$ & 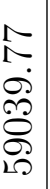 & 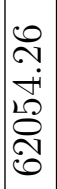 & 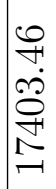 & 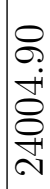 & 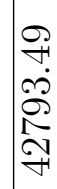 & \begin{tabular}{l}
$\sigma$ \\
$\sigma$ \\
0 \\
0 \\
$\infty$ \\
\multirow{1}{*}{} \\
$\Gamma$
\end{tabular} & 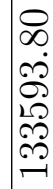 & 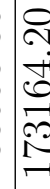 \\
\hline 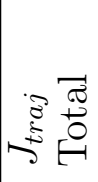 & 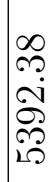 & 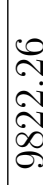 & है & 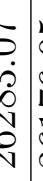 & $\begin{array}{l}0 \\
0 \\
0 \\
0 \\
0 \\
0 \\
0\end{array}$ & 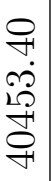 & 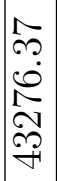 & $\begin{array}{l}1 \\
0 \\
0 \\
0 \\
20 \\
0\end{array}$ & 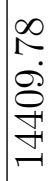 & $\begin{array}{l}\Omega \\
20 \\
20 \\
\Omega \\
\Omega \\
20 \\
\end{array}$ & 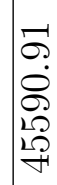 & 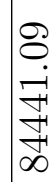 & 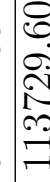 \\
\hline 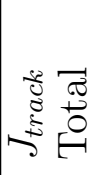 & 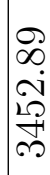 & 承 & 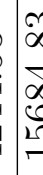 & 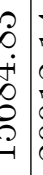 & 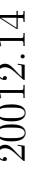 & 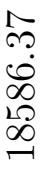 & $\begin{array}{l}2 \\
\infty \\
N \\
N \\
N \\
\infty \\
\infty \\
-1\end{array}$ & $\begin{array}{l}\stackrel{+}{+} \\
\dot{0} \\
\stackrel{1}{\infty} \\
1\end{array}$ & $\begin{array}{l}m \\
12 \\
12 \\
2 \\
2 \\
\Omega\end{array}$ & 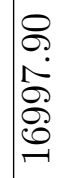 & 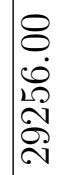 & 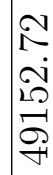 & 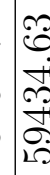 \\
\hline $\begin{array}{l}0 \\
.0 \\
0 \\
Z \\
Z\end{array}$ & $\begin{array}{l}0 \\
\Xi \\
\Xi\end{array}$ & 12 & 15 & 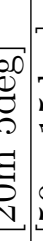 & 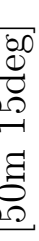 & 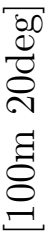 & 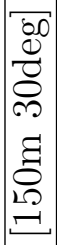 & $\begin{array}{l}80 \\
0 \\
0 \\
0 \\
0 \\
0 \\
0\end{array}$ & 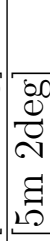 & 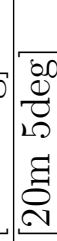 & 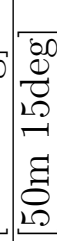 & 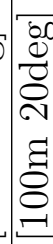 & 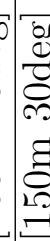 \\
\hline 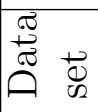 & $F$ & & 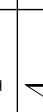 & & $\forall$ & $\nabla$ & $\nabla$ & 10 & 10 & 10 & סL & 10 & 10 \\
\hline
\end{tabular}


species data sets.

The data sets for this test case (data sets 6 and 7) were chosen for their length and complexity. Data set 6 shows a period of almost an hour of Shovelnose shark GPS data. Data set 7 shows almost the entire White shark data set, composed of just over two hours of White shark GPS data. The basic gaussian particle filter from test case 1 provided the shark state estimate. The optimal weighting of 0.50 , found from the results of test case 4 , was used for the tracking of data set 6 , and the optimal weighting of 0.75 , also found from the results of test case 4, was used for the tracking of data set 7. The use of a secondary AUV was implemented to aid in the shark's position estimate as seen in test case 6 .

To aid in making sense of the data, the Table 5.4 summarizes the findings of the test. This figure shows a comparison of the resulting cost functions and distances from the shark. Table 5.5 shows the difference between the actual shark location and the particle filter's estimate of the shark's location averaged over the length of the trial. This table also shows the standard deviation in that error.

Figure 5.22 and Figure 5.23 depict the path of the shark over the selected time frame as well as the path of the AUV. Figure 5.22 shows the response without any noise in the signal. In comparison Figure 5.23 show the path of the AUVs with the highest noise level [150m 30deg] in the signal. The x-axis of these graphs show the localized $\mathrm{x}$ coordinate of the shark or AUV in meters. The $\mathrm{y}$-axis shows the localized y coordinate of the shark or AUV in meters. The blue line shows the shark's path through the water. The green and cyan lines represent the $\mathrm{AUVs}^{\prime}$ paths in response to the shark's movements.

Figure 5.24 and Figure 5.26 show the distance from the AUV to the shark over time frame of the data set without noise. Figure 5.25 and Figure 5.27 depict the distance from the shark while affected by the highest level of noise tested. The 


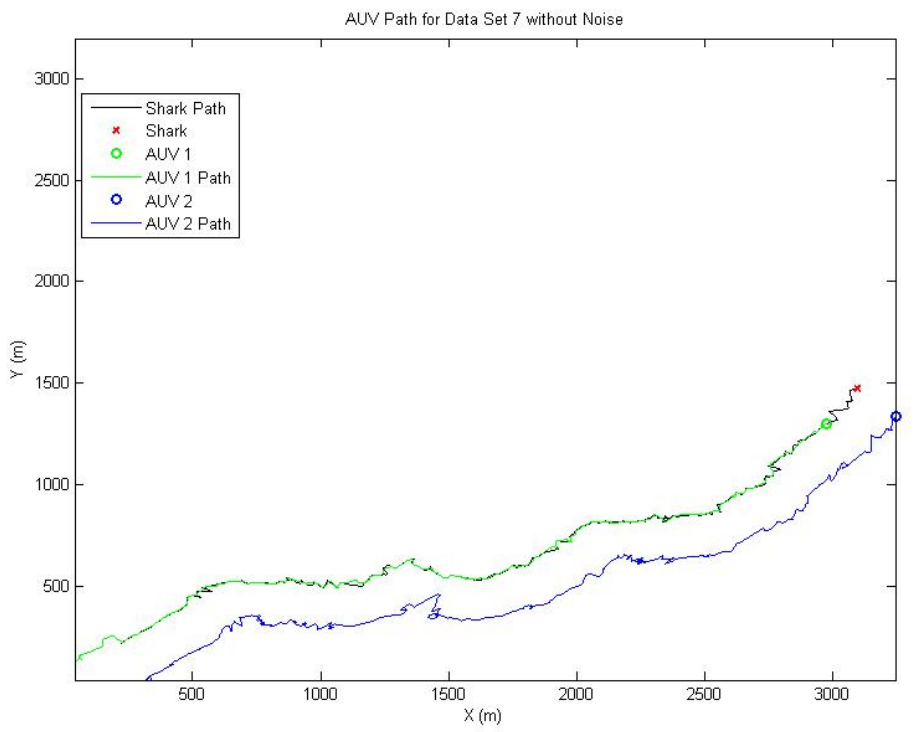

Figure 5.22: AUV Path for Data Set 7 without Noise

$\mathrm{y}$-axis of these graphs depict the distance from the shark in meters. The $\mathrm{x}$-axis of these graphs show the time in seconds at which that distance was recorded. The magenta line shows the distance the AUV is from the shark as a function of time. The cyan line represents the second AUV's distance from the shark. The red line shows the desired distance from the shark to avoid modifying it behavior. 


\begin{tabular}{|c|c|c|c|c|c|c|c|c|c|c|c|c|c|}
\hline 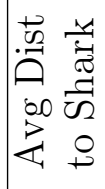 & D. & $\begin{array}{l}\infty \\
\infty \\
0\end{array}$ & $\left\{\begin{array}{l}\alpha \\
1 \\
0 \\
0\end{array}\right.$ & & & & $\begin{array}{l}\vec{\infty} \\
\dot{\sim} \\
\dot{\sim}\end{array}$ & 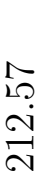 & $\begin{array}{l}\vec{b} \\
\stackrel{0}{0} \\
\ddot{A}\end{array}$ & $\begin{array}{l}\stackrel{m}{\sim} \\
\ddot{n} \\
\stackrel{n}{N}\end{array}$ & $\mid \begin{array}{l}\vec{H} \\
\dot{+} \\
\vec{N}\end{array}$ & $\begin{array}{l}m \\
\sigma \\
\dot{+} \\
\vec{N}\end{array}$ & $\begin{array}{l}\stackrel{9}{2} \\
0 \\
\stackrel{1}{N}\end{array}$ \\
\hline 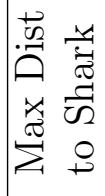 & : & $\begin{array}{l}0 \\
0 \\
15 \\
5 \\
5 .\end{array}$ & $\left\{\begin{array}{l}2 \\
\frac{a}{15}\end{array}\right.$ & & & 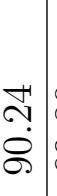 & $\begin{array}{l}8 \\
\infty \\
\dot{0}\end{array}$ & $\begin{array}{l}\text { N } \\
\frac{N}{N} \\
\text { N }\end{array}$ & 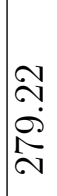 & $\begin{array}{l}a \\
\sim \\
\ddot{2} \\
\stackrel{2}{\sim}\end{array}$ & 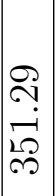 & 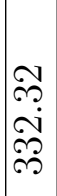 & $\begin{array}{l}20 \\
0 \\
\infty \\
0 \\
0\end{array}$ \\
\hline 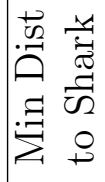 & $\begin{array}{l}0 \\
\stackrel{0}{0} \\
\stackrel{0}{-1}\end{array}$ & $\begin{array}{l}\mathscr{m} \\
\stackrel{\infty}{\infty}\end{array}$ & $\begin{array}{l}\frac{15}{2} \\
\frac{2}{7}\end{array}$ & & 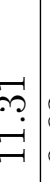 & $\begin{array}{l}30 \\
0 \\
0\end{array}$ & $\begin{array}{l}\stackrel{N}{I} \\
\dot{\imath} \\
\stackrel{-}{1}\end{array}$ & $\begin{array}{l}20 \\
\stackrel{10}{0} \\
\infty \\
-1\end{array}$ & 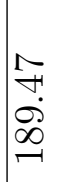 & $\begin{array}{l}0 \\
\infty \\
i \\
i \\
I \\
-1\end{array}$ & 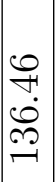 & $\begin{array}{l}4 \\
\stackrel{4}{6} \\
8\end{array}$ & 宓 \\
\hline 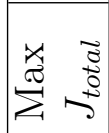 & $\begin{array}{l}\infty \\
0 \\
\infty \\
0 \\
0\end{array}$ & 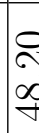 & $\begin{array}{l}6 \\
1 \\
6\end{array}$ & & مُ & 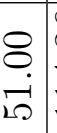 & 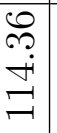 & $\begin{array}{l}\infty \\
\infty \\
\infty \\
\infty \\
-1\end{array}$ & $\mid \begin{array}{l}1 \\
\infty \\
\infty \\
\infty \\
-1 \\
-1\end{array}$ & $\begin{array}{l}\tilde{6} \\
0 \\
0 \\
20 \\
-1\end{array}$ & 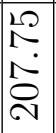 & 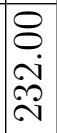 & 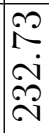 \\
\hline 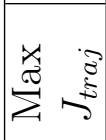 & $\stackrel{g}{+}$ & $\begin{array}{l}0 \\
2 \\
7 \\
7\end{array}$ & $\mid \begin{array}{l}5 \\
5 \\
n\end{array}$ & 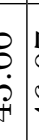 & $\begin{array}{c}5 \\
0 \\
0 \\
+\end{array}$ & 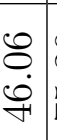 & $\begin{array}{l}\stackrel{\circ}{\infty} \\
\stackrel{2}{10} \\
\end{array}$ & $\stackrel{0}{\stackrel{0}{1}}$ & $\begin{array}{l}\sigma \\
\dot{\sigma} \\
\dot{0}\end{array}$ & $\begin{array}{l}\vec{\infty} \\
\infty \\
\infty\end{array}$ & \begin{tabular}{l}
1 \\
$\infty$ \\
$\infty$ \\
\hdashline \\
\hdashline \\
\hdashline
\end{tabular} & $\begin{array}{l}\sigma \\
0 \\
0 \\
ٍ \\
-1\end{array}$ & 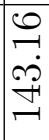 \\
\hline 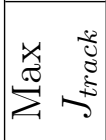 & $\begin{array}{l}\stackrel{ }{\sim} \\
\stackrel{+}{\sim}\end{array}$ & 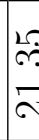 & के & & 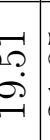 & 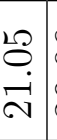 & $\begin{array}{l}\mathscr{0} \\
0 \\
\dot{2} \\
\dot{\rho}\end{array}$ & $\begin{array}{l}\stackrel{P}{7} \\
\infty \\
\infty \\
0\end{array}$ & 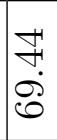 & $\begin{array}{l}\vec{\infty} \\
\infty \\
\infty\end{array}$ & \begin{tabular}{l}
1 \\
$\infty$ \\
$\infty$ \\
\hdashline \\
\hdashline \\
-1
\end{tabular} & $\begin{array}{l}8 \\
8 \\
10 \\
7 \\
7\end{array}$ & $\begin{array}{l}\hat{n} \\
0 \\
0 \\
=\end{array}$ \\
\hline 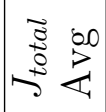 & $\begin{array}{l}\infty \\
\infty \\
10 \\
10\end{array}$ & $\begin{array}{l}0 \\
1 \\
15\end{array}$ & 8 & $\begin{array}{l}\dot{0} \\
\dot{0} \\
\dot{0}\end{array}$ & $\begin{array}{l}0 \\
0 \\
0 \\
0 \\
0\end{array}$ & $\begin{array}{l}n \\
\dot{y} \\
\dot{\theta}\end{array}$ & 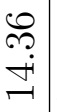 & 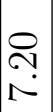 & 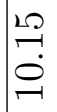 & $\begin{array}{l}\vec{\sim} \\
\infty \\
\infty \\
-1\end{array}$ & 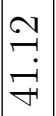 & $\begin{array}{l}\overrightarrow{0} \\
\dot{+} \\
\dot{H}\end{array}$ & تُ \\
\hline & Г & $\frac{m}{7}$ & $\frac{1}{\alpha}$ & $\begin{array}{c}0 \\
0 \\
+i\end{array}$ & $\begin{array}{c}\stackrel{e}{+1} \\
0 \\
0\end{array}$ & $\begin{array}{l}9 \\
0 \\
0\end{array}$ & $\begin{array}{l}N \\
\infty \\
\infty\end{array}$ & $\begin{array}{l}0 \\
0 \\
\infty \\
\infty\end{array}$ & $\begin{array}{l}+ \\
\infty \\
10\end{array}$ & $\stackrel{m}{\ddot{0}}$ & \begin{tabular}{|l|}
$\stackrel{N}{\vec{H}}$ \\
$\stackrel{\sim}{N}$
\end{tabular} & 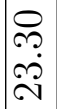 & $\begin{array}{l}\text { ㄱ. } \\
\text { Nं }\end{array}$ \\
\hline & $\begin{array}{l}\stackrel{\bullet}{ } \\
\sim \\
\sim\end{array}$ & है & $?$ & ? & $\underset{1}{0}$ & $\begin{array}{l}\vec{r} \\
\stackrel{1}{\infty}\end{array}$ & $\begin{array}{l}\stackrel{\partial}{+} \\
\dot{0}\end{array}$ & $\mid \begin{array}{l}\vec{H} \\
\stackrel{\infty}{\infty}\end{array}$ & 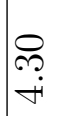 & $\begin{array}{c}\infty \\
0 \\
\infty \\
\infty\end{array}$ & $\mid \begin{array}{l}0 \\
0 \\
0 \\
\\
\end{array}$ & कृ & $\stackrel{0}{\stackrel{9}{1}}$ \\
\hline 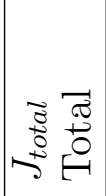 & 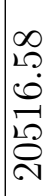 & 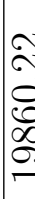 & 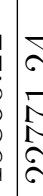 & c. & $\begin{array}{c}0 \\
0 \\
1 \\
5 \\
6 \\
0 \\
0 \\
0\end{array}$ & 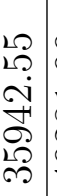 & 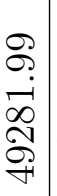 & \begin{tabular}{l}
\multirow{1}{N}{} \\
0 \\
0 \\
10 \\
0 \\
0 \\
10
\end{tabular} & $\begin{array}{l}20 \\
10 \\
03 \\
0 \\
10 \\
11 \\
1\end{array}$ & 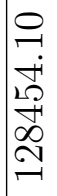 & 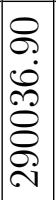 & 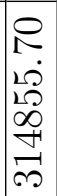 & 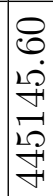 \\
\hline 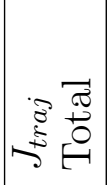 & 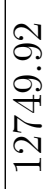 & $\begin{array}{l}\infty \\
\infty \\
\infty \\
i \\
\nabla \\
\nabla\end{array}$ & 8 & 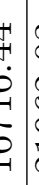 & 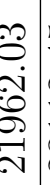 & 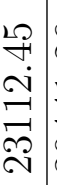 & 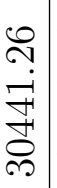 & 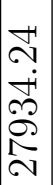 & 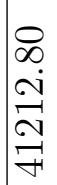 & 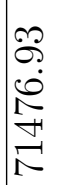 & 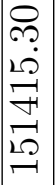 & 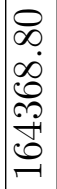 & 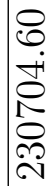 \\
\hline 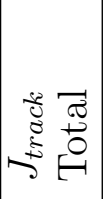 & $\begin{array}{l}0 \\
0 \\
0 \\
0 \\
1 \\
1\end{array}$ & 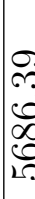 & ? & $R$ & . & 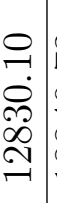 & $\begin{array}{l}2 \\
\\
\dot{0} \\
+ \\
\infty \\
\infty \\
-1\end{array}$ & 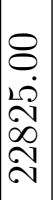 & 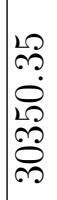 & \begin{tabular}{l}
$N$ \\
\hdashline \\
$N$ \\
$N$ \\
$\Omega$ \\
6 \\
20
\end{tabular} & \begin{tabular}{|c|}
0 \\
0 \\
$\dot{A}$ \\
0 \\
$\infty$ \\
$\infty$ \\
-1 \\
-1
\end{tabular} & $\begin{array}{l}8 \\
8 \\
60 \\
\infty \\
1 \\
0 \\
10 \\
-1\end{array}$ & 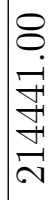 \\
\hline $\begin{array}{l}0 \\
0 \\
0 \\
z\end{array}$ & 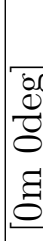 & 눈 & 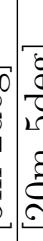 & 它 & 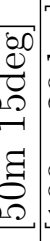 & 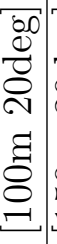 & 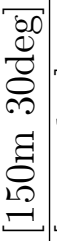 & $\begin{array}{l}0.0 \\
0 \\
0 \\
0 \\
E \\
0 \\
0\end{array}$ & 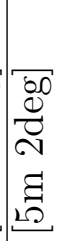 & 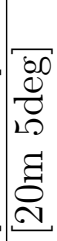 & 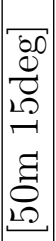 & 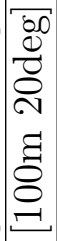 & 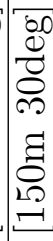 \\
\hline 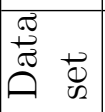 & & & & & 6 & 0 & 0 & $N$ & N & $N$ & $\Lambda$ & $N$ & \\
\hline
\end{tabular}




\begin{tabular}{|l|l|l|l|}
\hline $\begin{array}{l}\text { Data } \\
\text { set }\end{array}$ & Noise & $\begin{array}{l}\text { Avg } \\
\text { Error } \\
(\mathrm{m})\end{array}$ & $\begin{array}{l}\text { Standard } \\
\text { Deviation } \\
(\mathrm{m})\end{array}$ \\
\hline 6 & {$[0 \mathrm{~m} \mathrm{0deg}]$} & 0.51 & 1.15 \\
\hline 6 & {$[5 \mathrm{~m} \mathrm{2deg}]$} & 1.31 & 1.66 \\
\hline 6 & {$[20 \mathrm{~m} \mathrm{5deg}]$} & 2.16 & 2.28 \\
\hline 6 & {$[50 \mathrm{~m} \mathrm{15deg}]$} & 4.75 & 3.79 \\
\hline 6 & {$[100 \mathrm{~m} \mathrm{20deg}]$} & 5.68 & 4.49 \\
\hline 6 & {$[150 \mathrm{~m} \mathrm{30deg}]$} & 8.02 & 5.71 \\
\hline 7 & {$[0 \mathrm{~m} \mathrm{0deg}]$} & 7.00 & 11.07 \\
\hline 7 & {$[5 \mathrm{~m} \mathrm{2deg}]$} & 4.09 & 9.38 \\
\hline 7 & {$[20 \mathrm{~m} \mathrm{5deg}]$} & 10.82 & 17.33 \\
\hline 7 & {$[50 \mathrm{~m} \mathrm{15deg}]$} & 23.58 & 21.28 \\
\hline 7 & {$[100 \mathrm{~m} \mathrm{20deg}]$} & 30.50 & 26.93 \\
\hline 7 & {$[150 \mathrm{~m} \mathrm{30deg}]$} & 39.53 & 35.63 \\
\hline
\end{tabular}

Table 5.5: Average and Standard Deviation of Particle Shark Error

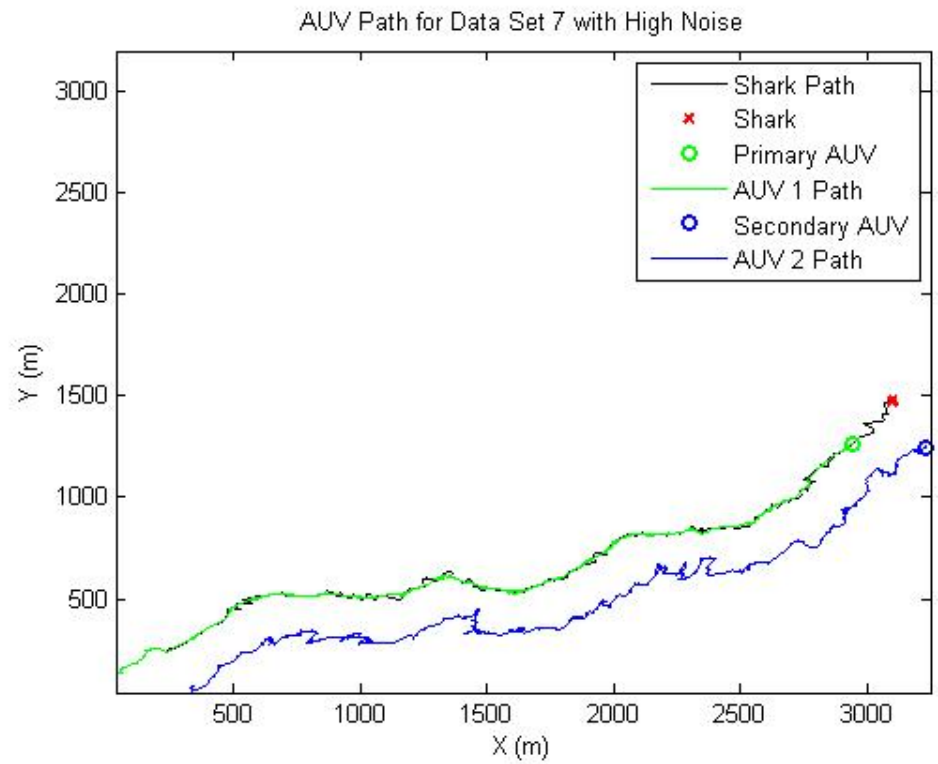

Figure 5.23: AUV Path for Data Set 7 with High Noise 


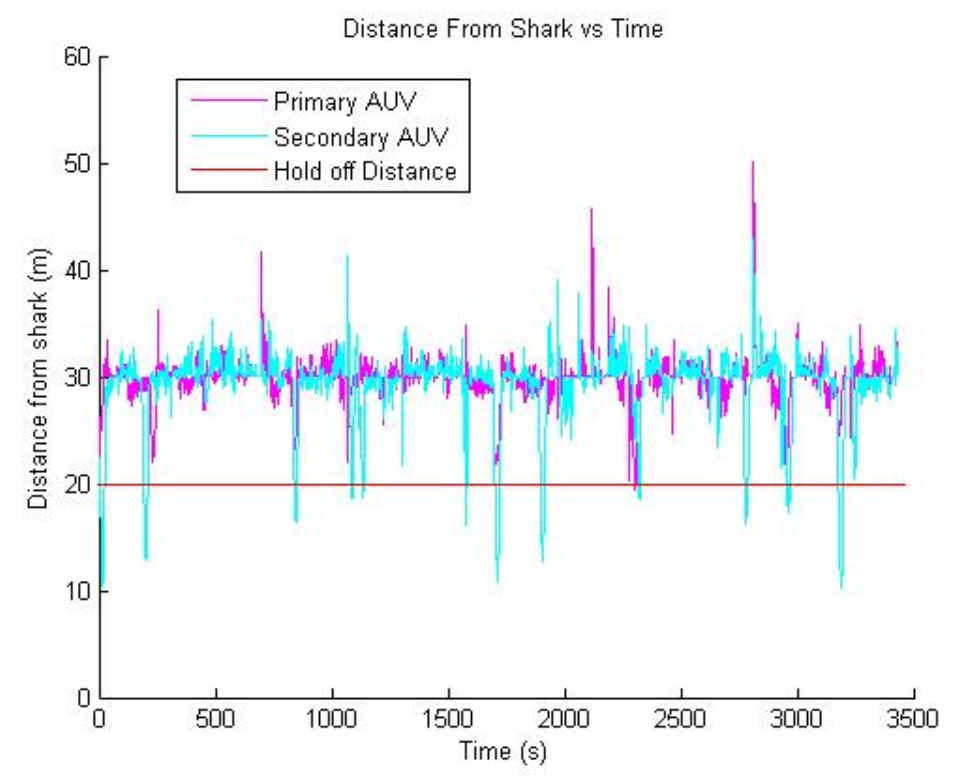

Figure 5.24: Distance From Shark for Data Set 6 without Noise

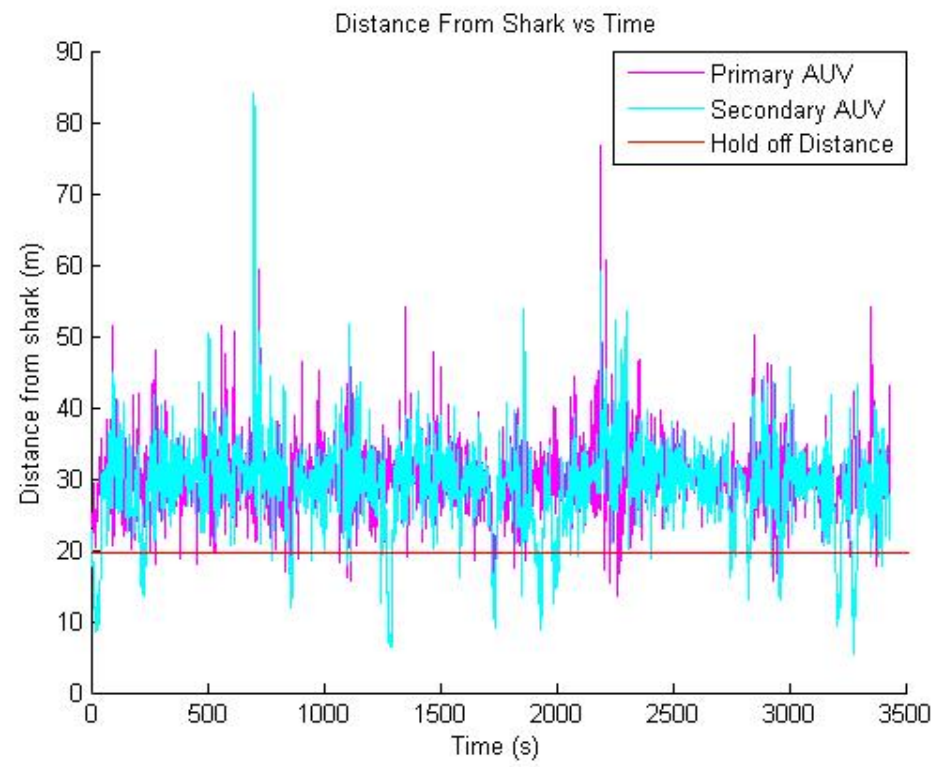

Figure 5.25: Distance From Shark for Data Set 6 with High Noise 


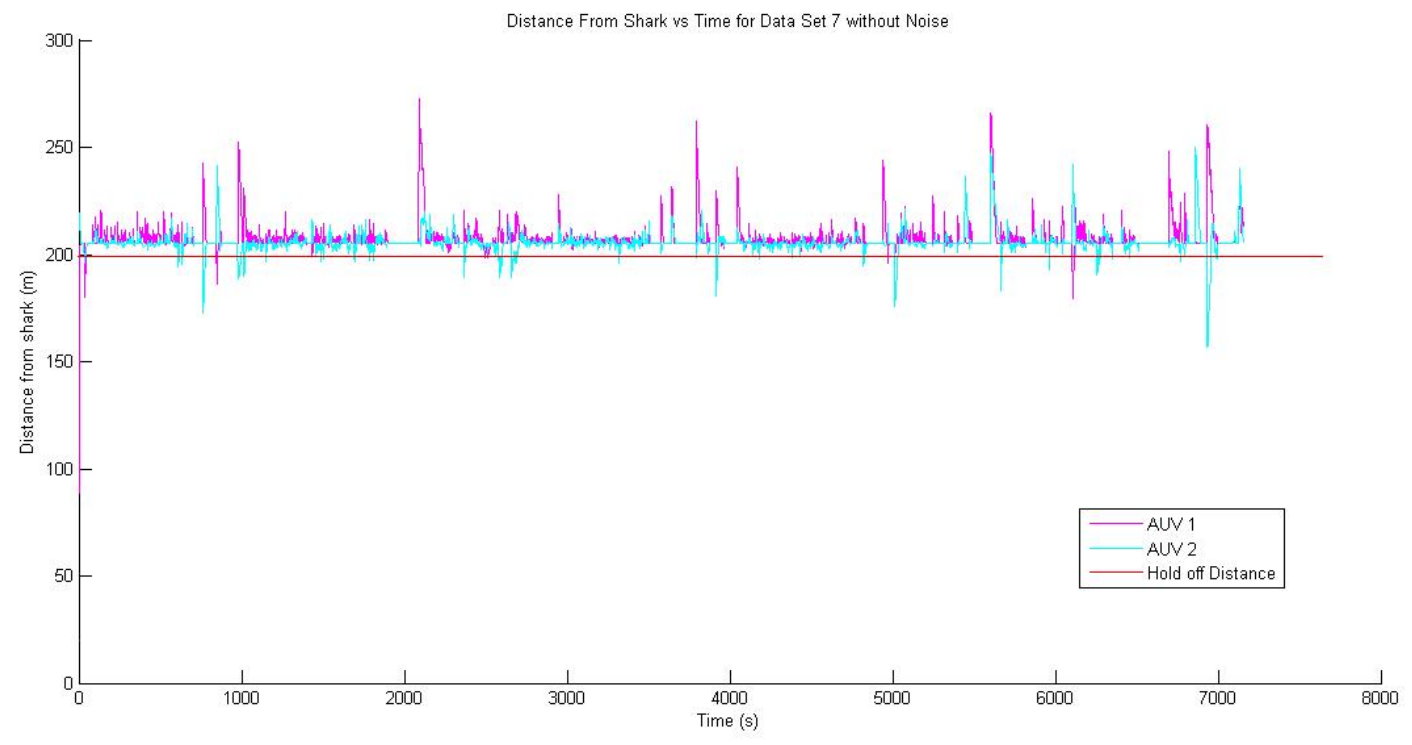

Figure 5.26: Distance From Shark for Data Set 7 without Noise

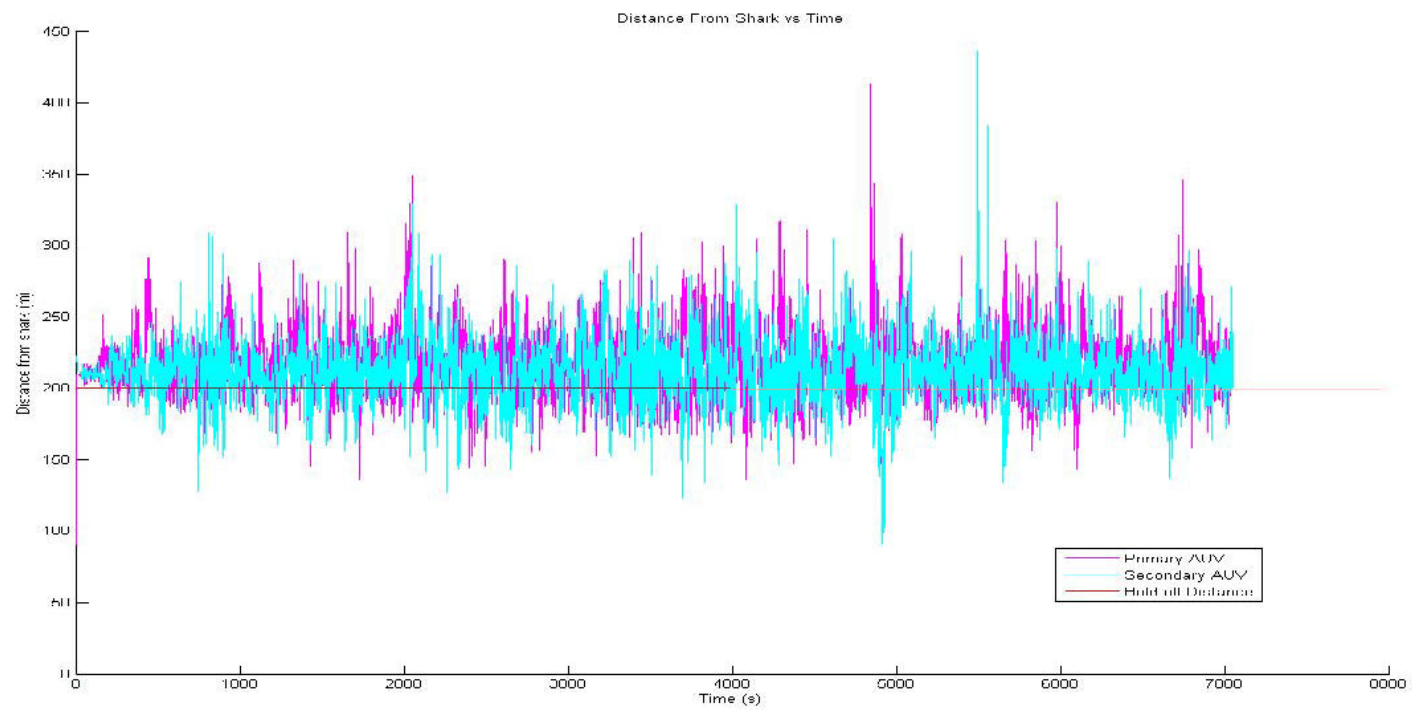

Figure 5.27: Distance From Shark for Data Set 7 with High Noise 


\section{Chapter 6}

\section{Discussion}

\subsection{Inherent Benefits of Solution Method}

There are several benefits of using an AUV to track a tagged shark over the current methods. As discussed in the introduction, current methods are lacking as they either are stationary, send back only a summary of the data or are very labor intensive. The use of an AUV allows the shark to be followed, resulting in further information on the migratory behaviors of sharks. The AUV can capture a wide range of data and possible even video and records movement on a much finer scale. The AUV is a far less labor intensive solution than actively tracking a shark from a boat or tossing sensors in the water then retrieving them before the shark leaves the sensor range. The AUV can be programmed to return to a specified location at the end of its mission making it far more of a deploy and forget solution. 


\subsection{Particle filter Accuracy}

The accuracy of two different particle filters were tested. The first particle filter was a basic particle filter. The second was a particle filter that took into account the current behavior of the shark to increase the accuracy of its estimation of the shark's position. The behavior based particle filter did well at characterizing the shark's position. The basic particle filter had more error associated with its estimate, but the standard deviation of the particles remained small.

The Figure 5.1 shows the error of each of the two particle filters. This error is the distance the estimated particle shark is from the actual shark reading. From this figure, it can be seen that the particle filters can estimate the state of the shark. The behavior based particle filter does an exceptional job of modeling the shark's location. The basic particle filter doesn't do quite as well. There are some interesting things to note on this graph. There are two or three locations towards the end of the trial at which the error of the basic particle filter seems to increase significantly. Looking at the shark data around these points in time, there are several periods of larger time intervals between shark tag readings, jumping from about 1-3 seconds per reading to several readings with 12-20 second intervals. Since the particle filter continues to propagate during the duration of the time between intervals, the estimated shark location moves farther and farther from the last reading. This is to be expected as the particle filter is attempting to estimate where the shark could be. The particles spread out representing the

possible vectors the shark could be travelling. This is supported by Figure 5.2 where at the same time steps the standard deviation of the particles also grows much larger.

Other than at those longer time steps, the error of the behavior based particle filter remains below 2 meters for the duration of the trail. The basic particle filter 
does slightly worse than the behavior based one and the accuracy hangs around the 5 meter mark. Throughout the duration of the trial, excluding the longer time interval points the standard deviation of both particle filters remains below 2 meters.

Something to note is that the addition of a second AUV greatly increased the accuracy of the particle filter. This is further characterized in depth in the section on the additional AUV.

The results from these accuracy tests correspond to how accurate the estimation of the shark's location will be. Both particle filters showed promising results. If these particle filters can be used to accurately estimate the location of the tagged shark, then the AUV can accurately navigate toward that shark.

\subsection{Path Following}

From looking at Figure 5.3 it can be seen that varying the path weighting values changes the AUV's path through the water. As expected, the blue line best follows the path of the shark and the green line less so. The red line representing the AUV movements with no path weighting bring up a point to consider. Even though the AUV has no inclination to follow the shark's path through the water, the AUV still has to do a lot of work to stay away from the shark. If the AUV still has to do all the work to maneuver itself out of the shark's way, why not have it put that effort towards following the shark's path to potentially acquire more information about the shark's environment?

The other side of this is does the AUV need to expend so much energy to stay away from the shark? The AUV attempts to stay far enough away from the 
shark to keep from influencing its movements, however, that distance is based on a moving AUV. If the AUV were to center itself then not move while the shark was within the holdoff buffer would the shark's behavior still be modified or would it simply become accustomed to the AUV's presence? The AUV could save large amounts of battery power by staying as a stationary observer until the shark is already swimming away past the point that the AUV would modify its behavior.

The path weighting has a big influence on the cost functions. This makes sense as path weighting determines how closely the AUV should attempt to follow the shark's path through the water. The distance from the shark's path is the $J_{t r a j}$ cost function. The higher the path weighting, the more the $J_{t r a j}$ cost function is reduced as seen in Figure 5.6. However this causes the AUV to cover more ground to ensure it is on top of the previous path of the shark thereby increasing $J_{\text {track }}$. Having the path weighting at 0 causes the AUV to solely prioritize distance from the shark. This causes a much lower $J_{\text {track }}$ value, but greatly increases $J_{t r a j}$, as seen in Figure 5.4.

\subsection{Optimal Path Weighting}

From the Path following test, the path weighting the AUV is using greatly affects the resulting cost functions. Since there is a tradeoff between an increased amount of power expended form following the shark's path and the amounts of additional information that could be recorded, it is clear that there should be some value in between that is an optimal solution. 
From the averaged $J_{\text {track }}$ values, it can be seen that the lower the path weighting, the less the cost of following the path. This is to be expected as it will always be easier to track a closer point than one that may be farther away. From the $J_{\text {trajectory }}$ values, the opposite if true; the higher the path weighting, the lower the cost of being far from the path. Again, this is to be expected as if the AUV is just going straight towards the shark, the odds of it overlapping the previous path of the shark is low. One interesting thing to note is that for any $w>0$ the cost of following the trajectory drops significantly because over time even a small path weighting will direct the AUV toward the previous trajectory of the shark. The $J_{\text {total }}$ value is the interesting and perhaps most important of the results. This value combines the costs of $J_{\text {track }}$ and $J_{\text {trajectory }}$. This value appears to be parabolic in nature. Moving towards either extreme of the path weightings results in an increase of the total cost. This represents the trade off of following the shark's path more accurately and the extra distance the AUV must go to accomplish it. Looking at the trials individually, the path weighting that minimizes this values ranges from $\mathrm{w}=0.25$ to 0.75 . Looking at the averaged results across either all the Shovelnose data or both species data, the best weighting that minimizes the total cost over the length of the trial is $\mathrm{w}=0.5$. Looking at the maximum cost values however, it can be seen that in general, the smaller path weightings have smaller maximum costs.

Looking at the AUV's path vs. the shark's path the success or failure of the AUV to maintain its distance from the shark can be evaluated. Looking at the average distance to the shark, it can be seen that regardless of the path weighting, the tracking algorithm maintains an average distance to the shark very close to the hold off distance plus the hold off buffer. The standard deviation of the average distance to the shark over all four of the Shovelnose shark data sets is 0.307 
meters. Similarly across all the data sets for all the various path weightings, the maximum distance from the shark remains fairly similar with just over a meter being the largest difference caused by different weightings over the Shovelnose shark data sets and just under a four meter difference seen in the White shark data set.

The variance in the minimum distance from the shark however is much greater with the greatest difference being just under 15 meters. In data set 3 with a path weighting of $\mathrm{w}=1.0$, the AUV comes particularly close, coming within 6.29 meters of the shark at one point it time. Compared to the results from data set 1 where the closest the AUV got was 19.37 meters, this value seemed like quite the outlier and could indicate disastrous overshoot or a big error in the controller. Upon further investigation, the smaller minimum distances to the shark all occur when the shark double backs on its trajectory through the water resulting in the previous path point jumping from one side of the hold off circle to the other while the shark is swimming at the AUV. This case can be seen in Figure 3.3. Data set 3 was chosen particularly because the shark did double back on itself quite frequently. This is one of the cases were the different species of shark has different repercussions for the controller. The White shark observed changes its bearing very infrequently and thus regardless of path weighting, the minimum distance from the shark remains very consistent.

Taking all this information into account, the optimal weighting for tracking of a Shovelnose shark was found to be $\mathrm{w}=0.5$. The optimal weighting for the tracking of a White shark was found to be $\mathrm{w}=0.75$. These results can be linked to the swimming patterns of the two shark species. The Shovelnose shark tends to swim in smaller circles, changing direction rather frequently. This results in it crossing its own path a lot causing the AUV to need to move out of the way. 
This means the AUV should be 'stuck' to the path less. In other words, the AUV should place less weighting on the path in the case of the Shovelnose shark as less weighting will keep it out of the shark's way more often. The White shark however is the complete opposite. It never once crossed over its path in the recorded data set. The White shark tended to swim in straight lines. It occasionally cut back towards its previous path, but then returned to the line it was following before. Due to this reason, the AUV should have a much higher path weighting as there is less concern the shark will suddenly swim back at the AUV.

Since Shovelnose and White sharks have very different swimming styles that require different optimal path weightings, other sharks may also require fine tuning to the path weighting for their particular swimming style. The other primary shark of focus, the Leopard Shark has a very similar style to that of the Shovelnose. Perhaps other open ocean sharks have similar swimming patterns to the White shark. The path weightings found in this section could serve as a starting point for in situ tuning for tracking other species of tagged sharks.

\subsection{AUVs}

The inclusion of a second AUV to the solution provides many benefits to the controller. In addition to any benefits found in the results of this section the use of a second AUV has several other benefits. The second AUV allows the primary AUV to be programmed to follow the shark at depth, recording details of its path through its environment, while the secondary communicates with GPS satellites to ensure accurate position records. This is assuming the AUVs are operating with a specific hierarchy and each determines its desired path point 
independently, only communicating information on the shark.

The possibility of the AUVs working together communicating opens the door to more advanced tracking operations. If a research team wishes to track the movements of a migratory shark for weeks or months, they could use a fleet of several AUVs to monitor the shark continuously. One AUV could relieve the other to return to the chase boat to recharge its batteries. In the event of a lost shark, the AUVs could work together to reacquire the target.

In Figure 5.15, the secondary AUV nicely maintains its path perpendicular to the primary AUV. As seen in figure 5.14, it can be seen that the secondary AUV also maintains the proper hold off distance from the shark. In figure 5.12, the shark abruptly changes direction around time $t=750$ seconds. The secondary AUV then swings around to return to its position to the right of the shark. This is interesting. This time corresponds to the distance from shark graph as the only time the secondary AUV entered the hold off distance from the shark. This test of the second AUV relies on its own code for positioning and reacts independently of the primary AUV, save for comparing the shark's location. It they were to communicate they positions and had a flexible hierarchy, at this point the primary AUV could move to the secondary location and the secondary take up directly following the shark. This would save battery life for both AUVs; however it would take more communication between the two.

As seen in the figures, there is a clear difference in the quality of the particle filter. The average error in the particle filter using a single AUV is 2.0 meters. The average error in the particle filter using two AUVs is only 1.0 meters. Using a second AUV cut the error of the particle filter in half! In figure 5.16, the peak in the error of the single AUV particle filter was 20.8. The particle filter using both AUVs had a maximum error of 14.8 ; roughly $2 / 3$ of the single AUV filter. 
Clearly the addition of a second AUV increased the accuracy of the particle filter, but what about the standard deviation of the particles?

Figure 5.17 shows the comparison of the standard deviations of the two systems. The average standard deviation in the particle filter using a single AUV is 1.4 meters. The average standard deviation in the particle filter using two AUVs is only 0.8 meters. The maximum standard deviation of the single AUV filter was 19.6 meters. The maximum standard deviation of the dual AUV filter was 9.0 meters. That is roughly 45 percent of the single AUV particle filter. This drop in the magnitude of the standard deviation means the AUV can be far more confident in the output of the particle filter.

\subsection{Future Planning}

The results of using a simple planner to extrapolate the future position of the shark did not yield the desired results. However, the test did produce interesting results. The predictor took the shark's current velocity and angular velocity and extrapolated the future position of the shark. The AUV then used that position to attempt to reduce the $J_{\text {track }}$ cost function by placing itself in the optimal position for the shark's future location.

In the case of both sharks, the longer the current velocity and angular velocity were extrapolated, the greater the error. Contrary to the theory, the lowest cost resulted from the real time tracking of the shark. This is most likely due to the rate at which the AUV updated its desired location. The idea of cutting the corner assumes a set path for both the tracker and the trackee. However, the AUV would continually recalculate the location it should aim for resulting 
in the increased $J_{t r a j}$ as expected, but it never follows through enough to reap the reward of the reduced $J_{\text {track }}$. Perhaps to get more benefit from this system of path planning, a different tracking algorithm is required. That is, one that has a lower refresh rate or one based on a buffer of location points to hit prior to choosing a new path. Future planning would also be very beneficial to a controller that took obstacles into account. This would allow the AUV to maneuver around these obstacles and may end up reducing the total cost.

The really interesting result of this trial was that for both sharks, there was a period of time that as the prediction time increased, the cost of acting on that prediction actually decreased. This can be seen in Figure 5.18 between 2 and 5 seconds into the future and Figure 5.19 between 10 and 23 seconds into the future. While this doesn't provide the AUV with any benefit due to the not predicting choice being the least cost, it does reveal something about the shark's nature. What this means is that each shark has a period in which they return to the location they would have been at had they continued with the same velocity and angular velocity. This could be an expression of the shark's movement through the water. The shark undulates as it moves through the water to cause forward propulsion. This could be why there is a quick jump in the error because of assuming constant velocity.

Despite not obtaining positive results from this test, the planning of AUV path by estimating the future position of the shark can be further explored. This is particularly true in the case of adding obstacles to the simulation. Interestingly, the particle filter itself works in the same manner as this to propagate the particles. Further research into the predicting of the shark's future movements is required. 


\subsection{Noise}

The effect of noise on the signal of the shark's position was investigated. In the ocean, there will be noise and error in the signal the AUV receives from the shark tag. Any proposed controller must be able to still track the shark despite the inaccuracy in the shark's position.

On the Shovelnose shark data set, the controller does not handle noise very well. As seen in Table 5.3, the controller starts out alright when a small amount of noise is added. The average $J_{\text {total }}$ only jumps up from 5.56 to 8.85. The average cost of $J_{\text {track }}$ only increases by 0.5 however the $J_{\text {traj }}$ nearly doubles from 3.39 to 6.18. There is a far more distinct difference in the cost between noise levels of [5m 2deg] and [20m 5deg]. The average $J_{\text {total }}$ nearly triples and individually, the average $J_{\text {track }}$ increases by over 7 and the average $J_{\text {traj }}$ increases by over 10 . This change in noise signifies the level at which the noise renders the controller ineffective. The costs associated with tracking the shark rapidly increase. The next increase in noise level also shows an increase in cost functions, but not nearly as big of a jump. Interestingly, additional increases in noise level actually reduce the $J_{\text {track }}$ costs.

As far as the max cost values are concerned, they all show only small increases until the last increase in noise where each max cost value jumps up sharply. Another key statistic on evaluating the controller response to the noise is in the distance from the shark. Even with the first addition of noise, the minimum distance from the shark dropped from 12.08 meters to only 1.68 meters. The second increase in noise level resulted in a minimum distance from the shark of only 0.02 meters. Getting this close to the shark would have a very high chance of modifying the shark's behavior. The maximum distance from the shark didn't increase much due to the added noise level of [ $5 \mathrm{~m} 2 \mathrm{deg}]$, however, with the next increase 
in noise to [20m $5 \mathrm{deg}]$, the maximum distance almost doubled from 53.70 meters to 103.98 meters. Additional increases in noise level also showed big increases in the maximum distance from the shark. The average distance to the shark actually decreased due to the first two noise levels, but jumped much higher at the noise level of [50m 15deg]. This decrease in the average distance to the shark is due to the AUV moving more inside the hold off area during the trial.

On the White shark data set, the controller held up slightly better to the increased noise levels. The first noise level increases the cost but not by very much. The second noise level causes the cost to almost double, but it is still not too high. The third noise level [50m $15 \mathrm{deg}]$ causes a big jump in the cost functions. This causes an increase in the average $J_{\text {total }}$ from roughly 2.5 times the original value to a little more than 4.5 times the original value.

The maximum values of the cost functions also show bigger increases in the higher noise levels. The max $J_{\text {track }}$ stays fairly consistent until the last noise level, where it increases from 67.72 to 115.83 . Both $J_{\text {traj }}$ and $J_{\text {total }}$ show large increases going from a noise level of [20m $5 \mathrm{deg}]$ to $[50 \mathrm{~m} 15 \mathrm{deg}]$. This is the same for the minimum distance to the shark. The larger decrease in this number is seen at the $[50 \mathrm{~m} 15 \mathrm{deg}]$ noise level. The average distance to the shark remains fairly constant for all noise levels, but shows an increase for the [100m 20deg] noise level.

Data set 7 initially showed less of a response to the noise. Over the range of noise levels from [0m $0 \mathrm{deg}]$ to $[20 \mathrm{~m} 5 \mathrm{deg}]$ the $J_{\text {total }}$ cost jumped up from 7.51 to 18.46. In comparison to the previous test on the smaller data set there was more of an increase in the total cost of following the shark (up from 5.56 to 26.39). Why there was a much bigger increase in the effect of the noise on the signal from the shark comes down to the $A U V^{\prime}$ s perspective. When the AUV is 
tracking close to the shark, having the correct distance is more important than the correct angle. However when the AUV is farther from the target, having the correct angle to the shark is more critical than having the right distance.

The problem in this case is in the accuracy over a distance. Think about shooting a rifle at a target. When fairly close to the target, a variance in about 2 degrees doesn't throw off the aim too much. Take a range of 20 meters at an angle of 2 degrees, assuming a right triangle, the shot could be off by 0.7 meters. In this case, the distance being off by 5 meters is a lot more than 0.7 meters. This distance is a quarter of the distance to your target and thus in comparison is the bigger error. However, when shooting from a larger distance, those 2 degrees can result in the aim being off by a far bigger factor. Take a range of 200 meters this time at an angle of 2 degrees, assuming a right triangle, the shot could be off by 6.98 meters. Compared again to the distance from the target (200 meters), this is just over a fortieth of the distance. Therefore less increase in the cost of tracking the shark is observed. This is the case of the White shark data set.

From this test, it is clear that the noise level in the signal from the shark tag is going to be a limiting factor in the implementation of this proposed solution. While following the Shovelnose Shark, the controller can still respond well to a noise level of [5m 2deg], but the increase to [20m $5 \mathrm{deg}]$ causes problems. Following the White Shark, the controller can handle slightly more noise. The controller can still function with a noise level of [20m 5deg] but starts to run into problems with the $[50 \mathrm{~m} 15 \mathrm{deg}]$ noise level. 


\subsection{Combined Methods Test}

Table 5.4 shows the results of the cost functions for each level of noise. Compared to data set 4 in Table 5.3, data set 6 has a slightly higher average base total cost. For increasing levels of noise, the controller in this test does much better. Up to a noise level of [20m $5 \mathrm{deg}]$, the total average cost only increases by roughly 10 percent. Compared to the slightly higher than 400 percent increase seen in the noise test. Up to a noise level of [100m 20deg] the increase in total average cost remains at less than 100 percent. Even at the highest noise level, the average $J_{\text {total }}$ is only 14.36. Comparing this to the $J_{\text {total }}$ of 39.03 seen in the noise test, it is clear that the addition of the particle filter and the second AUV greatly reduces the cost of tracking the shark. The Maximum values of the cost functions all remain relatively close until the final noise level where they increase significantly.

Data set 7 also showed a reduction in the cost of tracking and following the shark with the addition of the particle filter and second AUV. Compared to data set 5 in Table 5.3 , data set 7 has a slightly lower average base total cost. Until the highest two noise levels, the controller yields similar costs to the results seen in the noise test. These last two noise levels see a drop in cost, with the highest noise level cost dropping from roughly ten times the without noise cost to less than nine times the noiseless cost. The benefits of the second AUV and the particle filter can be seen when looking at the maximum values of the cost functions. While the $J_{\text {track }}$ max value does not change much, the $J_{\text {traj }}$ value is cut in half and the $\max J_{\text {total }}$ value is reduced by 109 .

Looking at Table 5.5 the accuracy of the particle filter can be seen. As the 
level of noise increases, so does the average error in the particle filter's estimate of the shark's location. Despite high levels of noise, the particle filter remains fairly accurate to the actual location of the shark. Compared to the amount of noise introduced to the system, the average error and standard deviation remain small. The average error for the Shovelnose data set remains less than 40 percent of the distance from the shark and the average error for the White data set remains at less than 20 percent of the following distance.

Comparing Figure 5.22 and Figure 5.23, the difference in the path of the AUVs due to an increase in the noise level can be visualized. The added noise causes the path of the AUVs to be slightly more erratic. This effect is more visible in the path of the second AUV. However, both paths look fairly similar to the results seen without noise and clearly the AUVs still follow the path of the shark as desired.

The distance the AUV kept from the shark also really benefitted from the addition of the particle filter and second AUV. As seen in Table 5.3, almost any amount of noise caused the AUV to stray close to the shark. In the final test, the AUV keeps its distance like expected from the shark. Of all the noise levels, the AUV got the closest to the shark at the level of [100m 20deg] at a distance of 9.63 meters. For the White shark, the results were similar. The minimum distance occurred again at a noise level of [100m 20deg], dropping to just under half the desired distance from the shark. However, compared to the 0.52 meters in the noise test, this puts the AUV much farther from the jaws of the shark.

The maximum distance from the shark also showed significant improvement. For the Shovelnose data set, the AUV never exceeded 100 meters from the shark. 
Compared to the 510 meter max distance seen in the noise test, this shows a marked improvement. The maximum distance from the White shark also showed a large improvement dropping from 800 meters to just over half that distance at 408.05 meters. For both data sets, the average distance from the shark showed little variation despite the increase in noise levels.

Comparing the results of test 6 and 7 , the benefits of the particle filter and the secondary AUV can be seen. These additions increase accuracy in the estimated location of the shark. They also reduce the cost of tracking the shark as well as increase the minimum distance to the shark. By utilizing these additions, the operable noise range of the controller was increased. For the Shovelnose shark, the real jump in cost occurred at the [100m 20deg] noise level, however, the higher noise level of [150m 30deg] actually produced better results in the distance from the shark, though increased the $J_{\text {total }}$ cost. For the White shark, the increase to a noise level of [50m $15 \mathrm{deg}]$ actually resulted in the largest increase in cost. However, the controller again showed better results in the distance from the shark at the highest noise level $[150 \mathrm{~m} 30 \mathrm{deg}]$. 


\section{Chapter 7}

\section{Conclusion}

The goal of this thesis was to provide a feasible solution to the problem of how to track a tagged shark through the water, as well as to investigate some of the key aspects of this tracking method.

\subsection{What this solution provides}

This solution of having an AUV track the shark offers several benefits over existing methods. First, it is a mobile platform, so data collection is not limited to a specific area like the stationary acoustic receivers. Second, it provides an easily recovered completely detailed account of the shark's movements and environment unlike the PAT tags that only transmit a summary of data and are difficult to recover. The AUV continuously records the signal from the shark for an extended period with minimal setup time, eliminating the large data gaps in the case of the labor intensive task of humans listening from a chase boat. Using the attached camera to the Iver2, video could be recorded when visibility allows without being within feet of the shark's mouth like the Tiger-cam. 


\subsection{Knowledge learned about this solution}

Several factors that may affect the success of the proposed solution were researched. The particle filter that would be implemented was tested and shown to accurately estimate the shark's location, particularly with the addition of a second AUV. This means that the offered solution will be able to accurately estimate the actual location of the shark in real-time or in the event of a lost shark.

The ability of the AUV to follow the shark's previous path through the water was investigated. The AUV was shown to accurately follow the path of the shark. This means that copious amount of additional data on the shark's preferences of path can be recorded, such as but not limited to, salinity, temperature, magnetic fields, depth, flora, visibility, etc.

The effect of that path weighting on the cost of tracking the shark were investigated and optimal path weightings were found for two species of sharks with vastly different swimming behavior. This allows the AUV to more efficiently track the sharks. It also shows that this controller works for different species of sharks, adding to its potential scientific benefit.

The addition of a second AUV showed possible areas of advancing the field. The second AUV was shown to maintain formation effectively without communication from the first AUV. However if the two were to communicate, the benefit in the accuracy of the particle filter was shown. This provides a starting point and area of further research for future students.

The effect of future path planning was explored. While this did not yield any benefits for this particular controller, it did show an interesting pattern in shark swimming behavior. Methods to make better use of this feature and potential areas of use were suggested.

The effect of noise in the signal from the tag was investigated. The level of 
noise at which the AUV could no longer effectively track and pursue the shark was found. This has the real world application of testing the code with the realistic input conditions and showing the extent to which the controller could still function as expected with imperfect inputs.

Finally the combined effect of all beneficial areas of research was tested. The controller was shown to work on extended and more complex shark paths and performing better under the influence of noise in the signal from the shark. This test shows the possibility of the use of $\operatorname{AUV}(\mathrm{s})$ in shark tracking.

\subsection{Limitations}

While this thesis strives to cover the key aspects of the proposed solution of using an AUV to track tagged sharks through the water, it is not all encompassing. This code uses basic kinematic equations to model the response of the AUV. The response of the AUV in the water is a far more complex higher order system. This simulation also does not take into account potential obstacles in the water.

\subsection{Future Work}

Having demonstrated the feasibility of using an AUV to track a tagged shark through the water, what is the next step? From here, actual ocean testing of this code is key to continuing this avenue of research. The creation of the physical acoustic system to be added to the Iver will enable actual tracking of fish tags through the water.

Another area of improvement to this project is the addition of tracking the 
shark at depth. The addition of a third dimension would be critical to learning more about the habitat of the sharks as the ocean's characteristics vary greatly with depth. This coding addition may require a different hydrophone setup on the Iver to get better accuracy in the $\mathrm{z}$ dimension. It was not added to this investigation as the raw data analyzed did not have relative depth associated with the signals.

A further area of investigation would be adding obstacles to the Iver's path planning. This could be simple collision detection and avoidance or even incorporating active mapping of the Iver's environment while tracking the shark.

Finally, the most obvious area for expansion is the actual tracking of the tagged sharks. This requires the acoustic receivers installed on the Iver to be tested. 


\section{Bibliography}

[1] An Introduction to Autonomous Mobile Robots, pages 3.4, 3.6. MIT Press, 2004.

[2] Mark F. Baumgartner, Lee Freitag, Jim Partan, Keenan R. Ball, and Kenneth E. Prada. Tracking large marine predators in three dimensions: The real-time acoustic tracking system. IEEE JOURNAL OF OCEANIC ENGINEERING, 33(2):146-157, 2008.

[3] Devika Bhat. Nicole the shark's epic swim across the ocean - and back. The Sunday Times, 2005.

[4] Dr. Ramon Bonfil. Shark tracker - tagging - pop-up archival tags, December 2010.

[5] B. D. Bruce, J. D. Stevens, and H. Malcolm. Movements and swimming behaviour of white sharks (carcharodon carcharias) in australian waters. Marine Biology, 150(2):161-172, 2006.

[6] Discovery Channel. Ocean of fear: Prefect predators. documentary, 2008.

[7] Yang Fan and Arjuna Balasuriya. Autonomous target tracking by auvs using dynamic vision. pages $187-192,2000$. 
[8] Yang Fan and Arjuna Balasuriya. Target tracking by underwater robots. Systems, Man, and Cybernetics, 2001 IEEE International Conference on, 2:696 - 701, 2001.

[9] D. Fields. The shark's electric sense. Scientific American, pages 74-81, 2007.

[10] Nathaniel Garcia. Ultrasonic shark-tag locator system for iver2 auv. Technical report, Calpoly San Luis Obispo, 2010.

[11] Kenneth J. Goldman and Scot D. Anderson. Space utilization and swimming depth of white sharks carcharodon carcharias at the south farallon islands central california. Environmental Biology of Fishes, 58:351364, 1999.

[12] Jeffery B. Graham, Heidi DeWar, N. C. Lai, William R. Lowell, and Steve M. Arce. Aspects of shark swimming performance determined using a large water tunnel. fj. exp. Biol, 151:175-192, 1990.

[13] Thomas M. Grothues, Joseph Dobarro, John Ladd, Amanda Higgs, George Niezgoda, and Dan Miller. Use of a multi-sensored auv to telemeter tagged atlantic sturgeon and map their spawning habitat in the hudson river usa. IEEE Autonomous Underwater Vehicles, pages 1-7, 2008.

[14] Y. Ho, A. Bryson, and S. Baron. Differential games and optimal pursuitevasion strategies. IEEE Transactions on Automatic Control, 10(4):385 389, 2003.

[15] Feifei Huang, Long Wang, Qining Wang, Ming Wu, and Yingmin Jia. Coordinated control of multiple mobile robots in pursuit-evasion games. pages 2861-2866, 2009.

[16] John W. Irza and Mukund N. Desai. Signal processing and data fusion for autonomous undersea vehicles. pages 393 - 400, 1989. 
[17] Fan Jiancong, Ruan Jiuhong, Liang Yongquan, and Tang Leiyu. An iterative learning process based on bayesian principle in pursuit-evasion games. pages $52-55,2010$.

[18] B. Kalyan, A. Balasuriya, H. Kondo, T. Maki, and T. Ura. Motion estimation and mapping by autonomous underwater vehicles in sea environments. Oceans 2005 - Europe, 1:436-441, 2005.

[19] A. Peter Klimley, Sallie C. Beavers, Tobey H. Curtis, and Salvador J. Jorgensen. Movements and swimming behavior of three species of sharks in la jolla canyon california. Environmental Biology of Fishes, 63:117135, 2002.

[20] Hayato Kondo, Toshihiro Maki, Tamaki Ura, Yoshiaki Nose, Takashi Sakamaki, and Masaaki lnaishi. Relative navigation of an auv using image-andacoustic based profiling systems. OCEANS '04, 3:1330 - 1335, 2004.

[21] OceanServer. Iver2-580-s specifications, December 2010.

[22] Florida Museum of Natural History: Ichthyology. International shark attack file, December 2010.

[23] Thomas G. Pfleger. Acoustic telemetry tags for fish in the ocean research, February 2011.

[24] T. Ura, J. Kojima, T. Nakano, H. Sugimatus, K. Mori, R. Hirotsu, and M. Yanagishawa. Experimental result of auv-based acoustic tracking system of sperm whales. OCEANS 2006 - Asia Pacific, pages 1-5, 2006.

[25] Keith Vickery. Acoustic positioning systems new concepts - the future. pages $103-110,1998$. 
[26] X. Wang, J. B. Cruz, Jr., G. Chen, K. Pham, and E. Blasch. Formation control in multi-player pursuit evasion game with superior evaders. Defense Transformation and Net-Centric Systems, 6578, 2009.

[27] Kevin C. Weng, Andre M. Boustany, Peter Pyle, Scot D. Anderson, Adam Brown, and Barbara A. Block. Migration and habitat of white sharks (carcharodon carcharias) in the eastern pacific ocean. Marine Biology, 52(4):877894, 2007.

[28] Alex Xydes, Dr. Mark Moline, Dr. Chris Lowe, and Dr. Christopher Clark. Behavior characterization and particle filter localization of a shovelnose shark. Technical report, Calpoly San Luis Obispo, 2010. 